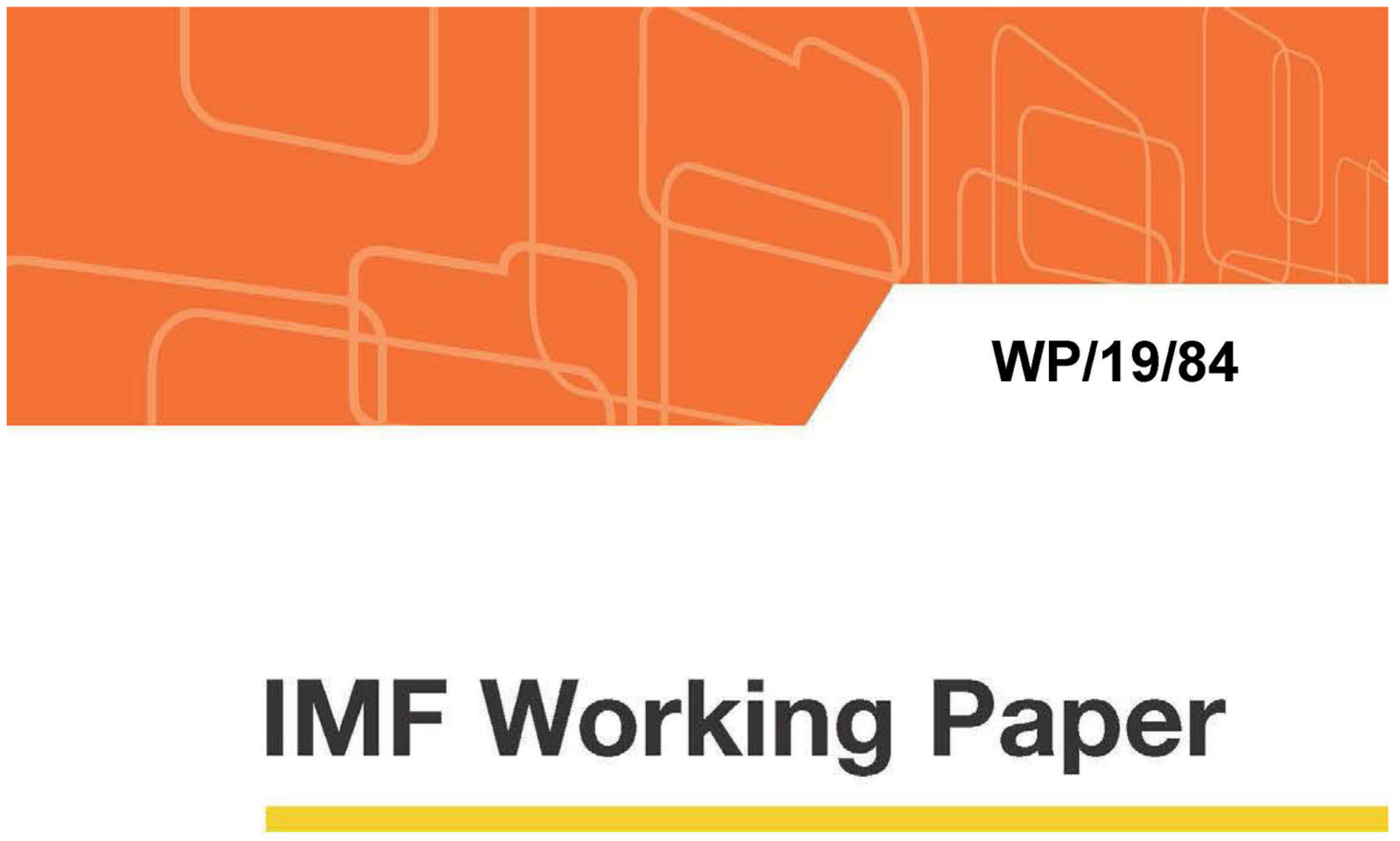

\title{
Enabling Deep Negative Rates to Fight Recessions: A Guide
}

\author{
by Ruchir Agarwal and Miles S. Kimball
}

IMF Working Papers describe research in progress by the author(s) and are published to elicit comments and to encourage debate. The views expressed in IMF Working Papers are those of the author(s) and do not necessarily represent the views of the IMF, its Executive Board, or IMF management. 


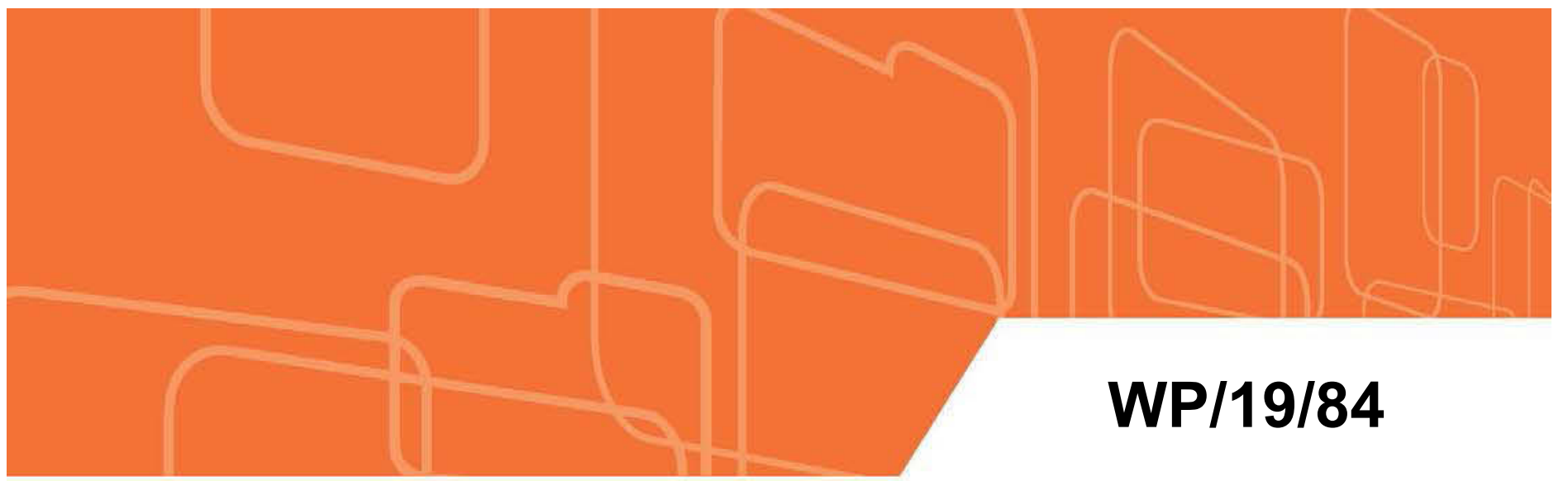

\title{
IMF Working Paper
}

\section{Enabling Deep Negative Rates to Fight Recessions: A Guide}

\author{
by Ruchir Agarwal and Miles S. Kimball
}

IMF Working Papers describe research in progress by the author(s) and are published to elicit comments and to encourage debate. The views expressed in IMF Working Papers are those of the author(s) and do not necessarily represent the views of the IMF, its Executive Board, or IMF management.

I N T ER N A T I O N A L M O NETAR Y F U N D 


\title{
IMF Working Paper
}

\author{
Asia and Pacific Department
}

\section{Enabling Deep Negative Rates to Fight Recessions: A Guide* \\ Prepared by Ruchir Agarwal and Miles S. Kimball}

Authorized for distribution by Tarhan Feyzioglu

April 2019

\begin{abstract}
IMF Working Papers describe research in progress by the author(s) and are published to elicit comments and to encourage debate. The views expressed in IMF Working Papers are those of the author(s) and do not necessarily represent the views of the IMF, its Executive Board, or IMF management.
\end{abstract}

\begin{abstract}
The experience of the Great Recession and its aftermath revealed that a lower bound on interest rates can be a serious obstacle for fighting recessions. However, the zero lower bound is not a law of nature; it is a policy choice. The central message of this paper is that with readily available tools a central bank can enable deep negative rates whenever needed - thus maintaining the power of monetary policy in the future to end recessions within a short time. This paper demonstrates that a subset of these tools can have a big effect in enabling deep negative rates with administratively small actions on the part of the central bank. To that end, we (i) survey approaches to enable deep negative rates discussed in the literature and present new approaches; (ii) establish how a subset of these approaches allows enabling negative rates while remaining at a minimum distance from the current paper currency policy and minimizing the political costs; (iii) discuss why standard transmission mechanisms from interest rates to aggregate demand are likely to remain unchanged in deep negative rate territory; and (iv) present communication tools that central banks can use both now and in the event to facilitate broader political acceptance of negative interest rate policy at the onset of the next serious recession.
\end{abstract}

JEL Classification Numbers: E4, E5

Keywords: negative interest rates, electronic money, monetary policy

Authors’ E-Mail Addresses: RAgarwal@,imf.org; miles.kimball@,colorado.edu

\footnotetext{
* We have greatly benefitted from feedback from seminar and conference participants at Harvard, MIT, Brown, Boston University, IMF, Brookings Institution Hutchins Center, Federal Reserve Bank of St. Louis, Bank of Japan, Bank of Thailand, Bank Indonesia, Bank of Korea, Federal Reserve Bank of Minneapolis, Sveriges Riksbank, Austrian National Bank, Bank of Israel, European Capital Markets Institute Conference, Czech National Bank, European Central Bank, BIS, Swiss National Bank, Federal Reserve Bank of Kansas, Bank of Canada/Central Bank Research Association Conference, Bruegel/Graduate School of Economics/Kobe University Conference, Bank of Spain, and Bank of Portugal. Among many others, we especially benefitted from interactions with Ben Bernanke, Markus Brunnermeier, Peter Conti-Brown, Giovanni Dell'Ariccia, Gauti Eggertsson, Emmanuel Farhi, Tarhan Feyzioglu, Marvin Goodfriend, Joshua Hausman, Robert King, Donald Kohn, Narayana Kocherlakota, Larry Kotlikoff, Signe Krogstrup, Greg Mankiw, Maury Obstfeld, Mahmood Pradhan, Matthew Rognlie, Ken Rogoff, Massimo Rostagno, Alp Simsek, Jeremy Stein, Larry Summers, Ivan Werning, and Oliver Wuensch.
} 


\section{Table of Contents}

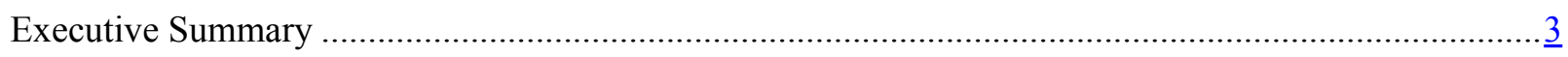

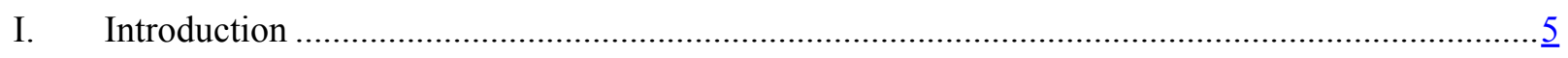

II. History of Thought on How to Create a Non-Zero PCIR ...........................................................

III. The Central Bank Cash Window and the Power to Create a Non-Zero PCIR ..............................12

IV. The Clean Approach: Using an Exchange Rate to Create a Non-Zero PCIR ...............................14

V. The Rental Fee Approach: Using a Rental Fee to Create a Non-Zero PCIR...............................20

VI. Managing the Side Effects of the Rental Fee Approach........................................................23

VII. Negative PCIR Based on the Price System vs. Quantity Restrictions........................................ $\underline{36}$

VIII. The Withdrawal Limit Approach and the Deposit Limit Approach .......................................... 37

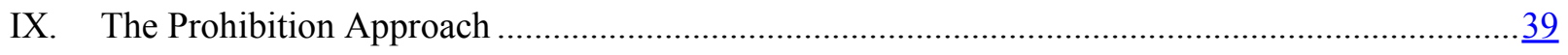

X. Combining the Rental Fee Approach and the Prohibition Approach …..................................... 45

XI. The Supply and Demand of Paper Currency: Contrasting Different Approaches to Enabling

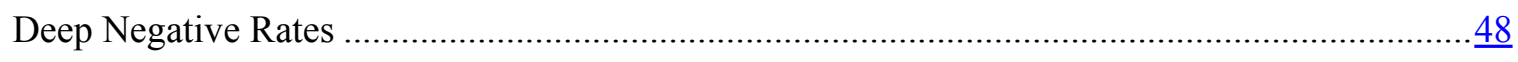

XII. Brief Literature Review on the Impact of Negative Rates on Bank Profitability and on the

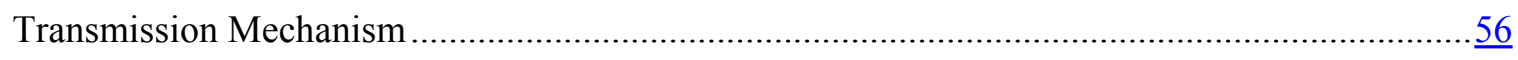

XIII. Is the Transmission Mechanism Different Once the Zero Lower Bound has been Broken? ..........61

XIV. Alternative Policies and Complementary Policies to Negative Interest Rate Policy...................... $\underline{72}$

XV. Using Communication Tools to Overcome Political Challenges in Implementing Deep

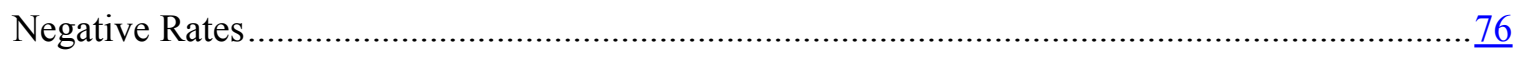

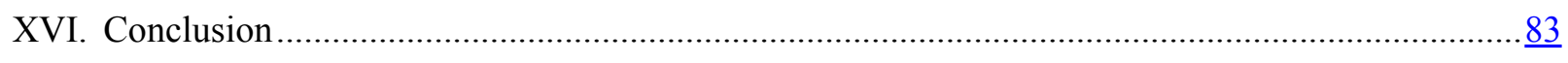

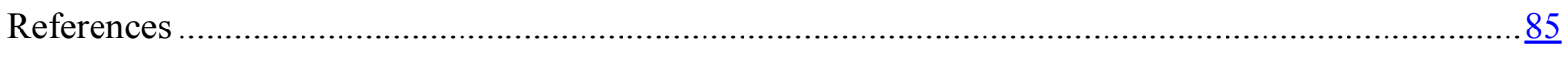




\section{Executive Summary}

After a decade of zero or near-zero rates, advanced country central banks have raised rates or are considering raising rates. With a modest recovery in the world economy, it may be appealing to think that this experience of zero or mildly negative rates was a once-in-a-lifetime experience. However, there is much reason to doubt that. Downturns are likely to happen again, and currently there is relatively little room available to advanced country central banks to fight them by interest rate cuts in the positive region. 500-600 basis points cuts in policy rates have been typical during recessions in advanced countries, but at present policy rates in most advanced countries remain too close to zero to make cuts of that size possible without using negative rates. Moreover, in the future, without the ability to implement negative rates, zero lower bound episodes are expected to occur frequently and are expected to be severe, lasting several years. Therefore, it is clear that the zero lower bound on interest rates has proved to be a serious obstacle for monetary policy.

However, the zero lower bound is not a law of nature; it is a policy choice. The central message of this paper is that with readily available tools a central bank can enable deep negative rates whenever needed - thus maintaining the power of monetary policy to end recessions within a short time.

The main contribution of this paper is to demonstrate that a subset of these tools can have a big effect in enabling deep negative rates with administratively small actions on the part of the central bank. To that end, we survey the history of thought on ways to create a negative paper currency interest rate (PCIR) and present additional new approaches available to central banks (see Table 1 below). Our organizing principles for the different approaches are to focus on (1) the role of banks and the private sector financial system in transmitting the negative paper currency interest rate, (2) whether the approach requires quantity restrictions on cash (or instead relies on the price system to alter the rate of return for paper currency), and (3) whether a negative paper currency interest rate is created through the capital gains term or the dividend term in the rate of return equation.

\begin{tabular}{|c|c|c|c|}
\hline & & Direct Negative PCIR Everywhere & Transmission Through Banks \\
\hline \multirow{2}{*}{$\begin{array}{c}\text { Negative PCIR based on the } \\
\text { Price System }\end{array}$} & Depreciating Cash & $\begin{array}{c}\text { (1) Eisler (1932) } \\
\text { (2) Buiter (2009) } \\
\text { (3) Tax Approach (Feldstein 2002; Correia et. al, 2013) }\end{array}$ & Clean Approach (Agarwal and Kimball, 2015) \\
\hline & $\begin{array}{l}\text { Negative Dividend } \\
\text { on Cash }\end{array}$ & $\begin{array}{l}\text { (1) Gesell (1906) } \\
\text { (2) Goodfriend (2000) } \\
\text { (3) Mankiw (2009) }\end{array}$ & Rental Fee Approach (this paper) \\
\hline \multirow{2}{*}{$\begin{array}{l}\text { Negative PCIR based on } \\
\text { Quantity Restrictions on Cash }\end{array}$} & Depreciating Cash & $\begin{array}{l}\text { Abolish Paper Currency Approach } \\
\text { (Buiter, 2009; Rogoff, 2015) }\end{array}$ & $\begin{array}{l}\text { (1) Withdrawal Limit Approach (Goodfriend, 2016) } \\
\text { (2) Deposit Limit Approach (this paper) }\end{array}$ \\
\hline & $\begin{array}{l}\text { Negative Dividend } \\
\text { on Cash }\end{array}$ & $\begin{array}{l}\text { (1) Prohibition Approach (this paper) } \\
\text { (2) Eliminate Large Bills Approach (Rogoff, 2017) }\end{array}$ & $\begin{array}{l}\text { Prohibition Approach Ban on Cash Electrification } \\
\text { (this paper) }\end{array}$ \\
\hline
\end{tabular}

Table 1: Options to Enabling Deep Negative Rates and the History of Thought

We argue that the best approaches for enabling deep negative rates (i.e. both at a minimum distance from the current monetary framework and the least costly politically) are those that both rely on banks for transmission and do not impose quantity restrictions on cash. Two approaches to enable deep negative rates that satisfy these criteria are: (a) "the clean approach" which is an electronic money 
system that takes paper currency off par, and (b) "the rental fee approach" which keeps paper currency at par within the financial system and the large corporate sector.

Relying on banks for transmission of a negative rate of return on paper currency reduces the implementation burden and political cost associated with negative rates. When working through banks, anything that would be a political problem for the central bank becomes a customer relationship management problem for the commercial banks. Commercial banks are likely to be better and more experienced in dealing with customer relations problems - even those with a new twist - than central banks are at dealing with grassroots political problems. After minimalist implementation (at the central bank cash window), the central bank can leave the rest up to the private sector. One key aspect of banktransmission approaches is that the less the central bank does and the more is done by commercial banks, the less new legislation is likely to be needed.

Relying on the price system to create a negative paper currency interest rate reduces the administrative burdens and drastic changes in the way people or institutions transact that would accompany quantity restrictions on cash. Avoiding drastic changes in the way people transact avoids one possible source of political opposition.

Thus, putting together these two points, approaches that rely on banks and the price system for transmission are arguably at a minimum distance from the current monetary system and likely to carry the least political cost.

The paper also discusses why standard transmission mechanisms from interest rates to aggregate demand are likely to remain unchanged in deep negative rate territory. We present arguments why, once the rate of return on paper currency becomes a policy variable, and the health of banks is attended to, the transmission mechanism for interest rate policy should be very similar when using negative rates as it is when using positive rates. Thus, when the rate of return on paper currency is a policy variable and the health of banks is attended to, central banks have unlimited monetary policy firepower; only the danger of overstimulating the economy limits how much stimulus central banks can provide.

In our view, central banks have only a short period to get their job done before getting blamed for a slow recovery and even for a low natural rate. Hence, as compared to using mild negative rates for a long period of time, the use of deep negative rates for a short time has political advantages.

One key complementary policy has the potential to help calm the politics of negative rates: using the interest-on-reserves formula to subsidize the provision of zero interest rates for small deposit accounts avoids both what would be a sore point for voters and a stress point for banks.

Finally, we discuss communication tools that central banks can use both now and in the event to mitigate political costs in implementing negative interest rate policy at the onset of the next serious recession. Thus, we think effective communication about negative rates involves three steps: (1) measuring markets' perception of the effective lower bound and using it as a policy instrument; (2) making the market aware of central bank tools that eliminate the effective lower bound and can help manage the associated side effects (if possible before the economy enters a recession); and (3) convincing the markets that the central bank is willing to use the new tools as called for. 


\section{Introduction}

In response to the Great Recession and its aftermath several advanced country central banks quickly cut their policy rates to near-zero. A few even went further by cutting rates into mildly negative territory. Now ten years later the Federal Reserve has started raising rates again, and several other central banks are contemplating similar action. With a modest recovery in the world economy, it may be appealing to think that this experience of zero or mildly negative rates was a once-in-a-lifetime experience. However, there is much reason to doubt that.

First, downturns are likely to happen again, and currently there is relatively little room available to advanced country central banks to fight them by interest rate cuts in the positive region. 500-600 basis points cuts in policy rates have been typical during recessions in advanced countries, but at present policy rates in most advanced countries remain too close to zero to make cuts of that size possible without using negative rates. Even in the U.S., where the Fed has started raising rates, the rates are expected to remain low compared to the post-war history. For instance, as of December 2018, the Federal Open Market Committee's projection of the Federal funds rate even beyond 2021 ranged between 2.5 and 3.5 percent. Therefore, if the zero lower bound is kept in place, there is likely to be little roomover the foreseeable future - to implement the size of rate cuts that were considered advisable in almost every recession over the past fifty years.

Second, in the future, zero lower bound episodes are expected to occur frequently and are expected to be severe, lasting several years. In their Brookings Paper on Economic Activity paper, Federal Reserve economists Michael Kiley and John Roberts (2017) run simulations of the U.S. economy, and show that due to a decline in the equilibrium real interest rate combined with the decline in the level of expected inflation, the zero lower bound on nominal rates could be binding 30-40 percent of the time in the future. They also find that these episodes are likely to persist for several years-resulting in poor economic performance-since monetary policy is going to be constrained by the lower bound during these episodes.

The former Federal Reserve Chair Ben Bernanke formally discussed the Kiley and Roberts (2017) paper at the Brookings conference, and stated: "If correct, their result reinforces the need for fresh thinking about how to maintain the effectiveness of monetary policy in the future, a point recently emphasized by San Francisco Fed president John Williams and others (and with which, I should emphasize, I very much agree).” (Bernanke, 2017.) 

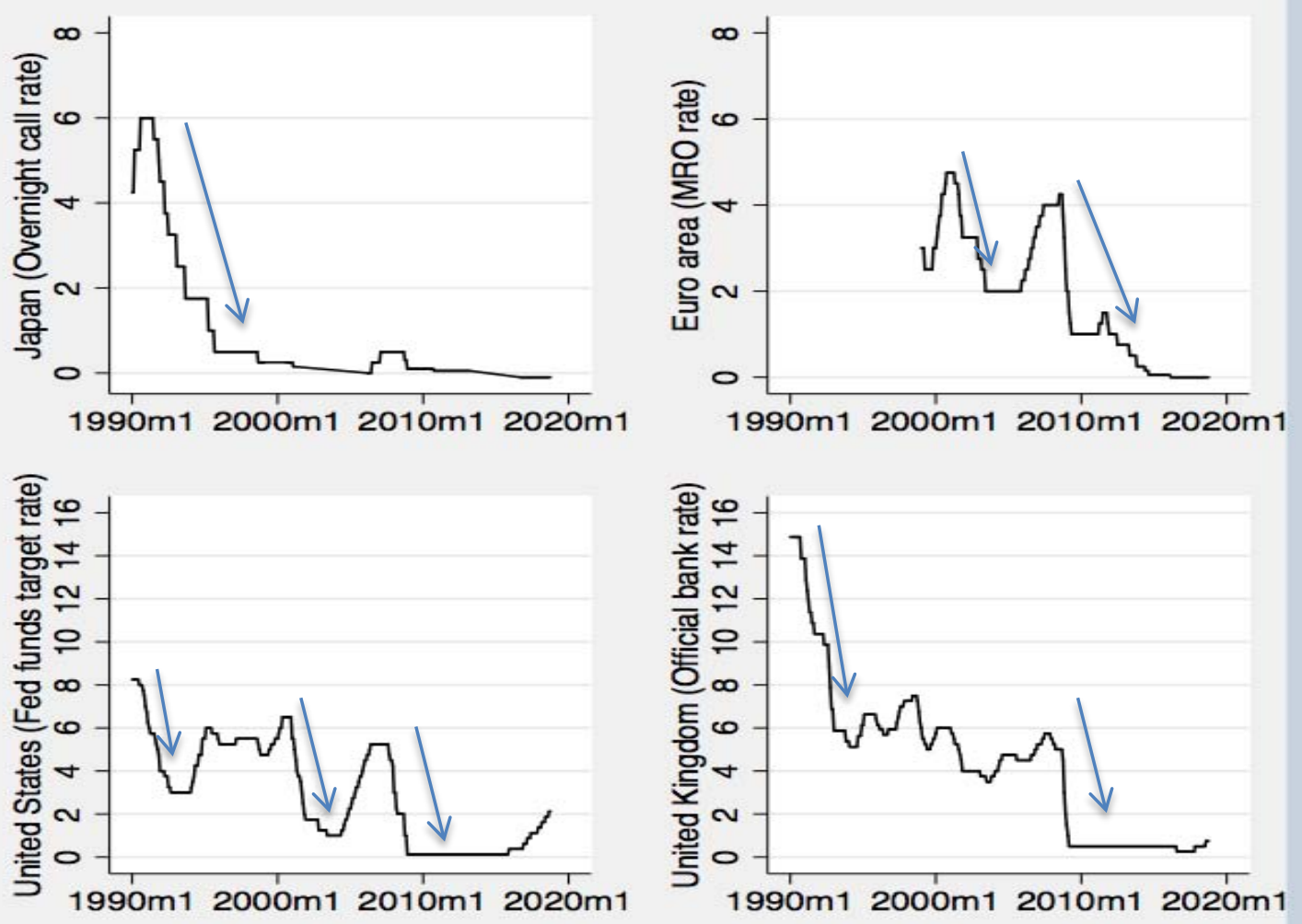

Figure 1: Central Bank Policy Rates in Selected Advanced Economies

In summary, ten years after the crisis, it is clear that the zero lower bound on interest rates has proved to be a serious obstacle for monetary policy. However, the zero lower bound is not a law of nature; it is a policy choice. We show that with readily available tools a central bank can enable deep negative rates whenever needed - thus maintaining the power of monetary policy in the future.

The central message of this paper is to demonstrate that a subset of these tools can have a big effect in enabling deep negative rates with administratively small actions on the part of the central bank. To that end, we survey the history of thought on ways to create a negative paper currency interest rate (PCIR) and present additional new approaches available to central banks. Our most important organizing principles for the different approaches are to focus on (1) the role of banks and the private sector financial system in transmitting the negative paper currency interest rate, and (2) whether the approach requires quantity restrictions on cash (or instead relies on the price system to adjust the value of paper currency). We argue that the best approaches for enabling deep negative rates (i.e. both at a minimum distance from the current monetary framework and the least costly politically) are those that both rely on banks for transmission and do not impose quantity restrictions on cash. Two approaches to enable deep negative rates that satisfy these criteria - discussed in greater detail below-are: (a) "the clean approach" which is an electronic money system that takes paper currency off par, and (b) "the rental fee approach" which keeps paper currency at par. These two approaches differ in our third organizing 
dimension: whether a negative paper currency interest rate is created through the capital gains term or the dividend rate term in the rate of return equation. This third organizing principle is useful in establishing a typology for the range of possible approaches, but is normatively less consequential than whether the central bank relies on the private sector for transmission and whether it works through the price system.

On the first dimension (the degree of reliance for transmission on banks and the rest of the private sector financial system), we argue that relying on banks to transmit the negative paper currency interest rate reduces the implementation burden and political cost associated with negative rates. When working through banks, anything that would be a political problem for the central bank becomes a customer relationship management problem for the commercial banks. And commercial banks are likely to be better and more experienced in dealing with customer relations problems - even those with a new twist - than central banks are at dealing with grassroots political problems.

As for implementation, all but one of the approaches we present that work primarily through commercial banks and the private sector financial system require implementation only at the cash window of the central bank. ${ }^{1}$ After minimalist implementation, the central bank can leave the rest up to the private sector. One key aspect of bank-transmission approaches is that the less the central bank does and the more is done by commerical banks, the less new legislation is likely to be needed. 'Doing a lot with a little' is more likely to be within the authority of a central bank than 'doing a lot with a lot'.

On the second dimension (quantity restrictions on cash vs. working through the price system), we argue that approaches relying on the price system to create a negative paper currency interest rate are better because imposing quantity restrictions on cash is likely to lead to a more drastic change in the way people transact, and in some approaches requires a higher administrative burden to implement. Avoiding drastic changes in the way people transact avoids one possible source of political opposition. Thus, it is likely that bringing about a negative paper currency interest rate using the price system is likely to face fewer and less intense political challenges.

Putting together these two points, we argue that approaches that rely on banks and the price system for transmission are at a minimum distance from the current monetary system and likely to carry the least political cost.

For much of our discussion, legal issues will be in the background. Potential legal issues - which can vary by jurisdiction - motivate our presentation of many different approaches to enable negative rates. One approach may be within a given central bank's authority or within the range of politically feasible legislation or administrative or executive action outside the central bank, while another may not. We see

\footnotetext{
${ }^{1}$ The exception is that one element of the "prohibition approach" works through the financial system: banning money market mutual funds backed by paper currency. Interestingly, in the US, this action does not require new legislation, but is also not within the power of the Fed: the SEC (Securities and Exchange Commission) regulates money market mutual funds.
} 
"the clean approach"- which creates an exchange rate between two forms of money (paper currency and electronic currency) - as the first-best, with the fewest undesirable side-effects (compared to the current monetary framework). ${ }^{2}$ Furthermore, the undesirable side effects it does have can be reduced significantly by warning the private sector to be prepared for cash being below par. However, central banks in some jurisdictions may currently face legal barriers to creating such an exchange rate. In case of such barriers, we present "the rental fee approach", which also creates a negative paper currency interest rate (PCIR) at the cash window - while keeping the exchange rate between paper currency and electronic currency at par. In case a central bank is unable or unwilling to use either of these two approaches, we also present other approaches. For example, "the prohibition approach" relies on demand-side restrictions to enable deeper negative rates. We view the prohibition approach as a messy, unattractive approach, but one that a government might fall into because it seems intuitive. Our discussion of it is both a description and a warning about the side effects associated with using this approach. Some of the side effects present in the prohibition approach are also likely to arise in several other approaches that do not rely on banks to transmit the negative PCIR.

We want to emphasize that the characterizations we give of various policy measures are characterizations from the standpoint of economic analysis and do not constitute legal characterizations. Careful discussion of the legal issues for each policy measure discussed here is urgently needed, but beyond the scope of this paper.

In addition to laying out a typology of approaches to enabling deep negative rates, we discuss the transmission mechanism of monetary policy under negative rates. We argue that the effects of an interest rate cut would be quite similar for countries that are cutting their rates in the positive region and countries that are cutting to a negative rate, or cutting rates within negative territory.

Finally, we discuss how to use communication tools effectively to overcome political challenges in implementing negative interest rate policy. The political costs of negative rates can be mitigated, though not eliminated. We present three measures that can be taken to reduce the political cost of deep negative rates.

Our view is that, when needed, deep negative rates are likely to be worth the political cost. After all, when facing a deep recession with little room to cut rates in the positive region, the choice is not between political calm for a central bank or a political storm for the central bank, but the political cost of negative rates on one hand weighed on the other hand against the opprobrium a central bank justifiably comes under when it fails to fulfil its mandate and return the economy to normal in a timely way. Nevertheless, reducing political costs where that is consistent with sweeping away any lower bound on interest rates

\footnotetext{
${ }^{2}$ In this paper we use the term "electronic money" to refer to credit balances in an account held in the books of the central bank, or in the books of a commercial bank. Note that the exact term is "book money", but we are going to call it "electronic currency" in many places.
} 
is not only directly helpful, but also makes the financial markets more likely to believe that the central bank will be bold enough to pursue a vigorous negative interest rate policy.

For all of the approaches we discuss, a key complementary policy that can calm the political waters is to encourage and support banks in providing zero interest rates on small deposit accounts even in situations where a wide range of assets - including large deposit accounts - are subject to negative interest rates. We argue that the interest on reserves formula can be used to subsidize the provision of zero rates on small deposit accounts. In addition to encouraging banks to protect small depositors, this subsidy insulates commercial banks from negative consequences to profitability from this provision of zero rates to small deposit accounts. Although encouraging and supporting the provision of zero rates for small deposit accounts is more central to some approaches than others, and is discussed in detail in that context, we view this complementary policy as important enough to all the approaches we discuss that no criticism of an approach is apt if it is leveled at a version of the approach that is stripped of this complementary policy of encouraging and supporting the provision of zero rates to small deposit accounts. $^{3}$

\section{History of Thought on How to Create a Non-Zero PCIR}

There is a long line of work on how to get a non-zero paper currency interest rate (PCIR). In 1916, Silvio Gesell proposed imposing a negative PCIR by requiring that stamps be purchased and affixed to paper currency periodically-effectively allowing the government to tax paper currency. This would discourage massive paper currency storage when interest rates go below zero, enabling deep negative rates. Marvin Goodfriend (2000) advocated a modern version of stamped paper currency - with magnetic strips on the bills that record the time a paper bill has remained outside the banking system. Despite widespread awareness among economists of the idea of stamped currency due to John Maynard Keynes discussing Gesell's idea in his The General Theory of Employment, Interest, and Money in 1936, it has never been implemented at a national level. We suspect this is in part due to political difficulties, as it requires an inconvenient and highly salient bureaucratic machinery to implement, and because it looks quite obviously like a tax, at least as salient as, say, gasoline taxes.

An alternate line of thinking for generating a negative PCIR — starting with Robert Eisler (1932) focuses on a depreciation mechanism for paper currency. Such ideas involve distinguishing between paper currency and electronic money (or "bank money," as Robert Eisler called it), with electronic money being the unit of account: the "real thing." This distinction makes it possible to engineer a depreciation of paper currency relative to electronic currency, thereby discouraging massive paper currency storage when faced with negative interest rates. This idea was to an important extent forgotten by the economics community and was revived in the modern period by Willem Buiter $(2007,2009)$.

\footnotetext{
${ }^{3}$ This tool is discussed in detail in section VI.B.i. In section XIII we argue that the transmission mechanism from negative interest rates to aggregate demand is broad-based enough that lowering rates on small deposit accounts is not needed for effective stimulus.
} 
Many academics, such as Buiter (2009) and Ken Rogoff (2015), have also suggested that a complete abolition of paper currency would eliminate the option of massive paper currency storage, eliminating the zero lower bound. While the complete abolition of paper currency would indeed clear the way for deep negative interest rates whenever deep negative rates were called for, such proposals remain difficult to implement since they involve a drastic change in the way people transact. The recent experience with demonetizing India's two largest bills and the associated adverse effects it created suggests that making significant changes to the way people transact remains challenging (Rogoff, 2017). The complete abolition of cash also entails a significant public debate on preserving privacy vs. discouraging crime. In many countries, a large fraction of households is currently unbanked, so moving to a completely cashless society may be difficult to do quickly without large transition costs. Therefore, Ken Rogoff (2017a, 2017b) has proposed a less costly approach of "a less-cash society, not a cashless society" to lower the effective lower bound on interest rates by eliminating large-denomination bills, or more powerfully by eliminating bills but keeping coins. (The larger and heavier the coins-especially for the highest denomination - the greater the storage cost relative to the value of the coins. $)^{4}$

Since the Great Recession, there have also been other novel ideas about eliminating the zero lower bound in the popular press and in the blogosphere. ${ }^{5}$ Such discussions have generally pushed the thinking towards understanding that zero is not an unavoidable lower bound for interest rates. For instance, in "It May Be Time for the Fed to Go Negative," Greg Mankiw (2009) discussed (but distanced himself from) a serial-number-lottery plan in which each year the Fed would pick a number between zero and 9 out of a hat, and all bills with a serial number ending in that number would no longer be legal tenderdemonstrating a clever way to achieve a negative 10 percent PCIR. Several economists, policymakers and journalists — notably Miles Kimball, Scott Sumner, David Beckworth, JP Koning, Andrew Haldane, Ben Bernanke, Izabella Kaminska and Matthew Yglesias - have also blogged or written in the press about various aspects of implementing negative rates and have contributed to understanding the nuts and bolts of negative interest rate policy.

Another approach, discussed by Martin Feldstein (2002), and later elaborated by Isabel Correia, Emmanuel Farhi, Juan Pablo Nicolini, and Pedro Teles (2013), uses tax policy. Public finance theory continues to identify tax policy equivalents to nontax policies. The tax approach involves identifying the tax policy equivalent to negative interest rates. To achieve the equivalent of a deep negative interest rate, the tax approach involves engineering an increasing path of consumption taxes, a decreasing path of labor taxes, and a temporary investment tax credit. Correia, Farhi, Nicolini, and Teles (2013) show that the increasing path of consumption taxes over time generates inflation in final goods consumer

\footnotetext{
${ }^{4}$ Throughout this paper, we use the phrase "paper currency" as a shorthand for any non-electronic currency, whether made of paper, plastic or metal. The key dividing line is between money that is instantiated as a numerical balance in a computer and can easily be reduced to reflect a negative interest rate, and money whose physical form requires a somewhat more involved procedure in order to have it subject to a negative interest rate. Marvin Goodfriend's (2000) suggestion of paper currency with an electronic strip is near this dividing line, but we would still put it on the "paper currency" side of the line.

${ }^{5}$ It is difficult to be fully comprehensive, but see Miles Kimball's negative interest rate policy page on his blog for links to various discussions of negative interest rate policy in the blogosphere and press: https://blog.supplysideliberal.com/emoney/
} 
prices; they assume prices in their New Keynesian model are sticky only for intermediate good varieties, while final goods prices are flexible. The decreasing path of labor taxes avoids any disincentive for work from the rising consumption taxes, while the temporary investment tax credit extends the equivalent of negative interest rates to investment goods. This approach allows the policymakers to overcome the zero lower bound with the use of a combination of standard fiscal tools.

One possible difficulty for this approach in practice would be that the tools are not directly under the control of the central bank, and for this and other obvious reasons using a tax approach is likely to be politicized. This approach will be cleaner for countries that have price stickiness in prices before taxessay a national sales tax added at the register-as opposed to price stickiness in prices after taxes - as is most common now in countries that have a value added tax (VAT). In jurisdictions that have a sales tax (as opposed to a VAT), another impediment of the tax approach is that sales tax are typically more limited in coverage than a VAT, as well as potentially more distortionary. In addition, Rogoff (2016) points out that a large portion of sales tax is collected on durable goods, which would lead to various distortions under the tax approach, unless the path of the sales tax on durables was very different from the path of the sales tax on nondurables. In addition, Rogoff emphasizes that another challenge of the tax approach is that it requires an explicit temporary path for fiscal policy that can be announced and made credible for it to be effective. Nevertheless, even rough facsimiles of the tax approach could be an effective policy compared to anything actually implemented historically during the Great Recession and its aftermath.

One feature of the approaches discussed so far in the history of thought (except the one that requires abolishing cash) is that they rely on a price system to generate a negative PCIR — without imposing any quantity restrictions on cash. By contrast, approaches such as abolishing cash or retiring large denomination bills focus on quantity restrictions on cash to generate a negative PCIR - for example by increasing the storage cost of a given value of paper currency.

Another feature of all the approaches discussed so far is that they focus fairly directly on the desired effect on households and firms without much discussion of transmission through banks and the financial sector more generally. By contrast, in the rest of the paper we will focus on approaches to generate a negative PCIR by relying primarily on banks for transmission of the negative rate on paper currency. The central ingredient that distinguishes these approaches-(a) the clean approach, (b) the rental fee approach, (c) withdrawal limit approach, and (d) the deposit limit approach-from the approaches discussed above, will be that the central bank needs to take only localized actions for implementation (mainly at its own cash window), leaving the rest to the price system and the banks.

We will also discuss a fifth approach: the prohibition approach. The prohibition approaches places quantity restrictions on cash. One element of the prohibition approach relies on the financial sector for transmission: a ban on the sale of assets backed by paper currency that can be traded electronically (such as an exchange-traded fund backed by paper currency). The rest of the elements of the prohibition 
approach require enforcement well beyond the legal financial sector. That is why the prohibition approach appears in both columns of Table 1 (above in the executive summary).

Among the approaches that emphasize bank (or financial-sector) transmission, the clean approach is developed in Agarwal and Kimball (2015). The rest of the bank-transmission-based approaches are developed in this paper, with the exception of the "withdrawal limit approach," which was presented by Marvin Goodfriend (2016) in his Jackson Hole speech "The Case for Unencumbering Interest Rate Policy at the Zero Lower Bound." Before we turn to presenting these approaches, we discuss how the central bank cash window can be used to generate a negative PCIR.

\section{The Central Bank Cash Window and the Power to Create a Non-Zero PCIR}

The public typically obtains cash from commercial banks by making withdrawals from automated teller machines (ATMs) or by cashing checks. But where do banks obtain the cash? To meet the demands of its customers, banks get cash from the central bank by using the central bank's cash window. The larger commercial banks typically have an account with the central bank, and the cash window allows the banks to exchange electronic currency in this account for paper currency ('cash').

For example, in the U.S., most medium and large banks maintain reserve accounts at the Federal Reserve. ${ }^{6}$ These banks can receive paper currency (cash) in exchange for electronic currency (reserves) by asking the Fed to debit their reserve account. That is, when a bank orders paper currency from the Fed, the Fed releases the shipment of paper currency from its cash offices to armored carriers for delivery to the bank, and at the same time debits an equivalent amount in the bank's reserve account maintained at the Fed.

Not all banks, however, have direct access to the Federal Reserve cash window, as some smaller banks maintain their required reserves at larger banks_-known as 'correspondent' banks —instead of directly at the Fed. These smaller banks typically obtain cash through their correspondent banks by paying a small fee for these services. The larger banks act as an intermediary: they get the cash from the Fed and pass it on to these smaller banks. ${ }^{7}$

At the cash window, the central bank typically treats a 100-dollar note as worth 100 electronic dollars and does not charge any substantial fees for the issuance or acceptance of paper currency. But a key message of this paper is that this is not the only possibility, since central banks' role as the source of

\footnotetext{
${ }^{6}$ Note that there are various types of accounts held by commercial banks at the central bank, (including current account, term deposits, settlement accounts for payment systems, etc.).

${ }^{7}$ See discussion under "How Currency Gets into Circulation" at the Federal Reserve website for further information: https://www.newyorkfed.org/aboutthefed/fedpoint/fed01.html
} 
paper currency gives them an underappreciated power to charge a non-zero paper currency interest rate to commercial banks at the cash window when not prohibited by law from doing so. ${ }^{8}$

For example, just as central banks determine the relative value of different denominations of paper currency by how they treat them at the cash window (i.e. two $\$ 10$ bills are worth one $\$ 20$ bill), ${ }^{9}$ they can also determine how much, say, a paper dollar is worth compared to an electronic dollar in a reserve account by how they treat the paper currency at the cash window.

Alternatively, central banks can charge a rental fee for paper currency issued.

These two possibilities have parallels in the long history of thought on eliminating the zero lower bound. Think about the paper currency interest rate (PCIR) as the nominal rate of return on holding paper currency as an asset. This return need not be zero. The nominal rate of return on paper currency (PCIR) can be written as:

$$
\begin{array}{r}
\text { Rate of Return }=P C I R=\left(\frac{\text { Dividend }}{P_{t+1}}\right)+\left(\frac{P_{t+1}}{P_{t}}\right)-1 \\
=\text { Dividend Yield }+ \text { Capital Gains Rate }
\end{array}
$$

Thus, if the central bank can affect the dividend yield or appreciation rate (or capital gains rate) of paper currency it can create a non-zero rate of return for holding paper currency. Proposals in the spirit of Eisler (1932), Buiter (2009), and Agarwal and Kimball (2015) are about targeting the capital gains rate (appreciation rate), while proposals in the spirit of Gesell (1916) and Goodfriend (2000) are in the spirit of targeting the dividend yield to create a non-zero rate of return for holding cash.

How is it that so much can be accomplished at the central bank's own cash window? A key insight is that if arbitrage profits are made by withdrawing paper currency, storing it and redepositing it at the cash window, it is the central bank that is on the losing side of the withdrawal and redeposit transactions. While paper currency storage must be part of the story, in terms of transactions, the arbitrage profits happen at the cash window. If the central bank takes action to avoid taking a hit to its balance sheet at the cash window, that necessarily implies that there will be no arbitrage profits for the private sector as a whole from paper currency withdrawal, storage and redeposit. And any arbitrage opportunity within the private sector from paper currency withdrawal, storage and redeposit would have to be at the expense of some other private sector actor.

\footnotetext{
${ }^{8}$ The legal situation will be different for different central banks.

${ }^{9}$ A good example to see that it is not the face value of the bills that determines the exchange rate between them is to imagine the Fed gradually phasing out $\$ 100$ bills by every year deducting $\$ 1$ from what it would give in exchange for a $\$ 100$ bill: after one year, $\$ 99$, after two years, $\$ 98$ and so on. If that is how the Fed treated a paper $\$ 100$ bill at the cash window, that is what it would be worth.
} 
An analogy makes clear how unbusinesslike the behavior is that would lead to a lower bound on rates from paper currency policy. Guaranteeing to forever freely trade paper currency for reserves at par with no substantial fees or restrictions when rates are deeply negative is like a car dealer promising to buy back a car at the sale price (no matter how far in the future) when the depreciation rate exceeds inflation. The car dealer would lose from such a deal. Although it is right for the central bank to care about much more than its own balance sheet, instituting policies at its cash window that will protect a central bank's balance sheet in a situation of deep negative rates will also serve the objective of eliminating any lower bound on interest rates.

Let us now discuss in more detail how the central bank can create a non-zero PCIR.

\section{The Clean Approach: Using an Exchange Rate to Create a Non-Zero PCIR ${ }^{10}$}

\section{A. The Exchange Rate Mechanism}

The first method relies on an electronic money system that targets the exchange rate between paper currency and reserves to create a non-zero rate of return (or equivalently a non-zero PCIR) for holding paper currency. Suppose the Fed wants to establish a negative 1 percent paper currency interest rate at the cash window. Then, at the beginning of the year, it will stand to exchange paper currency for electronic currency at par (i.e. 1 for 1) with banks at the cash window. At the end of the year, (a) when a commercial bank comes to the cash window of the central bank and hands in a paper 100-dollar note to have the money put into its reserve account, the Fed would add only 99 dollars to that commercial bank's reserve account; and (b) when a commercial bank came to the cash window of the Fed and asked for a paper 100-dollar note, only 99 dollars would be deducted from its reserve account. (Note that this exchange rate will predictably and gradually change throughout the year as per the principles of compound interest: a 100-dollar paper note would be worth 99.92 electronic dollars at the end of the first month, 99.83 electronic dollars at the end of the second month, 99.75 electronic dollars at the end of the third month, and so on.) This is equivalent to creating a crawling exchange rate between the two forms of money. Predictable changes in this exchange rate then generate capital gains and losses for paper currency. For the "clean" electronic money approach, set the first term in Equation (1) to zero and re-write it as:

$$
P C I R=\underbrace{\text { Dividend Yield }}_{0}+\underbrace{\text { Capital Gains Rate }}_{\text {Appreciation Rate }}
$$

The capital gains rate is the rate of appreciation (or depreciation) of paper currency relative to the electronic currency. In the above example, the appreciation rate is -1 percent per annum, which is equal

\footnotetext{
${ }^{10}$ This section draws on our earlier paper (Agarwal and Kimball (2015)).
} 
to the PCIR. This mechanism creates a crawling-peg between the two types of currencies - in this case with the paper currency smoothly depreciating by 1 percent over the course of the year. ${ }^{11}$

The Fed can easily defend such an exchange rate between paper currency and electronic money-just as, say, the Fed can easily defend the exchange rate between $\$ 20$ bills and $\$ 10$ bills-since it has the authority to create as much of either one as needed to satisfy banks' desires to change one into the other. In other words, the central bank has unlimited firepower for defending any exchange rate it declares between different forms of money under its jurisdiction.

\section{B. The Clean Approach to Enable Deep Negative Rates}

To overcome the zero lower bound the clean approach requires combining (a) the non-zero paper currency interest rate at the cash window using an exchange rate, and (b) using electronic money as the unit of account. Here, when we say that electronic money is the "unit of account," what is most important is that it be the unit in which prices are fixed. ${ }^{12}{ }^{13}$ It is not essential that all prices be expressed in terms of the electronic dollar, but it is important that prices for a significant fraction of expenditure be expressed in terms of the electronic unit of account. As discussed in Kimball (2015), the idea is that purchases paid for by credit card, debit card, checks, or electronic funds transfer would look exactly like they do now - in which case they would implicitly be denominated in the electronic unit of account.

Retailers who regularly accept both cash and cards would have the option of applying a storewide paper currency surcharge, assessed at checkout as sales taxes now are in the U.S. Although retailers could do this, they would not be required to. That is, while arbitrage would ensure that the exchange rate would hold throughout the financial system, it need not hold at retail shops that deal regularly with both cash

\footnotetext{
${ }^{11}$ Note that given the PCIR target and the initial condition that the exchange rate between paper currency and electronic currency starts at par, there is no additional freedom in choosing the exchange rate. Let $X$ denote the number of electronic dollars per paper dollar. Then $\mathrm{PCIR}=\mathrm{d} \ln (\mathrm{X}) / \mathrm{dt}$. This plus starting at par fully determines the path of the exchange rate from the pat of PCIR. To the extent that the exchange rate itself is a policy concern, one must tilt the PCIR toward the exchange rate objective. For example, in order to have the exchange rate at par as much of the time as is consistent with eliminating any lower bound on rates, we recommend having the PCIR at zero once (a) the desired target rate is positive and (b) the exchange rate has returned to par from a period when it is below par. This allows the exchange rate to then stay at par until negative rates are needed again instead of going above par during a prolonged period of positive rates. The current system can be seen as a monetary regime in which keeping the exchange rate between paper currency and electronic money at par at all times is considered such an important policy objective that it is worth a prolonged slump at the lower bound in order to preserve that exchange rate.

${ }^{12}$ Some scholars have opined that in a well-functioning monetary system the means of payment should coincide with the unit of account (Borio, 2018). Under the clean approach, electronic money is the primary means of payment and it does coincide with the unit of account, while paper currency is no longer the unit of account. Thus, under the clean approach, once one recognizes that the central bank has designated electronic money as the primary money for the purposes of means of payments (and that paper currency is only ancillary), it can be seen that the clean approach operates within the spirit of Borio's principle, as well as international efforts to ensure a unified exchange rate system. However, domestic law issues may be more complicated, since the unit of account as viewed from the perspective of the central bank does not necessarily govern all contracts. We discuss some of these issues below.

${ }^{13}$ The other important aspect of electronic money being the unit of account is that the confusion costs of inflation will be minimized by a zero inflation rate in the electronic unit of account, not by a zero inflation rate in terms of paper currency. See the discussion of the costs and benefits of repealing the zero lower bound and lowering the long-run inflation target in Agarwal and Kimball (2015).
} 
and credit or debit cards. As it is, in the United States, for example, many retail shops accept at par credit card payments that are worth as little as 97 cents or 98 cents on the dollar to them after credit card fees, even in states where treating cash payments and credit or debit card payments differently is fully legal. This holds true across a range of retailers that face quite different costs of handling paper currency. And other payments options with different net values are often accepted at par relatively to each other. If retailers who regularly accept both cash and card payments choose to keep cash at par when the bank discount on paper currency is only a few percent, this could reduce some of the political costs at the beginning of this policy. Retailers keeping paper currency at par would also mean a somewhat smaller portion of the transmission mechanism from purchases of cash goods. Fortunately, purchases of cash goods are not the most important part of the transmission mechanism. (We view the last sentence as an understatement.) In the U.S., for example, most large durables and intermediate goods are now purchased with some form of electronic money (including cards).

How can an exchange rate between paper currency and electronic money prevent any possible arbitrage without having to keep track of individual withdrawals and deposits of paper currency? The key is that the exchange rate is time-varying. Suppose the PCIR is kept more or less equal to other short-term rates by the crawling peg exchange rate. Then, just as a sundial keeps track of how much time has elapsed by the difference between where the shadow was at the start of the interval and where it is at the end of the interval, the exchange rate at the central bank's cash window keeps track of how much cumulative interest has been earned on paper currency to keep that cumulative interest equal to what would have been earned in electronic accounts over that interval.

The effective exchange rate at the cash window between paper currency and reserves can be implemented bureaucratically in different ways that are economically equivalent, but may have different legal statuses. For example, consider a time-varying fee on deposits of paper currency at the cash window by commercial banks. If this deposit fee gradually increases over time during a period of negative interest rates, it blocks what otherwise might be an arbitrage opportunity of withdrawing, storing and later redepositing paper currency. In the clean approach, this deposit fee would be on net deposits, which, ignoring other transactions costs, would establish an exchange rate- the price of a paper dollar in terms of an electronic dollar of reserves - equal to (1-deposit fee). ${ }^{14}$ Thus, a time-varying paper currency deposit fee effectively takes paper currency off par into a crawling-peg regime. In this

\footnotetext{
${ }^{14}$ If the (nonnegative) deposit fee were not on net deposits (that is, deposits minus withdrawals) but on deposits alone, then apart from transactions costs the exchange rate should in theory be equal to (1-deposit fee) in every period in which the banking system makes net deposits of paper currency, equal to 1 in every period in which the banking system makes net withdrawals of paper currency, and somewhere in between (1-deposit fee) and 1 inclusive when the banking system does not access the cash window. Theory also predicts that banks would trade paper currency among themselves in order to avoid the bid/ask spread at the cash window on anything other than the net deposit or net withdrawal for the banking system as a whole. Thus, this approach is not "clean": it seriously interferes with handling paper currency in a way similar to the current system. And it is a complex policy to fully analyze. However, if the PCIR implied by the exchange rate (1-deposit fee) is always at or below electronic interest rates, the bid/ask spread at the cash window guarantees that the rate of return from withdrawing, storing and redepositing paper currency is below other rates available to banks. Thus, there would be no arbitrage opportunities from paper currency storage; a one-way deposit fee can accomplish the basic task of eliminating any lower bound on rates. In some jurisdictions, a one-way deposit fee might be more consistent with a legal fiction that paper currency was still at par than a deposit fee on net deposits would be; those legal circumstances might make it an important policy to consider.
} 
crawling peg regime, gradual depreciation of paper currency relative to reserves generates a negative nominal rate of return for paper currency, where "nominal" is measured with a dollar of reserves as the numeraire.

We view the clean approach as being the policy that is at a minimum distance from the current monetary system consistent with eliminating the zero lower bound. In particular, the clean approach requires no extra regulations or quantity constraints. Its impact on the economy works entirely through the price system. As noted above, the exchange rate will hold throughout the financial system, but not necessarily at retail. (Indeed, under the electronic money system, one could use as a definition of the interior of the financial sector the region where the exchange rate holds more precisely than, say, 10 basis points.)

The clean approach generates a negative rate of return on paper currency located anywhere. Imagine a drug lord trying to spend some of his or her cache of cash. Since banks can get paper currency at a discount from the cash window of the central bank, and competition eventually causes banks to pass on cash at a discount (though perhaps not quite as big a discount), the drug lord's cash is also only accepted at a discount (barring a gun to the head). The gradual increase in the during the negative interest rate period means that the drug lord's cache of cash is also earning a negative rate of return.

For monetary policy, making the paper currency interest rate a policy instrument makes all the difference. The ability to vary the paper currency interest rate along with other key interest rates (which can be modified by standard means, even in negative territory), makes it possible to stimulate investment and net exports as much as needed to revive the economy, even when inflation, interest rates, and economic activity are quite low, as they were not long ago in many countries.

As mentioned in the introduction, a key complementary policy that can calm the political waters is to use the interest on reserves formula to subsidize the provision of zero rates on small deposit accounts. In addition to encouraging banks to protect small depositors, this subsidy insulates commercial banks from negative consequences to profitability from this provision of zero rates to small deposit accounts. (This tool is discussed in detail in this context in section VI.B.i.)

\section{Potential Side Effects of the Clean Approach}

The clean approach could have some undesired side effects; complementary policies can mitigate these side effects. The most serious side effects would arise only from areas in which the electronic currency was not treated fully as a unit of account. Here we list a few of these. First, there is likely to be a psychological and computational cost associated with paper currency being away from par. Anything new is likely to worry people, whether or not there is a good reason to worry. Beyond this psychological cost, there would be some computational cost—most consequentially for households. However, computationally, a surcharge on certain cash purchases is no more complex than sales taxes assessed at the time of the final sale - a form of sales taxes familiar in the U.S. (Even then, this cost is only incurred by households when retailers pass through a nonpar exchange rate.) Second, if old debt contracts are not 
stated in terms of the electronic unit of account, then borrowers may have an option to repay in paper currency when paper currency is cheaper than par. This problem can be addressed by legislation clarifying that debt contracts should be interpreted as referring to units of electronic (bank) money, or alternatively by debt contracts include clauses to handle situations when paper currency is away from par. For example, in the United States gold clauses — which, after being banned in 1933, have been legal again in the U.S. since 1977 - serve as a precedent for electronic payment clauses. ${ }^{15}$ Third, there can be confusion costs associated with people still thinking in terms of a paper currency numeraire. Fourth, if some prices are sticky in the paper currency then this could increase the cost of a higher inflation rate in terms of the paper currency. Fifth, there could be an inefficient tilt between cash goods and credit goods if there are sticky prices for both that prevent quick enough adjustment to reflect the changing exchange rate. These costs are all likely to be lower if electronic currency is treated fully as a unit of account or if cash transactions continue to be displaced by electronic transactions (thereby reducing the role of cash in everyday transactions). We discuss this in more detail in the next subsection.

\section{Encouraging Digitalization to Bolster Electronic Money as the Unit of Account}

In several countries paper currency is already being supplanted by electronic (or digital) payment methods. Debit cards, credit cards, phone payments, and app-based online transfers have become the principal payment methods in several advanced countries (as opposed to cash). If this trend continues, adopting the clean approach will come with lower costs and fewer side effects. Anything that raises the fraction of all transactions made in electronic form is helpful in making easier a transition to a situation in which paper currency is demoted. Moreover, greater prevalence of electronic transactions will increase the chances that the electronic currency will be treated fully as a unit of account. This puts a premium on encouraging the trend towards electronic transactions in normal times (when negative rates are not needed) to reduce implementation costs of the clean approach when negative rates are needed. For instance, a reduction in electronic transaction fees through innovation that disrupts the credit and debit card oligopoly could lead merchants to encourage greater use of electronic payments. Of course, such a push towards digitalization will need to also be combined with measures to ensure financial inclusion by reducing the number of people who are unbanked and ensuring broad access to electronic payment systems.

In this context, the recent exploration by some central banks of the idea of issuing a central bank digital currency - that is a widely accessible digital form of fiat money-could also be helpful. Such innovations are likely to further reduce the role of cash and increase the share of electronic transactions in the economy, if they were universally accessible. To make negative interest rates possible, central bank digital currency must be capable of having a nonzero interest rate. Assuming the central bank digital currency is introduced in normal times when interest rates are positive, having a positive interest

\footnotetext{
${ }^{15}$ The Gold Reserve Act 1934 was quite draconian since it disallowed certain types of contracts. By contrast, in line with these contracts becoming legal again in 1977, the policies discussed here allow parties freedom to engage in a wide variety of contracts.
} 
rate for the central bank digital currency should be popular. Such a positive interest rate in normal times would increase the opportunity cost of holding cash and accelerate the shift away from cash as a payment tool. And paying a positive interest rate in normal times sets a precedent for a negative interest rate on the central bank digital currency when necessary. To reassure people that there would be no confiscation of the central bank digital currency, it would be good to have an explicit guarantee that the interest rate on the digital currency would never be more than a fixed maximum spread below, say, the 3-month Treasury bill rate.

\section{E. Challenges to Implementing the Clean Approach}

In some jurisdictions issues of monetary law may make it difficult for a central bank to formally have an exchange rate between two different currency instruments that it issues. ${ }^{16}$ Below we present some ideas that could still make a clean approach feasible in such jurisdictions, but the exact details will depend on the local situation. ${ }^{17}$ Scholarly research on negative interest rate law is needed. For example, one important legal question that may matter for many jurisdictions is whether a paper currency deposit fee at the cash window is consistent with have paper currency legally at par, even though the economic effect is equivalent to being away from par. Another important legal question for many jurisdictions is whether an effective exchange rate (perhaps represented as a paper currency deposit fee) can be justified as a way for the central bank to recoup the costs of commercial banks using the cash window in a negative rate environment. Here, note that any arbitrage profits made through withdrawing, storing and redepositing paper currency at the cash window are at the expense of the central bank's balance sheet.

Second, a partial version of the clean approach could involve pre-announcing the right to apply the deposit fee only to newly issued paper currency after a certain date. While this would leave a certain quantity of old cash circulating at par, critically it would be only a finite quantity. To create an effective lower bound, one must withdraw, store, and redeposit paper currency freely at par, and do all of these in decisively equilibrium-rate-altering quantities. At present currency-in-circulation in most advanced countries stands between 3-10 percent of annual GDP (with a few notable exceptions such as Japan); while the value of bank deposits in these countries is typically more than ten times the currency in circulation. Furthermore, if the central bank announces this change sufficiently in advance of the time

\footnotetext{
${ }^{16}$ The fundamental set-up of our current monetary system is that (i) most central banks are by law required to issue means of payment (banknotes, book money) as per the unit of account established by law, (ii) that those means of payment are not only expressed in the unit of account, but are also mutually interchangeable and fungible (at least for financial institutions with access to the central bank's cash window); and (iii) that commercial bank book money is in principle equally interchangeable with central bank banknotes. Legally, the two latter features are achieved by considering the "account agreement" to be a "loan agreement" between account holder and (central) bank, pursuant to which the borrower (bank or central bank) must restitute the loaned amount to the lender (the account holder). (This qualification certainly applies to accounts with commercial banks; for central bank accounts the legal analysis is more complex, yet it is broadly accepted that central bank book money and banknotes are interchangeable for banks.) Given the contractual nature of that account arrangement, contractual parties can indeed agree upon specific features of that relationship (e.g., cash withdrawal fees, interest rates as a function of previous withdrawals), but the question is to what degree the courts will accept departures from the core legal set-up. In this context, after the new policy is undertaken with respect to making the electronic money (or book money) the official unit of account, the courts might interpret the contracts differently, but the specifics will depend on domestic law.
}

${ }^{17}$ In addition, the implementation will also need to ensure consistency with the IMF's legal framework. 
when negative interest rates will be needed, it will allow the central bank to naturally replace old banknotes with new banknotes as the lifespan of old notes come to an end.

Despite these potential solutions, what if the central bank chooses to keep paper currency at par or is forced to do so for political or legal reasons? While several central banks stuck at the zero lower bound have acknowledged the appeal of the clean approach, a few may still face legal or political challenges when taking paper currency off par. In the future, once one central bank blazes the trail, it is much easier for others to follow. But in the interim, can central banks enable deep negative rates if they are unable or unwilling to take paper currency off par? Yes. The next section presents one such alternative approach, which we call the "rental fee approach."

\section{The Rental Fee Approach: Using a Rental Fee to Create a Non-Zero PCIR}

If a central bank can find a legal path to do the clean approach, we recommend that approach, but if there are legal barriers, this section presents the "rental fee approach" as an alternative. ${ }^{18} \mathrm{We}$ see the rental fee approach as the second-best approach for enabling deep negative rates. It allows the central bank to create a negative PCIR at the cash window without taking paper currency off par at the cash window. While the rental fee approach can be almost as effective as the clean approach, it comes with some side effects - mainly in connection to pass-through of the rental fee and to profitability of banks.

We first discuss the rental fee at the cash window as a means of creating a non-zero PCIR without taking paper currency off par at the cash window. Then we discuss transmission of the rental fee through banks and the rest of the financial system. In section VI we discuss the side effects of the rental fee approach, and various tools that the central bank can use to manage these side effects.

\section{A. The Rental Fee Mechanism}

How would the Fed establish a negative 1 percent paper currency interest rate using the rental fee approach? Keeping paper currency at par at the cash window means that the Fed cannot change the appreciation rate, and will instead need to create a non-zero nominal rate of return on paper currency by changing the dividend rate. In the rental fee approach, the Fed would generate a $-1 \%$ PCIR by announcing a 1 percent per annum rental fee for commercial banks withdrawing paper currency from the cash window. Whenever a bank withdrew a 100-dollar note from the Fed, in addition to being debited 100 electronic dollars from its reserve account at the time of the transaction, it would pay 1 dollar per year as a rental fee to the Fed - which could be directly charged to the bank's reserve account at the Fed. This generates a $-1 \%$ PCIR. The fee can be levied on a monthly basis by the Fed to the commercial banks on the outstanding amount of cumulative net withdrawals of paper currency by the bank.

\footnotetext{
${ }^{18}$ The concept of 'rental fee' here is used as a metaphor to make it helpful to understand this approach, but it is not a legal description of the approach.
} 
Because the Fed continues to stand ready to exchange one electronic dollar for one paper dollar, the capital gains term in Equation (1) is zero. Thus,

$$
P C I R=\underbrace{\text { Dividend Yield }}_{- \text {Rental Fee }}+\underbrace{\text { Capital Gains Rate }}_{0}
$$

We use the analogy of a rental fee. What is rented is the "paperness" of a given amount of currency. The commercial banks are charged a rental fee for all cumulative net cash withdrawals they have taken out from the inception of the policy to the current date. Implementation is straightforward: central banks already keep track of the amount of net cash withdrawals by each bank. Creating a non-zero PCIR at the cash window using this method requires no action beyond what happens at the central bank's own cash window. However, it puts a substantial burden on commercial banks to figure out how to transmit or transform the rental fee imposed at the cash window when they provide paper currency to their customers.

The rental fee mechanism is equivalent to a central bank imposing a negative interest rate on a bank's cash holdings beyond its cash holdings at the inception of the policy. That is, in interlocking clauses, a central bank can put any bank with access to the cash window on the hook for (i) whatever paper currency interest rate the central bank decides to charge (ii) on that bank's cumulative net withdrawals of paper currency after a certain date-(iii) regardless of who actually ends up with that paper currency. Then it is up to the bank to figure out how and whether to pass on to its customers the negative paper currency interest rate it faces on that extra paper currency.

To avoid inconveniencing households, the central bank could set an exemption amount for this policy, allowing banks to withdraw amounts up to the net withdrawal of paper currency on behalf of customers up to that per-customer, per-month limit. The amount could be set at a level that would not inconvenience households that depend most heavily on being able to pay in cash, but would prevent large-scale withdrawals. ${ }^{19}$

\footnotetext{
${ }^{19}$ One loophole in this mechanism for imposing negative interest rates on cumulative net withdrawals of paper currency would be if a bank went bankrupt after withdrawing a large amount of cash at the cash window and handing off that cash to favored individuals. But surely the number of banks that have access to the cash window willing to intentionally go bankrupt to help favored individuals get paper currency not subject to the negative interest rate is limited, and there may be some way for the government to prosecute the individuals who organized this scheme of using bankruptcy to circumvent the negative interest rate on additional paper currency. In many countries, recall that direct access to the cash window is a valuable privilege that only the medium- and larger-sized banks enjoy. These are well-established and well-regulated banks and are precisely the banks that are less likely to be willing to go bankrupt to engineer such schemes. Moreover, the correspondent banks with direct access to the central bank cash window that do not plan to go bankrupt themselves will remain on the hook for any cash they withdraw from the central bank, and so will be cautious about giving large amounts of cash to a smaller bank that might go bankrupt (intentionally or unintentionally).
} 


\section{B. Current Implementation of the Rental Fee Mechanism at Central Banks}

While the rental fee mechanism may sound esoteric, a version of it was put into place by the Swiss National Bank (SNB) in 2014. The SNB's negative rate policy imposes such a charge to banks for excess paper currency withdrawals. ${ }^{20}$ In their implementation, a negative interest rate is charged only on the portion of the bank's reserves ("sight deposit balance") at the SNB that exceeds a certain threshold. The calculation of the exemption threshold explicitly takes into account the net increase in cash holdings. That is, the exemption amount for a given bank's sight account balance at the SNB that is not subject to negative rates is reduced one-for-one for any net increase in its cash holdings since 2014. This effectively imposes a charge to banks (equivalent to the rental fee) for excess paper currency withdrawals.

In 2016, the Bank of Japan (BoJ) followed in the footsteps of the SNB. Their implementation of negative interest rate policy is similar to that of the SNB: the BoJ adjusts up the portion of bank reserves to which negative rates apply one-for-one when the bank exchanges its central bank reserves for cash. ${ }^{21}$ The main difference between the BoJ implementation of the negative PCIR is that the BoJ only subjects the bank's own holding of paper currency to the PCIR, and does not include paper currency the bank passes on to its customers. Therefore, the negative PCIR is not on the (excess) cumulative net withdrawals (as in the case of SNB), but rather on the storage of paper currency by the bank. However, in the future, if a bank starts making large paper currency withdrawals to pass paper currency on to customers, the BoJ could take action to discourage the flow by subjecting the entirety of cumulative net withdrawals to the negative PCIR as the SNB does, or the entirety of cumulative net withdrawals beyond an exemption limit to the negative PCIR.

So far, these central banks charge the negative PCIR through the formula for interest on reserves, but there is no reason it needs to stop there if very large amounts of paper currency are withdrawn. That is, banks can be charged interest on cumulative net cash withdrawals quite apart from how their reserve accounts are handled. Then, there would be no limit to how low the marginal paper currency interest rate could go using the mechanism of a negative rate on cumulative net cash withdrawals.

\section{The Rental Fee Approach to Enable Deep Negative Rates in Brief}

Once one recognizes the power of the central bank to charge a non-zero paper currency interest rate (PCIR) to commercial banks - using the rental fee method - the main remaining concern for the central bank is about how to facilitate the efforts of commercial banks to "pass on" the negative interest rate on paper currency in some form to other parts of the economy. This concern is only about minimizing side effects. Establishing a negative PCIR at the cash window in line with the target rate and interest rate on reserves ensures that there is no way to make arbitrage profits at the expense of the central bank by

\footnotetext{
${ }^{20}$ https://www.snb.ch/en/mmr/reference/pre_20141218/source/pre_20141218.en.pdf

${ }^{21}$ https://www.boj.or.jp/en/announcements/release 2016/k160129a.pdf
} 
withdrawing, storing and redepositing paper currency. The ability to block that arbitrage opportunity by means of the rental fee removes any lower bound on rates.

In evaluating the seriousness of the side effects of the rental fee, note that when dealing with other banks, large corporate customers - or even wealthy individuals - commercial banks could simply pass on the cash rental fee directly, in the same form. In these cases, the transactions costs and dangers of customer bankruptcy will often be manageable. Hence our emphasis is on the issues in dealing with small retail customers. In the rental fee approach, one can think of "the financial system" as the interior of that part of the economy in which the paper currency rental fee is passed on as a per-unit-time fee.

The key idea of the rental fee approach is to combine negative policy rates with (a) a negative PCIR at the cash window using the rental fee mechanism, and (b) use a combination of tools to manage the side effects of the rental fee mechanism, given the inevitable awkwardness in commercial banks' attempts to effectively pass on the negative PCIR to retail customers. The next section discusses how to manage the side effects of the rental fee approach.

\section{Managing the Side Effects of the Rental Fee Approach}

We first discuss each of the key side effects of the rental fee approach, then circle back to discuss what steps can be taken to manage these side effects. Three side effects stand out: (i) the bank profitability problem, (ii) the cash-rental-fee-pass-through problem, and (iii) the 'Gresham's Law' problem. The three side effects arise because under the rental fee approach paper currency is not taken off par, which makes it harder to pass the negative rates through to all of a bank's customers. All three side effects could be avoided by using the clean electronic money approach instead. (As noted above, in the clean approach, the most serious side effects would arise only from areas in which the electronic currency was not treated fully as the unit of account.)

\section{A. Side Effects of the Rental Fee Approach}

\section{i. The Bank Profitability Problem}

Bank managements around the world have expressed great fears about falls in profitability with negative interest rates. For central banks, the concern is with bank balance sheets, which are affected by bank profitability. Negative rates affects bank balance sheets through various channels; the net impact depends on the business model of the bank. Several of these channels improve bank balance sheets when interest rates are cut. The one channel that hurts bank balance sheets when interest rates are cut has to do with the difficulty of passing negative rates through to retail depositors. We discuss the various channels in detail below.

The first channel by which a cut in rates affects bank balance sheets is the valuation effect. Because of standard maturity transformation, banks often hold long-term assets financed by short-term liabilities. The gap between the maturities on the asset- and liability-side of the bank balance sheet is referred to as 
the "maturity gap" or the "duration gap". When interest rates are cut, banks with a positive maturity gap will experience capital gains on net because the bank's mostly long-term assets have greater capital gains in response to an interest rate cut than the capital losses of the bank's mostly short-term liabilities.

The second channel is the default channel. Cuts in interest rates tend to reduce default probabilities of those borrowing from banks - both because lower interest rates reduce the interest burden of the borrowers across all their debt (thereby improving their ability to service debts), and because lower rates improve corporate profitability and the income of households due to improvements in the economy. Therefore, lower rates are associated with lower defaults and loan losses for banks, improving their profitability.

The third channel is the fees and commission income channel. When interest rates are lower, fees and commission income tend to rise. For example, in Sweden, low interest rates had a positive impact on the market for Swedish corporate bonds, which generated higher fees for major Swedish banks that had significant underwriting and advisory services (see Riksbank Monetary Policy Report, April 2016). So, lower interest rates tend to improve the fees and commission income for banks, improving their profitability.

The fourth channel is the net interest income channel. Since the above channels all typically lead to a positive impact on bank balance sheets when interest rates are cut, the main concern for bank balance sheets due to negative rates must come from the net interest income channel. ${ }^{22}$ Net interest income is defined as the difference between interest income and interest expense. The interest income comes from banks lending to corporations, households, and holding other interest-bearing assets; while interest expenses come from interest paid to retail (household) depositors, institutional depositors (such as corporations, government agencies, financial institutions), and interest on wholesale funding (such as repo financing). Experience in countries that have used negative interest rates suggests that the passthrough of negative rates to money market rates and deposit rates of institutional clients (e.g. large corporates) operate similarly in negative interest rate territory as in the positive territory, but there is a downward stickiness in retail bank deposit rates for households. The stylized fact is that banks often shield retail depositors from negative rates (Turk, 2016, Bech and Malkhozov, 2016, and Jensen and Spange, 2015).

If rates could also be cut for depositors just as much as they fall for a bank's lending, a bank's net interest margin would be unaffected by rate cuts. But, by and large, commercial banks have been afraid to cut their retail deposit rates below zero due to some combination of customer relations concerns and the concern that retail customers can substitute into small-scale paper currency storage. As a result, evidence suggests that cuts in interest rates in the negative region cause net interest margins to fall for those banks that have the heaviest reliance on retail deposits. The distinction in pass-through between retail deposits

\footnotetext{
${ }^{22}$ However, note that if negative rates stimulate the economy, the increased banking activity can also have a positive effect on net interest income.
} 
and institutional deposits is likely driven by (a) the ease of small-scale paper currency storage (due to spare storage capacity in the typical household) relative to large-scale paper currency storage, (b) the ease of small scale paper currency transactions relative to large-scale paper currency transactions (due to spare transactions capacity by the typical household and the economies of scale institutional investors and firms get through electronic transactions) and (c) the greater initial difficulty households have compared to institutions in understanding negative interest rates.

Theoretically, the limited pass-through to retail deposits could lead the net interest margin to decline enough that this effect could overwhelm all of the other positive effects on bank balance sheets from interest rate cuts. The theoretical literature suggests that in the absence of tools to effectively make transfers from the central bank to commercial banks, the bank transmission channel may become ineffective when interest rates go low enough (Brunnermeier and Koby, 2016 and Eggertsson, et al., 2017, 2019). However, as discussed below, there are many ways in which central banks can — and when real-world central banks employ negative rates, $d o$ - to effectively make transfers to commercial banks to help the balance sheets of the commercial banks.

Overall, the empirical literature finds very benign effects of negative rates on bank profitability thus far across all countries that have experimented with negative interest rates (Jose Lopez, Andrew Rose, and Mark Spiegel, 2018) ${ }^{23}$. However, if central banks implement deeper negative rates in the future without using the clean approach it is possible that difficulty in passing the negative rates through to retail deposits could create a serious bank profitability problem. Recognizing this as a potentially big worry for both the central bank and commercial banks, in the second half of this section we discuss tools the central bank can deploy to manage this side effect of the rental fee method (and of some other approaches we discuss later).

\section{ii. The 'Pass-Through of the Rental Fee' Problem}

Although the central bank can easily charge a negative PCIR on cumulative net cash withdrawals by a commercial bank, it is probably not as easy for that commercial bank to charge a negative PCIR to its retail customers on their cumulative net cash withdrawals. In principle, a bank could charge such a "rental fee" on net cash out to a customer, but what is to stop a customer from withdrawing a large amount of cash, then cutting all ties to the bank? (This is analogous to the intentional bankruptcy discussed above, but much easier.) Even if a contract still obligated the former customer to keep paying the rental fee on the net cash out, it is a lot of trouble for the bank to track that customer down and collect the fee-especially for modest amounts.

As a result, commercial banks are likely to charge a substantial one-time fee on withdrawal of cash to make it worth their while to give out cash, or add restrictions on cash withdrawals. This would interfere with the normal use of paper currency. Such one-time fees and additional cash withdrawal restrictions

\footnotetext{
${ }^{23} \mathrm{We}$ include a fuller discussion of both the theory and empirical papers in the literature review section (section XI).
} 
might not happen immediately but would be likely to emerge over time (and of course would depend on exactly what interest rate the central bank is imposing, and how long banks expect negative interest rates to last).

In order to be prepared to do this, banks would want to modify existing deposit contracts to allow them to charge such fees or put in place restrictions when depositors exchange electronic deposits for cash. Note that imposing such fees or restrictions is not the same as suspending redemption of deposits or imposing fees for redemption - customers would be free to transfer their deposits electronically with no restrictions or fees. That is, the fees and restrictions we are talking about are only about inhibiting conversion from electronic money to cash, not about movement of electronic money between banks. Therefore, the big drawbacks of suspending convertibility should not apply in this case (Cipriani, Martin, McCabe and Parigi (2014)).

Commercial banks would likely experiment with different approaches to the fees they charge their customers for giving out paper currency. One option would be to charge a fee for cash withdrawals at both the ATM machines and at teller windows proportional to the cash withdrawn. Some ATM machines already impose a quasi-proportional usage fee by combining fixed ATM withdrawal fees (usually ranging between $\$ 3-5$, but even higher in cash-intensive venues such as bars and casinos) with cash withdrawal limits per ATM transaction. For example, when the withdrawal limit per transaction is $\$ 200$ and the ATM withdrawal fee is $\$ 3$, withdrawing $\$ 600$ will require three transactions and incur a fee of $\$ 9$. On the other side of the coin, some banks now charger higher fees at the teller window than at the bank's ATM in order to discourage use of human tellers and save on staffing costs. It is a short step from these existing practices to charging a fee for cash withdrawal at both ATMs and at the teller window, as would be important when banks remain on the hook for a rental fee on any paper currency that passes through them. To make the ATM and teller-window fees more acceptable for customers, banks could allow each customer to withdraw cash up to a limit every month without any fees (or for reduced fees), whether or not that is subsidized by the central bank. ${ }^{24}$

As highlighted earlier, the pass-through problem should only be an issue for small retail customers. For more sophisticated customers, such as businesses, banks are likely to find ways to pass through the rental fee directly. This could be done simply by charging the businesses on their monthly statement a rental fee for the cumulative amount of cash they have withdrawn from the bank. Moreover, to mitigate the risk of a business withdrawing a large quantity of cash and cutting ties to the bank, banks could chose a maximum amount of cash they are willing to rent out to each business (similar to an overdraft limit on checking accounts). And just as for overdrafts, the modified banking contracts would need to ensure

\footnotetext{
${ }^{24}$ To the extent banks may guess wrong about the duration or depth of the negative PCIR policy, there will be risks to bank balance sheets when they sell or buy paper currency with a one-time fee (as a bank that withdraws cash for the central bank and sells it for a one-time fee will continue to be charged a rental fee by the central bank for the cash withdrawal even if it no longer holds the cash). If the policy is introduced early enough, that paper currency circulation is within historical norms, then the size of this risk is likely to be modest. We would predict that derivative or guarantee markets would develop allowing banks to offload these risks to speculators. The development of such derivative or guarantee markets should be encouraged precisely to enable banks to hedge against these risks.
} 
that the businesses remain liable to the bank for the rental fee even after otherwise cutting ties to the bank.

\section{iii. $\quad$ The Gresham's Law Problem}

A modern version of Gresham's Law states that bad money drives out good money when there is a fixed exchange rate between the two currencies (Dutu, Nosal, and Rocheteau, 2005). The classic example of this is a case in which a mint issues two types of silver coins - one containing, say, half as much silver as the other - but the government gives both coins the same denomination. In this case Gresham's Law predicts that the lighter-weight silver dollar (referred to as 'bad money' because it is overvalued) is more likely to circulate, as there will be incentives to hoard or melt the heavier-weight coin (the 'good money').

Gresham's Law depends for its operation on some obstacle to the bad money and good money simply having an exchange rate between them. This could be because of legal requirements that anything one can buy with a given face value of good money one can also buy with that face value of bad money. Or it could be because it is inconvenient to ascertain whether something is good money or bad money during a routine transaction. (Note however, that Gresham's Law depends on it being easy enough to tell the difference between good money and bad money that people are identifying good money and taking it out of circulation - in the classic case, either to melt down or hoard.)

Under the rental fee approach, there are three types of money, all easy to tell apart: electronic money, paper currency with a rental fee obligation attached, and paper currency "in the wild" without a rental fee obligation attached. While the exchange rate between electronic money and paper currency with a rental fee obligation attached remains 1:1, the exchange rate between paper currency with a rental fee obligation attached and paper currency in the wild without a rental fee obligation attached need not be 1:1. Indeed, there should at least implicitly be a premium on paper currency in the wild. Gresham's Law suggests that money that has an implicit premium while there is an official exchange rate of 1:1 is likely to be withdrawn from circulation. But it is possible that, when it is as easy to tell two types of money apart as it is to tell paper currency in the wild apart from paper currency with a rental fee obligation attached that a reasonably liquid exchange rate would emerge between these two forms of paper currency.

One factor that would help keep paper currency in the wild from going at an explicit premium at goods and services retailers would be credit-card contracts that prohibit a surcharge for credit card usage relative to paying with paper currency. But some retailers might be able to accept paper currency at a discount — which is equivalent to having paper currency worth a premium. And banks might be able to pay a premium for paper currency.

The possibility that a fluctuating but relatively liquid premium would arise on paper currency in the wild (with no rental-fee obligation attached) instead of a Gresham's Law withdrawal of paper currency from 
circulation is part of the reason we do not consider the rental fee approach to be "clean." Nevertheless, because the exchange rate between paper currency in the wild and paper currency with a rental fee obligation attached is not a direct action of the central bank, and the rental fee approach maintains a 1:1 exchange rate between electronic money and any paper currency the central bank does deal with directly, the legal requirements some central banks face for paper currency being at par could be satisfied even if there is what (in defending the central bank legally) can be characterized as a gray market exchange rate between the paper currency the central bank disburses and paper currency in the wild.

The fluctuations in the exchange rate between wild and tame paper currency - or equivalently in the rental fee approach, between wild paper currency and electronic money-would arise primarily from changing expectations of the future path of the rental fee imposed by the central bank: the lower the PCIR imposed at the cash window, the higher the premium on wild paper currency. We predict that these fluctuations from changing expectations about a rental fee in the rental fee approach would be less than the fluctuations in the exchange rate for paper currency if, as discussed below, issuance of new paper currency were stopped, or a quantitative limit were placed on withdrawals from the cash window. A key reason for this prediction is how conducive to irrational speculation stopping issuance or a quantitative limit on paper currency withdrawals might be.

In the rental fee approach, a premium on wild paper currency that is expected to depreciate as the negative interest rate period gets closer to its end generates a negative expected return on wild paper currency. Thus, arbitrage conditions can be satisfied without any ability to make arbitrage profits on the withdrawal, storage and redeposit of paper currency. We discussed above how no profits are available from commercial banks withdrawing tame paper currency from the cash window, then storing and redepositing it at the cash window. Commercial banks then have ample incentive to set one-time fees on paper currency they give out to avoid any arbitrage at their expense. That is, commercial banks have ample incentive to make wild paper currency expensive enough to obtain that there is no expected arbitrage profit to be had by others who withdraw paper currency from commercial banks that becomes wild at the moment of that withdrawal. They might make a mistake in setting the withdrawal fees too low-but would quickly realize they had set the withdrawal fees too low if the quantity of withdrawals was unusually high.

Further analysis of the case in which a liquid exchange rate arises between wild paper currency and tame paper currency is relatively straightforward. And the particular type of inconvenience from such a situation is also easy to understand. Therefore, for the rest of this section, we focus on the other case in which at official 1:1 exchange rate has enough influence that Gresham's Law operates to drag wild paper currency out of circulation. (This is most likely to be the relevant case when rental fee is of modest size and expected to be of modest duration.) In addition to reduced circulation of paper currency due to hoarding, the Gresham's Law case might also lead to centralization of paper currency storage. We discuss reduced circulation and centralized paper currency storage in turn. 
Reduced circulation of paper currency due to the Gresham's Law problem: Even without an explicit and well-known exchange rate between wild paper currency and the other two forms of money (electronic money and tame paper currency), households and small businesses will value wild paper currency more than electronic currency. If they can't readily sell it at a premium, they will have incentives to hoard paper currency, instead of using it as a medium of exchange. This in turn will lead to reduced circulation of paper currency in the system. This could be burdensome and costly for some households and small businesses, especially for those that rely heavily on cash transactions. On the other hand, a silver lining of reduced circulation of paper currency would be that it encourages electronic transactions and the adoption of technology that facilitates electronic transactions. By raising the fraction of electronic transactions - and encouraging irreversible investments in digital payment systems - the Gresham's Law effect would make it easier for the central bank to use the clean approach based on an electronic unit of account at a later date.

Another silver lining of the Gresham's Law effect would be making law enforcement easier. While many individuals use paper currency for perfectly legal purposes (and some may even have an 'irrational' preference for cash), an important part of the demand for paper currency is driven by the desire to keep secrets from the government. As Ken Rogoff (2016) puts it, in addition to the legal taxpaying domestic economy, the sources of demand for cash include the (a) not-so-law-abiding domestic underground economy-including both tax evasion and criminal activities, and (b) the global economy - including both legal and illegal demand.. ${ }^{25}$ Imposing a rental fee on cash withdrawals does not eliminate the freedom to use cash, but makes large-scale murky cash withdrawals stand out more, thereby facilitating law enforcement.

Centralization of paper currency storage: A second Gresham's-law-related side effect of the rental fee approach is that it could create incentives for setting up businesses to do paper currency storage. Some individuals may find it profitable to set up businesses that "hoover up" paper currency from households and small businesses to centralize paper currency storage. This is mainly a problem in connection with a policy that encourages banks to allow households to withdraw a certain amount of paper currency each month without fees by letting the commercial banks avoid the rental fee on that amount. If banks face a negative PCIR on all cash withdrawals then it will be difficult for papercurrency-storage businesses to get hold of cash: banks wouldn't give cash out for free and household's wouldn't be able to get cash out for free to "sell" to these businesses. Those with private hoards of cash in the economy would also have no incentive to sell to these businesses, since they already get the benefits of a zero interest rate on that cash (speaking of that cash as if it were at face value). On the other hand, if households are allowed a monthly exemption amount for rental-fee-free cash withdrawals, then they may have an incentive to withdraw the maximum amount and "sell" the paper currency to

\footnotetext{
${ }^{25}$ It is important for advocates of the "privacy" provided by paper currency to identify the social benefits from the help paper currency provides in keeping other kinds of secrets from the government and from the help paper currency provides in keeping secrets from firms and individuals outside the government.
} 
businesses at a premium in exchange for electronic money, which they could then spend. Thus, the possibility of centralization of paper currency storage would make any given exemption amount for paper currency withdrawals more costly because fewer individuals would withdraw less than the maximum.

The side effects of the rental fee approach depend on whether Gresham's Law applies or if instead a liquid exchange rate arises between wild paper currency and the other two forms of money (tame paper currency and electronic money, which are at par with one another). In either case, we believe the side effects, even without any management, are acceptable compared to the large costs of accepting a lower bound on rates. However, we believe these side effects of the rental fee approach would be worse than the side effects of the clean approach, even with management.

\section{B. Tools to Manage the Side Effects of the Rental Fee Approach}

The most important side effect of the rental fee approach is on bank profitability. The key measure we recommend to deal with that side effect is for the central bank to subsidize the provision of zero interest rates to small retail deposit accounts. ${ }^{26}$ This measure is also likely to reduce the amount of political heat a central bank faces for its negative rate policy. Negative interest rates on small retail deposit accounts would be highly salient to the public and would be well-covered by journalists. For this and other reasons, we view negative interest rates on small retail deposit accounts as something to be avoided. The cash-rental-fee pass-through problem is the next most serious issue. The pass-through problem is primarily one for the commercial banks to solve themselves, but to the limit of its regulatory authority and its suasion with other bank regulatory agencies and legal authorities, the central bank should support the commercial banks in pursuing the necessary contract modifications and modifications of business practices.

It is unclear which will best describe the equilibrium for wild paper currency: (i) Gresham's Law, (ii) a liquid fluctuating exchange rate for wild paper currency relative to tame paper currency and electronic money, or (iii) something in between. In any of these cases, tools of the prohibition approach may be helpful in addressing whatever combination of Gresham's Law effects and a fluctuating exchange rate for wild paper currency arise. We discuss using tools of the prohibition approach to address such side effects in Section X: "Combining the Rental Fee Approach and the Prohibition Approach." Alternatively, Gresham's Law effects and a fluctuating exchange rate for wild paper currency can simply be accepted. In Table 2 we label the use of tools of the prohibition approach to deal with these side effects as optional.

\footnotetext{
${ }^{26}$ Having a zero interest on a portion of reserves when the market rate is negative is a subsidy from the perspective of economic analysis, but may not be seen formally as a subsidy by the banks. Nevertheless, any design will need to deal with the issues of central banking law.
} 
The Rental Fee Approach to Enabling Deep Negative Rates

\begin{tabular}{|c|c|c|}
\hline Economic Actor & $\begin{array}{c}\text { Effects of Negative Rates/ Side-Effects of } \\
\text { Rental Fee Approach }\end{array}$ & $\begin{array}{c}\text { Central Bank Tools to Manage Effects / Side- } \\
\text { Effects }\end{array}$ \\
\hline \multicolumn{3}{|c|}{ Effects of Negative Rates } \\
\hline Main Worry for the Central Bank & Possibility of Cash Arbitrage & Rental Fee Mechanism at the Cash Window \\
\hline \multicolumn{3}{|c|}{ Side-Effects of Rental Fee Approach } \\
\hline $\begin{array}{l}\text { Big Worry for Both Commercial Banks and the } \\
\text { Central Bank }\end{array}$ & Bank Profitability & $\begin{array}{l}\text { Subsidy for Providing Zero Rates for Small Accounts; } \\
\text { Negative Lending Rates }\end{array}$ \\
\hline Worry for Commercial Banks & Pass-Through of the Cash Rental-Fee & $\begin{array}{l}\text { Supporting Bank Contract Modifications; } \\
\text { Exempting Cash Withdrawals up to a Limit }\end{array}$ \\
\hline Additional Worry for the Central Bank & $\begin{array}{l}\text { Gresham's Law Effect } \\
\text { (Reduced Circulation of Paper Currency and } \\
\text { Centralization of Paper Currency Storage) }\end{array}$ & Tools from the Prohibition Approach (Optional) \\
\hline Inconvenience for Cash Users & $\begin{array}{l}\text { Fluctuating Exchange Rate for Wild Paper } \\
\text { Currency }\end{array}$ & $\begin{array}{l}\text { Large Exemption Levels for Cash Withdrawals Combined } \\
\text { with Tools from the Prohibition Approach (Optional) }\end{array}$ \\
\hline
\end{tabular}

Table 2: Effects and Tools of the Rental Fee Approach to Enabling Deep Negative Rates

Background assumptions. In discussing these tools to deal with side effects of the rental fee approach, let us take as background assumptions, first that the central bank has already taken electronic rates negative: the target rate, the Treasury-bill rate and the rate that applies to marginal additions to reserves. For this approach, a negative lending rate (such as the one currently in place at the ECB in its targeted longer-term refinancing operations-TLTROs) is not essential but is an additional tool to shore up bank profitability.

Second, assume that the central bank has established a negative PCIR between central banks and commercial banks at the cash window using the rental fee method. This ensures that commercial banks do not have any arbitrage opportunity to hoard cash. In addition, this ensures that commercial banks have incentives to avoid freely 'renting' out cash to its own customers, as it is costly for the banks to obtain cash from the central bank due to the rental fee.

Third, assume that there is a negative between-tax-year interest rate in the tax system. (The within-taxyear interest rate is less important because the amount of lending to the government that can be done by tax-prepayment within the tax year is limited by tax liabilities within that year, and this effective ceiling on zero-interest-rate lending to the government within the tax year becomes lower as the tax year comes closer to its end.) Even if the condition of a negative between-tax-year rate within the tax system did not hold, it is not easy to use the tax system as if it were a bank because the taxpayer cannot strictly control the timing of refund or repayment. 
Kimball and Kimball (2015) discuss the interaction of negative interest rates with the tax system in some detail for the US case. In the U.S., current law gives the Secretary of the Treasury the authority to set the between-tax-year interest rate in line with other short-term rates. This should allow the Secretary of the Treasury to set a negative between-tax-year rate if other short-term rates are negative. In other jurisdictions, there may be legal or political constraints in imposing a negative between-tax-year interest rate in the tax system. Alternatively, the leadership of the tax authority could be against the negative interest rate policy. Even in these cases, it is unlikely that the tax authority would want the tax system to be a place for people to store funds at a zero interest rate. The typical tax authority is likely to view such activities as disruptions to its normal operations. So they would be likely to find ways to discourage such behavior. For example, the tax authority might put quantitative limits on prepayments — say, by declaring that prepayments beyond a certain percentage would be treated as donations to the tax authority. ${ }^{27}$

\section{i. Using the Interest on Reserves Formula to Subsidize Zero Rates for Small Households}

The bank profitability problem arises in large measure from the difficulty banks face in passing on negative rates to their small retail depositors, which squeezes net interest margins. Experience with negative interest rates in Switzerland, Sweden, Denmark, and the eurozone indicates that as rates are cut below zero, negative interest rates are not immediately passed through to the small-scale bank accounts held by the typical household.

Banks are likely to make a distinction in their strategy towards legacy customers and hot-money customers. Legacy customers with de facto loyalty to a given bank are a long-run source of profits; if their accounts are not too large, shielding them from modest negative interest rates may not cost that much and may be worth a lot in not alienating them. Hot-money customers have little loyalty; the fact that they take advantage of a bank's above-market zero deposit rate today doesn't mean they will be there generating profits next year. So, there is relatively little lost from making new customers who are more likely to be hot-money customers face negative deposit rates. In addition, customers who have very large accounts are expensive to give a zero deposit rate in a negative rate environment. Moreover, those who are most expensive to give an above-market rate to tend to be more sophisticated and so less likely to quit a bank out of sheer emotional pique over negative rates. The upshot is that in an environment of negative interest rates, banks may shield most retail depositors (but not large, sophisticated depositors) from negative rates. Shielding retail depositors from negative rates may hurt banks' profitability.

\footnotetext{
${ }^{27}$ A similar argument can be made that the tax authority, in a reactive mode, would be likely to try to strenuously discourage large tax payments in paper currency when paper currency was below par in the clean approach. The tax authority might even be able to get a legislative "technical correction" enacted to prevent large paper currency payments if it found itself unable to discourage such payments in other ways. Note again that such reactive motivations do not rely on either the tax authority or the legislature approving of the negative interest rate policy itself.
} 
The bank profitability problem can be readily handled by transferring funds to banks when necessary, using existing central banking tools. For example, several central banks have already been doing this using a tiered interest-on-reserves formula. Danmarks Nationalbank has a negative interest rate on its certificates of deposit (CDs) but allows banks to place amounts up to a certain limit in their current account at a zero interest rate. The current account limit is set low enough to ensure transmission from the CDs to the money-market rates. The Swiss National Bank (SNB) allows a similar exemption from negative interest rates on any amount of deposits a bank holds below an exemption threshold. The SNB sets the exemption threshold at twenty times the minimum reserve requirements in reporting period 2014, minus the net increase in cash holdings since then. The Bank of Japan (BoJ) uses a three-tier system: reserves up to a certain balance earn 0.1 percent (basic balance), the next tier earns 0 percent (macro-add on), while the rest is subject to negative interest rates (policy-rate balance).

As mentioned above, another tool that has been used to transfer funds to banks is the European Central Bank's negative lending rate through its targeted longer-term refinancing operations (TLTROs). Under TLTRO II, banks are able to borrow at the deposit facility rate (-0.4 percent) up to a limit, as long as they meet certain benchmarks for lending targets.

Building on these precedents, we recommend that central banks pursuing any approach to negative interest rate policy - including the clean approach — use the interest-on-reserves formula to subsidize banks in providing zero rates to small household deposit accounts. For example, a two-tiered system could be designed to be equivalent to a subsidy to the deposit rates for household accounts below a certain size-say enough to provide a zero interest rate on an average balance over a month of, say, 5000 euros for a couple or 2500 euros for an individual, for an adult's main bank. Such a system could be based on fully voluntary reporting by banks after individuals voluntarily sign up to get the subsidy. (Those with more than one bank would have to designate one bank for this effective subsidy.) Rogoff (2016) has advocated similar mechanisms to shield small depositors from negative rates.

We see four virtues to tying the amount of deposits with the central bank that a private bank can get zero interest rates on to the amount of household balances up to a given per-adult limit:

1. It takes care of the bank profitability problem, or the bulk of the bank profitability problem.

2. The limit defining what amounts of money are over the limit provides a marker for banks in explaining to customers that large accounts will have the over-the-limit amount subject to negative interest rates. This should make pass-through to large accounts a bit easier for the banks.

3. Being able to get zero interest rates on small-scale deposit accounts should reduce the incentive for households to do small-scale paper currency storage. 
4. Avoiding negative interest rates on small deposit accounts avoids a potential political problem for the central bank. Because this would also be a customer relations problem for the commercial banks, the central bank should be able to rely on the commercial banks to avoid negative deposit rates as long as those banks can do so without hurting the bottom line. The subsidy through the interest-on-reserves formula ensures that banks can provide zero rates for small deposit accounts without hurting their bottom line.

If (i) the central bank is successful at avoiding massive paper currency storage, with its attendant disintermediation (a key objective in most of the policies discussed in this paper) and (ii) the central bank subsidizes the provision of zero rates to small deposit accounts, banks should only have a profitability problem if they fail to pass on negative rates to those with large deposit accounts. Fortunately, experience in Switzerland, Denmark, and Sweden suggests that the more sophisticated bank customers who have large accounts or have commercial accounts adjust quickly to negative interest rates after a few weeks of bitter complaining. The objective of a two-tier system is to have negative interest rates prevail generally in the markets, but shield from negative interest rates those who are the least able to understand negative interest rates - and perhaps to accomplish a bit of redistribution as well (though clearly not redistribution toward the poorest of the poor, who may not have bank accounts at all). ${ }^{28}$

\section{ii. Supporting Bank Contract Modifications that Help Banks Discourage Cash Withdrawals}

As discussed, once the negative PCIR is enforced at the cash window, banks will have a strong incentive to discourage cash withdrawals to avoid handing out cash at a loss. The banks would want to modify existing contracts or business practices in order to discourage depositors from withdrawing too much paper currency. Discouraging depositors from withdrawing too much paper currency is also in the interest of the central bank, so the central bank should support banks in modifying contracts and business practices to achieve this goal. In most jurisdictions, there is already a wide range of contracts and practices allowed in commercial law, and the central bank is a key regulator of banks. Where other bank regulators have a say, the central bank should ask them to also support commercial banks in their efforts to limit the total quantity of cash withdrawals. ${ }^{29}$

Focusing first on household depositors, here are some of the ways commercial banks might discourage large cash withdrawals:

\footnotetext{
${ }^{28}$ Note that worrying about redistribution per se is typically not a mandated central bank objective in the context of monetary policy. Monetary policy actions do have redistributive effects. For example, there has been criticism of the regressive redistributive effects of quantitative easing (QE). By contrast, the policies proposed here do not present such concerns-and in fact have the opposite impact by redistributing towards lower-income households (although not redistribution towards the poorest of the poor, who may not have bank accounts at all.)

${ }^{29}$ Note that, in general, the primary purpose of supervisory rules is to achieve soundness of banks and use of such rules to pursue monetary policy objectives may raise legal issues that will need to be addressed.
} 
- Put fees on each withdrawal transaction at a bank's own ATMs and impose a maximum amount for each cash withdrawal.

- Impose similar fees at the human teller windows.

- Alternatively, discontinue cash withdrawals at the teller window, directing customers to the ATMs.

- Keep a low inventory of cash in the branch (other than in the ATMs themselves), so tellers could often tell customers honestly: "I can't; I don’t have enough cash here at my window."

All of these fees, restrictions, and obstacles will seem more acceptable to customers if there is a certain amount of paper currency withdrawal each month that is exempt from these fees, restrictions, and obstacles. In addition to regulatory help, the central bank can support banks in their efforts to deal with the rental fee at the central bank's cash window by subsidizing the banks in giving household depositors some amount of paper currency each month that is exempt from fees and restrictions. For example, in a "pass-back" of the exemption levels the commercial banks apply to customers, the central bank could allow banks to withdraw rental-fee-free cash at the cash window up to a monthly limit calculated as:

$$
\sum_{\text {retaildepositors }} \min (\text { max per retail depositor, actual amount withdrawn by depositor })
$$

Again, as with the subsidy for the provision of zero rates up to a limit, depositors would need to provide an identification number and designate a primary bank which would receive the subsidy in order to avoid double-dipping. Note that, as with the subsidy for the provision of zero rates up to a limit, the perdepositor limit on the central bank's exemption amount for no-rental-fee cash withdrawals should make it easier for commercial banks to explain why they need to charge fees or impose restrictions beyond that limit.

Although household depositors are likely to feel a bank's policies are more fair if there is an exemption amount, if they sense that a paper dollar in the wild is more valuable than a dollar in the bank, they are likely to withdraw more than in normal times. The worst case in this regard, which would lead many to withdraw the limit each month, would be if they could easily sell the paper currency at a premium to businesses that were centralizing paper currency storage. The central bank might want to announce early on that it would lower the per-depositor limit on the exemption amount of cash withdrawals if cash withdrawals rose above the historical norm, or if signs of widespread centralization of paper currency storage by paper currency storage businesses arose.

If there were a liquid exchange rate on wild paper currency, an exemption amount for paper currency withdrawal would be equivalent to a simple transfer from the bank to the customer. Still, representing 
this as an exemption amount for paper currency withdrawal coupled with a proportional rebate if less than the maximum is withdrawn might be attractive to customers.

Turning to business depositors, it is uncommon for businesses to have a need to make net cash withdrawals over the course of a month. Many businesses take in cash and need to make net cash deposits over the course of a month. And many businesses need to exchange some of the large bills that they get from customers for smaller bills to give as change to give to customers. There are illegitimate reasons businesses might want to take out paper currency, such as aiding worker tax evasion or paying bribes. But legitimate reasons for net cash withdrawals by businesses over the course of a month are uncommon. (Getting an initial stock of change for a new cash business might be one of the more common legitimate reasons for net cash withdrawal by a business.) It should be possible for banks to charge fees in such uncommon situations without causing too much of a ruckus.

\section{Negative PCIR Based on the Price System vs. Quantity Restrictions}

In addition to a bank-centric approach to enabling negative rates, we recommend a price approach. Nevertheless, it is worth discussing quantity approaches both as other alternatives and also to explain why we don't recommend them unless the price approaches are infeasible. In this section we walk through our taxonomy of options to enable deep negative rates, and clarify the distinctions between the quantity and price approaches to enabling deep negative rates.

In our $2 \times 2 \times 2$ taxonomy of options to enable deep negative rates, there are three dimensions: (1) whether the government is acting directly on a wide swath of the economy or relying on the financial system to transmit the negative paper currency interest rate, (2) whether the approach requires quantity restrictions on cash or instead relies solely on the price system to alter the rate of return for paper currency), and (3) whether the negative rate of return for paper currency is achieved through the dividend term or the capital gains term in the rate of return equation.

\begin{tabular}{|c|c|c|c|}
\hline \multicolumn{4}{|c|}{ Options to Enabling Deep Negative Rates by Imposing Negative Paper Currency Interest Rates } \\
\hline & & Direct Negative PCIR Everywhere & Transmission Through Banks \\
\hline \multirow{2}{*}{$\begin{array}{l}\text { Negative PCIR based on the } \\
\text { Price System }\end{array}$} & Depreciating Cash & $\begin{array}{c}\text { (1) Eisler (1932) } \\
\text { (2) Buiter (2009) } \\
\text { (3) Tax Approach (Feldstein 2002; Correia et. al, 2013) }\end{array}$ & Clean Approach (Agarwal and Kimball, 2015) \\
\hline & $\begin{array}{l}\text { Negative Dividend } \\
\text { on Cash }\end{array}$ & $\begin{array}{l}\text { (1) Gesell (1906) } \\
\text { (2) Goodfriend (2000) } \\
\text { (3) Mankiw (2009) }\end{array}$ & Rental Fee Approach (this paper) \\
\hline \multirow{2}{*}{$\begin{array}{l}\text { Negative PCIR based on } \\
\text { Quantity Restrictions on Cash }\end{array}$} & Depreciating Cash & $\begin{array}{l}\text { Abolish Paper Currency Approach } \\
\text { (Buiter, 2009; Rogoff, 2015) }\end{array}$ & $\begin{array}{l}\text { (1) Withdrawal Limit Approach (Goodfriend, 2016) } \\
\text { (2) Deposit Limit Approach (this paper) }\end{array}$ \\
\hline & $\begin{array}{l}\text { Negative Dividend } \\
\text { on Cash }\end{array}$ & $\begin{array}{l}\text { (1) Prohibition Approach (this paper) } \\
\text { (2) Eliminate Large Bills Approach (Rogoff, 2017) }\end{array}$ & $\begin{array}{l}\text { Prohibition Approach Ban on Cash Electrification } \\
\text { (this paper) }\end{array}$ \\
\hline
\end{tabular}

Table 3: Revisiting the Approaches to Enabling Deep Negative Rates 
In the history of thought section, we reviewed several approaches that apply a negative PCIR directly to a wide swath of the economy. These approaches are listed in the first column of Table 3 in the top three rows: a fully explicit and official, legislated dual currency system, direct taxation on every piece of paper currency whenever it is used in any transaction, and the abolition of paper currency. (In the table, we categorize the abolition of paper currency as a quantity approach, but it could also be seen as a price approach, since if the price of paper currency drops to zero, the quantity does not matter. ${ }^{30}$ ) In addition, we have reviewed two approaches that lie at the intersection of bank-centric approaches and price-based approaches: namely the clean approach and the rental fee approach (our recommended approaches). In the next sections we will discuss approaches that lie at the intersection of bank-centric approaches and quantity-restriction approaches - namely the withdrawal limit approach, the deposit limit approach, and the prohibition approach. The prohibition approach has both bank-centric and universally applied elements, and therefore it also appears in the intersection of the 'direct negative PCIR everywhere' approaches and 'quantity restrictions' approaches. The key feature of the quantity restriction approaches is that they impose restrictions on either the withdrawal, storage, or redeposit of cash. This is in contrast to price approaches that operate entirely through the price system with no physical restrictions on cash.

\section{The Withdrawal Limit Approach and the Deposit Limit Approach}

All approaches to eliminating a lower bound on interest rates must have some obstruction to earning a near-zero return on paper currency through the simple arbitrage of withdrawing paper currency at the cash window, storing it, then depositing it again at the cash window at a fixed exchange rate. Two quantitative limits that can be implemented at the cash window alone to short-circuit this arbitrage are quantitative limits on withdrawals of paper currency at the cash window and quantitative limits on deposits at the cash window.

Marvin Goodfriend (2016) discusses quantitative limits on withdrawals. ${ }^{31}$ He argues that interest rate policy can and should be unencumbered expeditiously in a future crisis so that negative interest rates can be made freely available and fully effective as a realistic policy option. Putting a ceiling on the stock of paper currency short-circuits any unlimited option for a paper currency arbitrage, and so avoids any lower bound on interest rates. This ceiling on the stock of paper currency would create a freely floating

\footnotetext{
${ }^{30}$ In most cases, a government can cause the price of paper currency to drop to zero simply by renouncing that paper currency. The recent demonetization of some bills in India is a case in point. However, it is not always so simple: paper currency without Saddam Hussein's picture on it retained value in the Kurdish region of Iraq even when the Kurdish use of these bills was not supported by interaction with the central government of Iraq during the period between the 1990-1991 Gulf War and the 2003 Iraq War. This episode in monetary history deserves careful study.

${ }^{31}$ In section "VI.ii. Introduce a Flexible Market-Determined Deposit Price of Paper Currency," Goodfriend begins by discussing a quantity-of-paper-currency rule that effectively imposes both withdrawal and deposit limits with no daylight between them. But he ends the section by discussing a policy that would use withdrawal limits alone, and his historical parallels are more relevant to this case. Here is the relevant passage: "If thought desirable, the central bank could run an asymmetric float - and intervene to absorb the excess supply of currency whenever the deposit price of paper currency threatened to fall below par." Goodfriend does not discuss the use of deposit limits by themselves.
} 
exchange rate between paper currency and bank money when net withdrawals would have been made if paper currency were at par. When central banks cut interest rates into the negative region, the paper currency would be driven above par, and would then be expected to fall towards par at a rate equal to the negative nominal interest rate. This would make the public indifferent between holding deposits in banks that pay negative rates and holding paper currency that is expected to depreciate at an equivalent rate. We call this the "withdrawal limit approach."

The converse approach is to put quantitative limits on deposits. Under the "deposit limit approach" the central bank announces that in the future each bank that has access to the cash window would be limited in a calendar year to cumulative net deposits in a year of no more than $\mathrm{x} \%$ of the paper currency they had on their books at the beginning of the year. The key would be to choose $\mathrm{x}$ to be a level that is nonbinding in normal times, but would get in the way of paper currency arbitrage in times when interest rates have recently been negative. ${ }^{32}$ In addition, in the deposit limit approach, the central bank would want to announce that it might reduce $\mathrm{x}$ if it saw the amount of paper currency withdrawn balloon up, thereby preserving the option to experiment with the right threshold to discourage paper currency arbitrage. This approach would also create a floating exchange rate for paper currency, but it would do so by relying on limits on paper currency deposits rather than paper currency withdrawals, and it would push the value of paper currency below par rather than above par.

While both of these approaches share with the clean approach taking paper currency off par, they retain exchanging paper currency at par as an option for banks in one direction. The chief drawback of these approaches is the inconvenience and public consternation in having, at least de facto, a floating exchange rate for paper currency, which might be quite volatile. By contrast, the clean approach has a sedate, continuous, differentiable path of the exchange rate for paper currency.

Between the withdrawal limit approach and the deposit limit approach, one big difference is that the deposit limit approach has a nonpar exchange rate during a later period when there are net deposits, while the withdrawal limit approach has a nonpar exchange rate during an earlier period when there are net withdrawals. On the one hand, having paper currency at par during the early-on crisis atmosphere is an advantage of the deposit limit approach. However, there is then a credibility problem: In a later period, when the worst of the crisis has passed, will the central bank really limit deposits of paper currency? Therefore, a central bank limited to a quantitative withdrawal limit and a quantitative deposit limit as tools to enable deep negative rates might want to combine a withdrawal limit with a deposit limit that, if credible enough, should make the withdrawal limit nonbinding.

Another difference between the withdrawal limit approach and the deposit limit approach is that for the paper currency people already hold, withdrawal limits enhance that paper currency as an asset,

\footnotetext{
${ }^{32}$ The technical condition we have in mind for "interest rates have recently been negative" is a time $t$ when over some interval ending at time $t$, cumulative interest rates have been negative. Or more precisely, one could think of a time $t$ for which some interval ending at $t$ has a cumulative negative interest rate larger than the storage cost of paper currency.
} 
generating a capital gain for paper currency already in circulation, while deposit limits hurt paper currency as an asset, generating a capital loss for paper currency already in circulation. ${ }^{33}$ Goodfriend (2016) alludes to a less obvious dimension of the asset-enhancing effect of withdrawal limits in this sentence: "The inconvenience of the flexible deposit price of currency might be offset to a degree by the fact that [with withdrawal limits but no deposit limits] paper currency would perform as a hedge against income and consumption risk, since the deposit price of currency would rise whenever nominal interest rate policy turned negative to fight a recession."

\section{The Prohibition Approach}

The most heavy-handed approach to enabling deep negative rates is "the prohibition approach." This is both a description and a warning that it is a very messy approach for central banks to take when they feel (i) they need to implement negative rates (ii) without taking paper currency off par without imposing a negative PCIR at the cash window and (iii) without imposing quantitative deposit limits or withdrawal limits at the cash window. Since under this approach the central bank cannot impose any limits on the supply of paper currency, it will have to concentrate all its efforts on limiting the demand for paper currency. Also ruled out in the prohibition approach is lowering the rate of return for paper currency directly either by a rental fee or by a depreciation mechanism. Instead, in the prohibition approach, the effective rate of return for paper currency is lowered by putting legal obstacles in the way of paper currency storage and the use of stored paper currency as collateral.

The prohibition approach goes as far as possible in avoiding any explicit or implicit exchange rate for any type of paper currency relative to other forms of money. But it does not entirely keep paper currency at par: for example, paper currency with a history of illegal storage would probably go at a discount relative to paper currency without such a history. In other words, the prohibition approach introduces new categories of tainted cash.

\section{A. What is the Nature of the Feared Paper Currency Arbitrage and Disintermediation?}

It is important to understand the nature of the key arbitrage that needs to be obstructed. Assuming all government-controlled electronic rates are negative, paper currency really is the main instrument that offers an arbitrage opportunity. ${ }^{34}$ Modern finance is based primarily on electronic money (i.e. bank money, numbers in a computer, etc.). An arbitrage starting and ending in electronic money is what will interest those in the financial sector. In that context, to create an effective lower bound, one must

\footnotetext{
${ }^{33}$ Let us make two remarks about capital gains and losses for paper currency already in circulation. First, as noted above, a variety of evidence suggests that a large share of paper currency is held by criminals. Second, any capital gain for paper currency holders is a capital loss for the central bank, for which that paper currency is a liability. If withdrawal restrictions enhance the value of paper currency already in circulation, this is an increase in the value of the money supply, and should reduce the amount of seignorage available to the central bank. But any such effects on the central bank's balance sheet must be seen in the context of the effects on the central bank's balance sheet of the rest of the negative interest rate policy.

${ }^{34}$ Private firms do not have the disregard for profits and the deep pockets needed to pay an above-market rate on an equilibriumrate-altering quantity of funds. In addition, assets whose prices vary freely (including existing debts whose secondary-market price can freely vary) cannot create an effective lower bound.
} 
withdraw paper currency freely at par, store large quantities of paper currency safely (safely from both criminals and from the government), then redeposit paper currency freely at par, and do all of this in decisively equilibrium-rate-altering quantities. In the clean approach, the time-varying deposit fee ('the exchange rate mechanism') preempts this arbitrage, while under the rental fee approach the negative PCIR on banks preempts this arbitrage. Under the prohibition approach, we will discuss how various steps can be taken (and have already been taken) to limit arbitrage opportunities and other side effects. As we will see, each of these steps is separately helpful in obstructing the arbitrage.

With so many tools ruled out, can the prohibition approach work? The answer, we believe, is "Yes." For the most part in this paper, we have taken the point of view of central banks. But spare a moment to appreciate the herculean task of paper currency arbitrageurs if collectively they are to impose a lower bound on interest rates. Especially if a central bank has pursued large-scale asset purchases of government debt at the long-term end of the yield curve, a deep negative interest rate policy could easily lead to the bulk of the national debt still in private hands carrying negative rates. To avoid those negative rates through paper currency storage, that debt needs to be sold to the central bank for reserves, those reserves need to be traded in for paper currency, then an amount of paper currency close to the entire national debt needs to be stored with reasonable safety from thieves - and safe from the government if the government has made large-scale paper currency storage illegal. For the US, this would mean storing an amount of paper currency close to $\$ 20$ trillion. A nontrivial task!

Of course, long before the national debt has been converted to paper currency — which is what is required in order to enforce a lower bound on rates - the central bank will be concerned about the disruption to the banking system from disintermediation (potential depositors substituting away from banks to paper currency). To counteract this poisonous side effect of people sidestepping banks and using cash instead, a crucial complement to the prohibition approach is subsidizing the provision of zero rates to small household accounts. This reduces disintermediation from small-scale storage by households "in empty coffee cans." With large-scale storage outside the home directly prohibited (as discussed below), the hope is that most businesses and rich households that now keep funds in deposit accounts will continue to keep most of those funds in deposit accounts, thereby keeping the total extent of disintermediation manageable.

As a theoretical matter, we want to point out that even without any additional prohibitions, paper currency arbitrage on the scale of the national debt is a gigantic task in most countries. Whenever one sees the simple equation $i \geq 0$ or the like in an economic model, one should remember that the equation operates through the conversion of the entire national debt (or the portion with a negative yield) to paper currency, which is then stored. In the real world, where the lower bound on rates is located is quite speculative. No one knows how hard it is to store that much paper currency.

What is easy to predict is that concerns about disintermediation will arise long before the entire national debt, or close, has been converted into paper currency and stored. Hence, models that focus on the effects 
of negative interest rates on the banking system are likely to be of more relevance to central banks than models with equations similar to $i \geq 0$ that sidestep any discussion of the effects of low rates on the banking system.

\section{B. Four Tools for Enabling Deep Negative Rates Using the Prohibition Approach}

Let us now consider the types of prohibitions that might be imposed and how well they might limit disintermediation. We organize the tools for the prohibition approach into two categories. (1) The first set of tools is about interrupting paper currency arbitrage by banks and large firms. (2) The second set of tools is about interrupting paper currency arbitrage by more shadowy entities - particularly new businesses that focus on paper currency storage that would try to skirt the usual regulatory structures (Table 4). The first set of tools is less intrusive than the second set. All the prohibition approach tools targeting banks and large firms would be superfluous if there were a rental fee at the cash window (since the rental fee ensures that the negative PCIR is transmitted throughout the financial system and to large firms). By contrast, the second set of tools aimed at interrupting arbitrage beyond the financial and large corporate sector could be also useful to deal with some side effects of the rental fee approach.

\begin{tabular}{|c|c|}
\hline \multicolumn{2}{|r|}{ Summary of the Prohibition Approach } \\
\hline Aims & Tools \\
\hline $\begin{array}{l}\text { Discourage Paper Currency Storage by } \\
\text { Existing Firms }\end{array}$ & $\begin{array}{l}\text { (1) Ban Electrification of Cash } \\
\text { (a) Prohibit Electronic Funds Backed by Cash } \\
\text { (b) Ceiling on Storage of Paper Currency by Public Firms and Large Private Firms }\end{array}$ \\
\hline $\begin{array}{l}\text { Discouraging New Business Models for } \\
\text { Paper Currency Storage }\end{array}$ & $\begin{array}{l}\text { (2) Ban Storage of Paper Currency as a Business } \\
\text { (3) Restrict the Cross-Border Movement of Paper Currency } \\
\text { (4) Retire Large Denomination Bills }\end{array}$ \\
\hline
\end{tabular}

Table 4: Aims and Tools of Prohibition Approach

The four tools we discuss under the prohibition approach are (i) banning electrification of paper currency, (ii), banning storage of paper currency as a business, (iii) putting restrictions on flows of paper currency in and out of the country and (iv) retiring large denomination notes. We want to emphasize here that not all of these steps are necessary, and each additional step will add to the ability of the central bank to use deeper negative rates. We have listed the steps in order of priority, with the most important first.

\section{i. Banning Electrification of Paper Currency}

"Banning electrification of paper currency" comprises two actions: (a) prohibiting any mutual fund, exchange traded fund, money market fund or any other vehicle that provides electronic funds backed by paper currency, and (b) putting a ceiling on holdings of paper currency by any publicly listed firm or firm above a given size. The ceiling on holdings of paper currency by publicly listed firms is important in two ways. First, given the aim of aiding economic recovery that motivates the negative interest rate policy, the government wants firms to invest in ways that add to aggregate demand instead of storing 
paper currency. (Small, unlisted firms typically have a high enough hurdle rate for investment that storing paper currency, beyond transactions purposes, would not be attractive to them in any case.) Second, the ceiling on holdings of paper currency by publicly listed firms forestalls the possibility that their stocks or bonds could serve as relatively liquid assets backed by paper currency.

We see this measure as the first step (and the least intrusive step) under the prohibition approach. It alone goes a long way toward interrupting the arbitrage opportunity. In the absence of a convenient, relatively liquid, electronically tradable or electronically transactable asset backed by paper currency, the number of investor dollars that are attracted to investing in paper currency should be greatly reduced. The liquidity of liquid securities typically depends heavily on the support of law. ${ }^{35}$ Therefore, if the government says, for example, that no security can be backed for more than $3 \%$ of its value by paper currency, and that publicly listed firms and firms above a given size cannot have more than $3 \%$ of their assets as paper currency, it should go a long way toward pushing down the effective lower bound on interest rates.

We count banning electrification of paper currency as a measure that uses transmission through banks. Thus, in the taxonomy of options to enable negative rates (Table 3) banning electrification of paper currency appears under the column "Transmission Through Banks." The rest of the prohibition approach appears under the column "Direct Negative PCIR Everywhere". Banning electrification of paper currency prevents the general public from accessing the paper currency arbitrage opportunity conveniently through the regular financial system. This leaves the central bank with the problem of dealing with storage that could emerge in the shadows of the economy.

In some jurisdictions, banning the electrification of paper currency may be within the regulatory purview of the central bank. But in many jurisdictions, securities regulation and regulation of corporate cash holding falls to other regulators or is unregulated. Hence, banning the electrification of paper currency would often require broader support for enabling negative rates than simply a decision by the central bank. In some jurisdictions it would require legislation. In any case, banning electrification of paper currency is likely to be less controversial than the next measure we discuss: banning paper currency storage as a business.

\section{ii. Banning Paper Currency Storage as a Business}

Banning paper currency storage as a business requires legislation; it is likely to be beyond the authority of most central banks. The purpose of banning paper currency storage as a business is to block new entrants from storing paper currency while skirting the usual banking and financial regulatory structure.

\footnotetext{
${ }^{35}$ Cryptocurrencies are currently exploring the limits of how convenient an electronic security can be with only the permission of law and not the active support of law. Crucially, they do not claim to be backed by anything other than a promise not to create too many. When a security claims to be backed by something, regulation serves an important role in reassuring investors about the actual presence of that backing. And it is not at all certain whether cryptocurrencies could survive active attempts by governments to ban them.
} 
It is likely that the efficient scale of a paper currency storage firm would be large. This and the substantial sunk costs in setting up such a firm as a going concern mean that even the threat of a future action banning this business could do a lot to stunt the growth of commercial paper currency storage. The power of regulatory and legislative risk to inhibit commercial paper currency storage is important in view of the high hurdle this measure faces to becoming reality. How confident will an entrepreneur be that the politics of banning paper currency storage won't shift in an adverse direction once the business has grown to $\$ 1$ trillion? On the upside is only a slice of the uncertain value of future cumulative negative interest rates beyond the period of time it takes to set up the business. On the downside is losing one's entire sunk cost.

Banning paper currency storage as a business comprises two laws. First, no one can legally be paid for storing someone else's paper currency. Second, no one can legally pay more than par for paper currency. These two measures would make it difficult to centralize and reap economies of scale in the storage of paper currency. Note that paying above par serves here mainly as a diagnostic for an enterprise being a paper currency storage business. An above-par exchange rate for paper currency is not itself a concern here.

Even if there is no rental fee leading banks to impose fees or otherwise restrict paper currency withdrawal (and therefore driving the shadow price of paper currency above par), it is likely to be difficult to get households go to the trouble of giving a paper currency storage business cash if the household only gets par for the paper currency. In drafting the law, above-par payment for paper currency could be defined as any reason that households would go to that trouble. Here is an obvious example of how that definition would help: if businesses can't legally pay above par for paper currency, they also can't sell merchandise for a lower price if someone pays cash. (They could impose a cash surcharge if they wanted. It would be best to leave that legal in case the clean approach is pursued later on.) Altruistic motivations to give paper currency at par are an interesting subcase. It is not at all obvious that nonprofits would be tempted to get into large-scale paper currency storage, but if they did, this could be banned by a separate clause in the law.

When banning paper currency storage as a business is used in conjunction with a rental fee at the cash window, the prohibition on paying more than par for paper currency, if it can be enforced, is likely to be an even bigger problem for those who want to centralize paper currency storage. Everyone should sense that the shadow price of paper currency is above par as banks impose withdrawal fees and other restrictions.

Note that perfect enforcement of the ban on paper currency storage as a business is not needed. In the US, there could be $\$ 100$ billion of dollars worth of additional paper currency storage by illegal paper currency storage businesses without causing a serious amount of disintermediation. (Remember that the negative interest rates themselves cause a powerful stimulus to counteract any contractionary effect of 
a modest amount of disintermediation on aggregate demand.) And $\$ 100$ billion would be far short of the $\$ 20$ trillion or so needed to impose a lower bound on interest rates.

\section{iii. Putting Restrictions on Cross-Border Movement of Paper Currency}

The primary purpose of restricting paper currency flows in an out of a country is to avoid offshore money market mutual funds backed by paper currency and offshore paper currency storage businesses. In some circumstances, these might be kept in check by cooperation from foreign governments. But in any case, controls on the movement of paper currency across national borders would not be a big departure from current practice. Currently, to fight money laundering, terrorist financing and tax evasion many countries impose limits or declaration requirements on cross-border cash flows above a certain threshold.

\section{iv. $\quad$ Retiring Large Denomination Notes of Paper Currency}

Retiring large denomination notes of paper currency increases the storage cost of paper currency. Ken Rogoff (2017a, 2017b) has championed this idea. The key limitations on the power of this measure are first, many components of the storage cost of paper currency - such as security and insurance costsdepend on value, not bulk, and second, even with denominations as low as $\$ 1$ bills, a large value can be stored in a small space, so that the size of the physical component of the storage cost is not that large. (Think of the value of cash that could fit into a standard container filled with \$1 bills.) Ken Rogoff's suggestion of limiting non-electronic currency to coins is more likely to provide significant leeway for deep negative rates through adding to physical storage costs. Nevertheless, banning high denomination bills is likely to be somewhat helpful. Banning high denomination notes may also serve a signaling role in helping to convince the market that a central bank will be willing to do other measures if necessary.

The European Central Bank (ECB) announced in May 2016 that it would stop issuing 500 euro notes (its highest denomination note) by the end of 2018. The banknotes still retain their value and can be exchanged at the national central banks for an unlimited period of time - there is no deadline on redemption. While their press release cited "concerns that this banknote could facilitate illicit activities", this step also directly enables deeper negative rates by slightly raising the physical cost of storing a given value of paper currency. But for negative interest rate policy, the importance of eliminating the very highest denomination bills is mainly in conjunction with a ban on paper currency storage as a business: the more space taken up by paper currency of a given value, the easier it is to detect that stored paper currency. That is, if storing paper currency as a business becomes an "illicit activity," eliminating the highest denomination bills may help reduce that activity. Note that while removing high denomination bills already in circulation would be helpful, the continued existence of previously issued high denomination bills is not a serious concern for negative interest rate policy: disintermediation relative to the status quo requires additional bills beyond those already in circulation. 
We distinguish conceptually between eliminating high denomination notes and the full abolition of paper currency, which immediately eliminates any lower bound, but raises the practical issues and privacy issues discussed above.

\section{Monitoring the Prohibition Approach}

Each of the tools in the prohibition approach can be used separately. There is a lot of uncertainty about the effectiveness of each of these tools; if one tool doesn't complete the task, another tool can be added (including tools from the other approaches). "Effectiveness" can be defined as how much one can push down the lower bound on rates before side effects become serious. For the prohibition approach, the side effect of greatest concern is reduced use of the banking system: disintermediation. This should be monitored closely. In addition, there are two paper currency metrics that should be monitored: the stock of paper currency demanded and the black-market price of untraceable paper currency. If any of these metrics flash red, the central bank should consider doing something more. In the prohibition approach, "something more" tends to be a discrete step rather than a continuous adjustment.

\section{Combining the Rental Fee Approach and the Prohibition Approach}

What can be done if one has the dual policy objective of both (a) eliminating any lower bound on rates and (b) keeping exchange rates between all forms of one's currency as close to par as possible? Though under some circumstances even the clean approach only takes paper currency slightly off par, with this dual policy objective, it is easy to suppose that the clean approach, the withdrawal limit approach and the deposit limit approach are all ruled out. That leaves the tax approach, the rental fee approach and the prohibition approach. We have nothing to add about the tax approach. But we do want to spell out how a combination of the rental fee approach and the prohibition approach — with a subsidy by the interest on reserves formula for the provision of zero rates to small deposit accounts - could aim for this dual policy objective of eliminating any lower bound and keeping paper currency close to par. (The subsidy for the provision of zero rates to small deposit accounts both dramatically reduces the bank profitability problem and reduces incentives for disintermediation by households even if those households can obtain an exemption amount of paper currency without additional fees.)

Why combine the rental fee approach and the prohibition approach? The great virtue of a rental fee is that a PCIR at the cash window in line with rates on other safe liabilities of the government guarantees that there are no paper currency arbitrage profits to be had by the private sector as a whole. The rental fee also makes serious disintermediation less likely because one way or another, the paper currency that would be needed for disintermediation is more difficult to obtain. But under the rental fee approach, there are three types of money: electronic money, paper currency with a rental fee obligation attached, and paper currency "in the wild," without a rental fee obligation attached. While the exchange rate between electronic money and paper currency with a rental fee obligation attached remains 1:1, paper currency in the wild may trade at a premium. Tools from the prohibition approach may help in reducing the premium on wild paper currency. 
The combination of policies that might work to keep the premium on wild paper currency down is to (a) have a large exemption amount for rental-fee-free monthly cash withdrawals by households together with (b) a ban on paper currency storage as a business. Without the ban on paper currency storage as a business, households would be likely to withdraw the exemption maximum in paper currency each month and selling everything they don't need for transactions to the paper currency storage businesses. Being up against a binding constraint on rental-fee-free monthly cash withdrawals implies that the value of rental-fee-free paper currency would be above par. But if paper currency storage businesses can be suppressed, then a large exemption amount for rental-fee-free monthly cash withdrawals would lead to most households withdrawing less than the exemption amount. Indeed, without paper currency businesses to sell paper currency to, many households would have difficulty getting together the electronic funds needed to trade to their banks for large amounts of paper currency. For a household that is withdrawing less than the exemption amount for rental-fee-free monthly cash withdrawals, wild paper currency is effectively at par.

Wild paper currency being at par for the typical household does not mean that there are no corners of the economy in which wild paper currency would be above par, but wild paper currency being at par for the typical household might satisfy the policy objective of staying close to par. Here, recall that part of the way to diagnose a paper currency storage business is that it pays above par for paper currency. Even with a combination of the rental fee approach, the prohibition approach, subsidies for the provision of zero rates to small accounts, and a large exemption amount for rental-fee-free monthly paper currency withdrawals, there would be some black market in which wild paper currency traded above par, but the typical household would have little reason to obtain paper currency from that black market since they could get up to the exemption amount at par from their bank. And if a ban on paper currency storage as a business is effective, the typical household would have trouble locating a paper currency storage business from which they could get an above-par exchange rate for paper currency.

Unlike many other illicit activities, the continued existence of some black-market paper currency storage businesses is not dangerous. The objective of banning paper currency storage as a business in this combination approach is only to give the typical cash user the convenience of a par exchange rate in daily life. If successful, banning paper currency storage as a business helps achieve this by making the exemption amount nonbinding for most households.

Another contrast with other illicit activities is that for the plausible negative interest rate policies, the incentive to use the black market for above-par wild paper currency is likely to be much weaker than the strong demand for forbidden consumption goods such as drugs or prostitution or forbidden investment goods such as banned weapons or forbidden gambling (which is harder to classify theoretically).

In combining of the rental fee approach and the prohibition approach, it is banning paper currency as a business that is the key tool from the prohibition approach. When the rental fee approach is implemented, 
neither the electrification of paper currency, nor cross-border flows of cash, nor large denomination bills pose serious obstacles to enabling deep negative rates. ${ }^{36}$ And it is hard to see how banning electrification of paper, controlling cross-border movements of paper currency or eliminating large denomination bills by themselves would help much in keeping the exchange rate for wild paper currency that the typical household sees closer to par without a ban on paper currency storage as a business. However, banning electrification of paper currency, controlling cross-border movements of paper currency or eliminating large denomination bills all reinforce the banning of paper currency storage as a business: (i) banning electrification of paper currency helps close possible loopholes in the law banning storage of paper currency as a business, (ii) controlling cross-border movements of paper currency makes it harder to have a paper currency storage business offshore, and (iii) eliminating large denomination notes makes harder to hide illegal paper currency stores.

While we believe that this combination of the rental fee approach, the prohibition approach, subsidies for the provision of zero rates to small deposit accounts and a large exemption for rental-fee-free withdrawals of paper currency each month has an attractive set of properties, the big challenge of the combination approach is that, like the full prohibition approach, it needs legislation. If the legislative barrier can be overcome, then the rental fee approach combined with banning of paper currency storage as a business might go a long way toward ensuring that all forms of paper currency remain close to par even in far reaches of the wild. Moreover, in states of the world in which one can get a ban on paper currency as a business legislated, one can probably also get the other tools of the prohibition approach written into that legislation (as well as authorization for a rental fee at the cash window, if that was not already within the authority of the central bank).

To summarize, starting from the rental fee approach with a liberal exemption amount for rental-fee-free paper currency withdrawals, adding a ban on paper currency as a business reinforced by the other tools of the prohibition approach might make the exemption amount non-binding for the typical household, which means the typical household would see wild paper currency as being at par.

Conversely, starting from the prohibition approach, the rental fee at the cash window guarantees that there is no paper currency arbitrage relative to the central bank, and one way or another makes it more costly for people to obtain the paper currency that would be needed for serious disintermediation. By contrast to a rental fee with an exemption amount, hard withdrawal limits would not allow for unusual situations when it is of high value to someone to withdraw a lot of cash. The rental fee with an exemption

\footnotetext{
${ }^{36}$ Note that the rental fee approach by itself limits the dangers from electrification of cash and cross-border flows of cash. This is because banks that have access to the cash window will be on the hook for any cash withdrawals they make. Therefore, they will be unwilling to supply cash at par to entities that would want to set up funds backed by cash, either domestically or abroad. And with the ability to push the PCIR at the cash window as low as needed, the change in the storage cost of paper currency that would come from eliminating large denomination bills does not matter much. And none of these three measures can do much to keep wild paper currency closer to par in the absence of a ban on paper currency storage as a business. As a result, the analysis of the rental fee approach with any or all of these three elements of the prohibition approach is very similar to the analysis of the rental fee by itself. Only the banning of paper currency storage as a business makes a big difference in combination with the rental fee.
} 
amount creates a softer withdrawal limit that allows people to withdraw beyond that if they compensate the bank for the rental fee. Unless a rental fee at the cash window is legally barred, we see few justifications for pursuing a ban on paper currency as a business without adding to that ban a rental fee at the cash window. And, as mentioned above, it seems an unlikely situation that a ban on paper currency storage as a business can be legislated but a rental fee at the cash window can't be authorized. ${ }^{37}$ (It is more likely that banning electrification of paper currency, controlling cross-border movements of paper currency or eliminating large denomination bills is legally/politically possible, but a rental fee at the cash window is not.)

\section{The Supply and Demand of Paper Currency: Contrasting Different Approaches to Enabling Deep Negative Rates}

Graphing the supply and demand for paper currency can illuminate the consequences of different paper currency policies: the effective lower bound with no change in paper currency policy, the clean approach, the rental fee approach, and the prohibition approach.

\section{A. The Demand for Paper Currency: The Rate of Effective Return on Cash (ROERC) Curve}

The demand for paper currency curve, labeled the Rate of Effective Return on Cash (ROERC) curve, quantifies the benefits of holding cash and is drawn from the perspective of households and firms in the economy that use cash for transactions or have the opportunity to hoard cash as a store of value. The quantity of paper currency the public wants to hold for transaction or other purposes is likely to depend on the interest rate they can earn from alternate investments. Therefore, the $\mathrm{x}$-axis in the ROERC curve graph represents the quantity of paper currency in the private sector, while the y-axis represents the rate of effective return on cash (Figure 2).

There is always some demand for paper currency to keep secrets from the government or others. For example, paper currency is needed for tax evasion and other illegal activities. When the quantity of paper currency in private hands is small, the rate of effective return on paper currency ("cash") is far above its superficial store-of-value return of zero, since there would be a scarcity of paper currency for tax evasion and other illegal activities. At a somewhat higher quantity, where the demand for paper currency for the sake of tax evasion and illegal activities is mostly satiated, the demand for paper currency for transactional convenience could still lift the effective return on paper currency substantially above its superficial store-of-value return. But a high enough quantity of paper currency can satiate the demand for paper currency for the sake of convenience in legal transactions as well, leaving only the store-ofvalue return to paper currency. This reasoning corresponds to a downward-sloping ROERC curve that flattens out at the store-of-value return to paper currency.

\footnotetext{
${ }^{37}$ It seems more likely that banning electrification of paper currency, controlling cross-border movements of paper currency or eliminating large denomination bills is legally/politically possible but a rental fee at the cash window is not.
} 


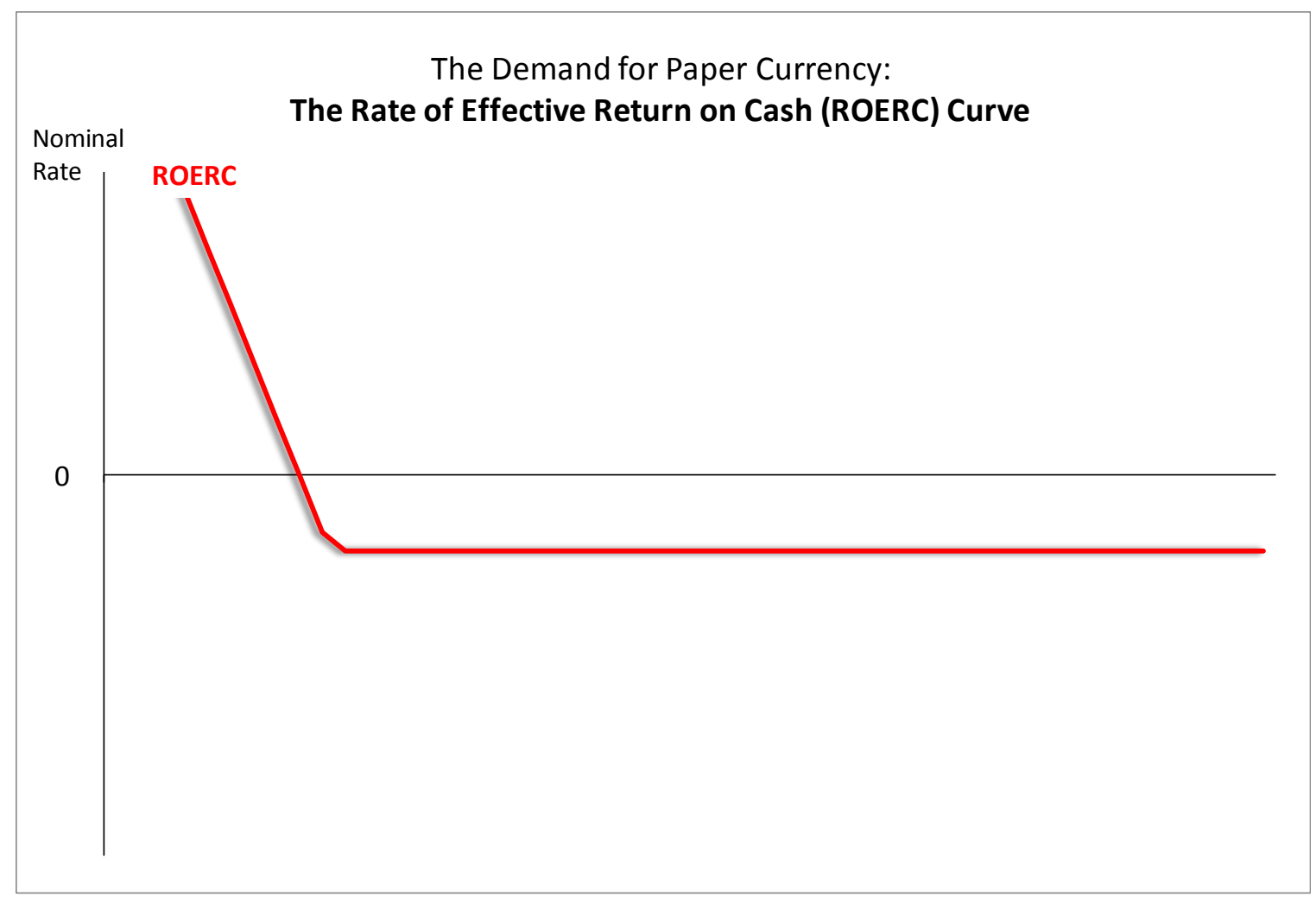

Figure 2: The Demand for Paper Currency

In the classical zero lower bound (ZLB) argument, the rate of effective return on cash cannot be pushed below zero, since cash guarantees a zero interest rate. Therefore, at a zero interest rate the demand for paper currency becomes perfectly elastic, making the public unwilling to leave funds in electronic accounts or other assets earning a negative interest rate. This would imply that the ROERC curve becomes flat at zero beyond a certain point. The flat part of the ROERC curve in this case is the liquidity trap that generates a zero lower bound. ${ }^{38}$

In practice, given storage costs, the rate of effective return on cash can be pushed below its superficial return of zero. For example, if there is a constant storage cost of paper currency, then the ROERC curve becomes flat at a nominal interest rate somewhat below zero after a certain point (Figure 2). This interest rate is the effective lower bound, equal to minus the storage cost of paper currency as an annual percentage of its value. (In a later subsection we will discuss the case in which the storage cost of cash is not constant.)

\footnotetext{
${ }^{38}$ The endogenous capital gains and losses from the floating exchange rate of the withdrawal limit and deposit limit approaches would make the ROERC curve vertical whenever the relevant withdrawal or deposit limit is binding. We will not pursue graphs for the withdrawal limit and deposit limit approaches further here.
} 


\section{B. The Supply of Paper Currency: The Opportunity Cost of Cash (OCC) Curve}

The supply of paper currency curve, labeled the Opportunity Cost of Cash (OCC) curve, focuses on the opportunity cost of supplying cash from the perspective of commercial banks.

At the cash window, banks can exchange reserves (electronic currency) for paper currency. Thus, the maximum possible quantity of paper currency is the entire monetary base. One part of the opportunity cost is the value of reserves to satisfy required reserves on deposits; the value of deposits to a bank contributes to the opportunity cost of cash. Then, beyond reserve requirements, banks may want to hold excess reserves; the value of excess reserves also contributes to the opportunity cost of cash. Finally, interest on reserves contributes directly to the opportunity cost of cash.

When the monetary base is extremely large the need for required reserves and for excess reserves will get close to being satiated, and the opportunity cost of cash will be driven down to the interest rate on reserves. That is, when reserves are large enough, the main opportunity cost for banks to supply one additional unit of cash to its customers is simply the forgone interest on excess reserves held at the central bank-which is the IOR. Graphically, this corresponds to the flat part of the OCC curve on the left end of the OCC curve (Figure 3). The value of retaining some reserves, both to support deposits and for a buffer stock, creates a steep portion of the OCC curve to the right. This picture of the OCC curve is informed by Ricardo Reis's (2016) Jackson Hole Symposium paper in which he argues that for the U.S. the value of reserves - and therefore the opportunity cost of paper currency — rises above IOR when excess reserves fall below about $\$ 1$ trillion. ${ }^{39}$ This gives an idea of where the kink in the OCC curve might be.

\footnotetext{
${ }^{39}$ Note that total required reserves in the US have been less than $\$ 200$ billion, rising from about \$40 billion in 2007 to $\$ 190$ billion in 2018 .
} 


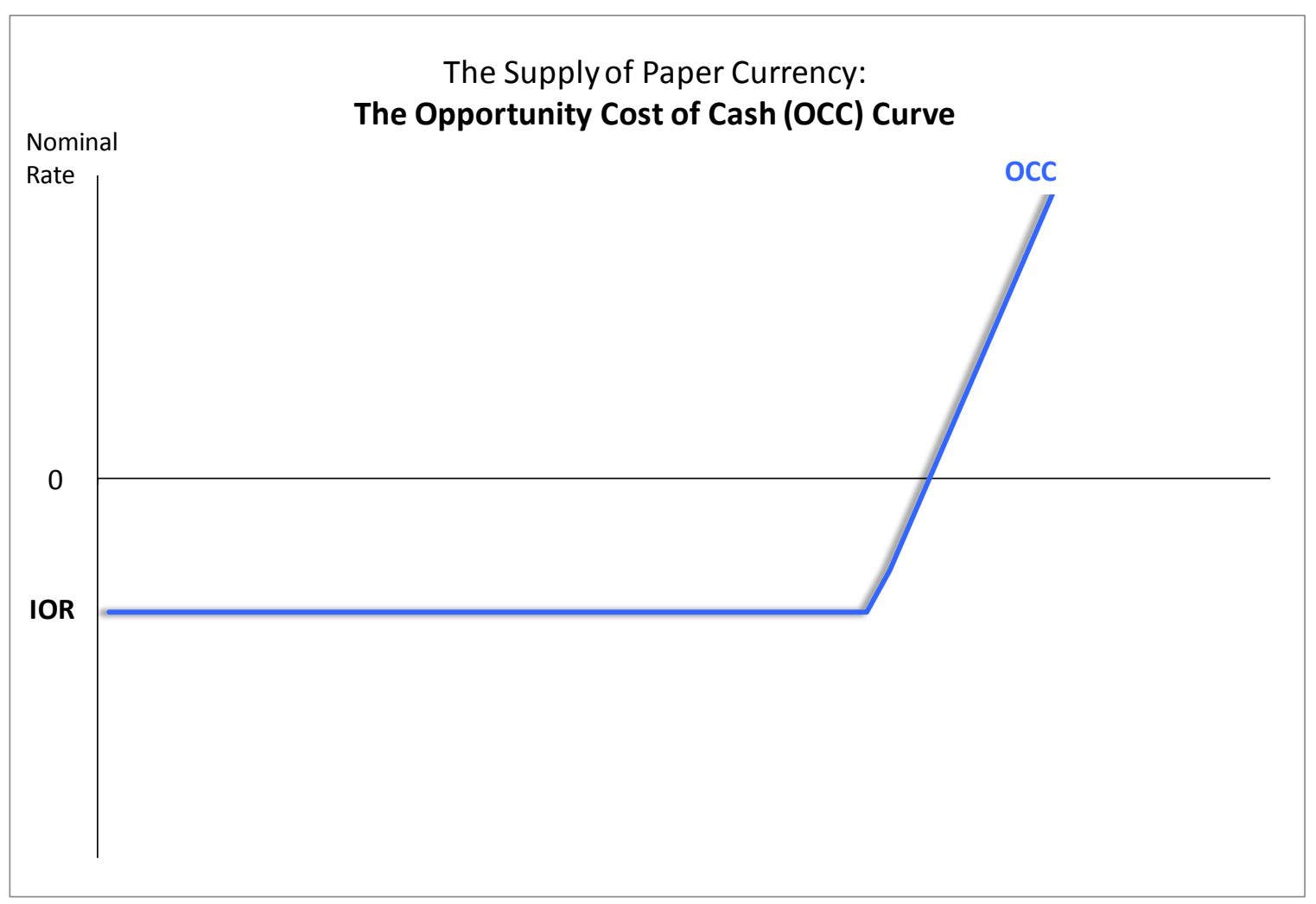

Figure 3: The Supply of Paper Currency

\section{Putting the ROERC and OCC Curves Together}

Let us turn now to the equilibrium between paper currency demand and supply. Figure 4 shows the case in which the effective lower bound (ELB) is slightly below zero due to a constant storage cost of paper currency. The IOR is shown as already lower than the ELB. That is, IOR $<E L B<0$.

The figure for the classic zero lower bound argument with no storage cost of paper currency would look very similar to Figure 4, except that the ROERC curve becomes flat at zero instead of at a level slightly below zero as it is in Figure 4. 


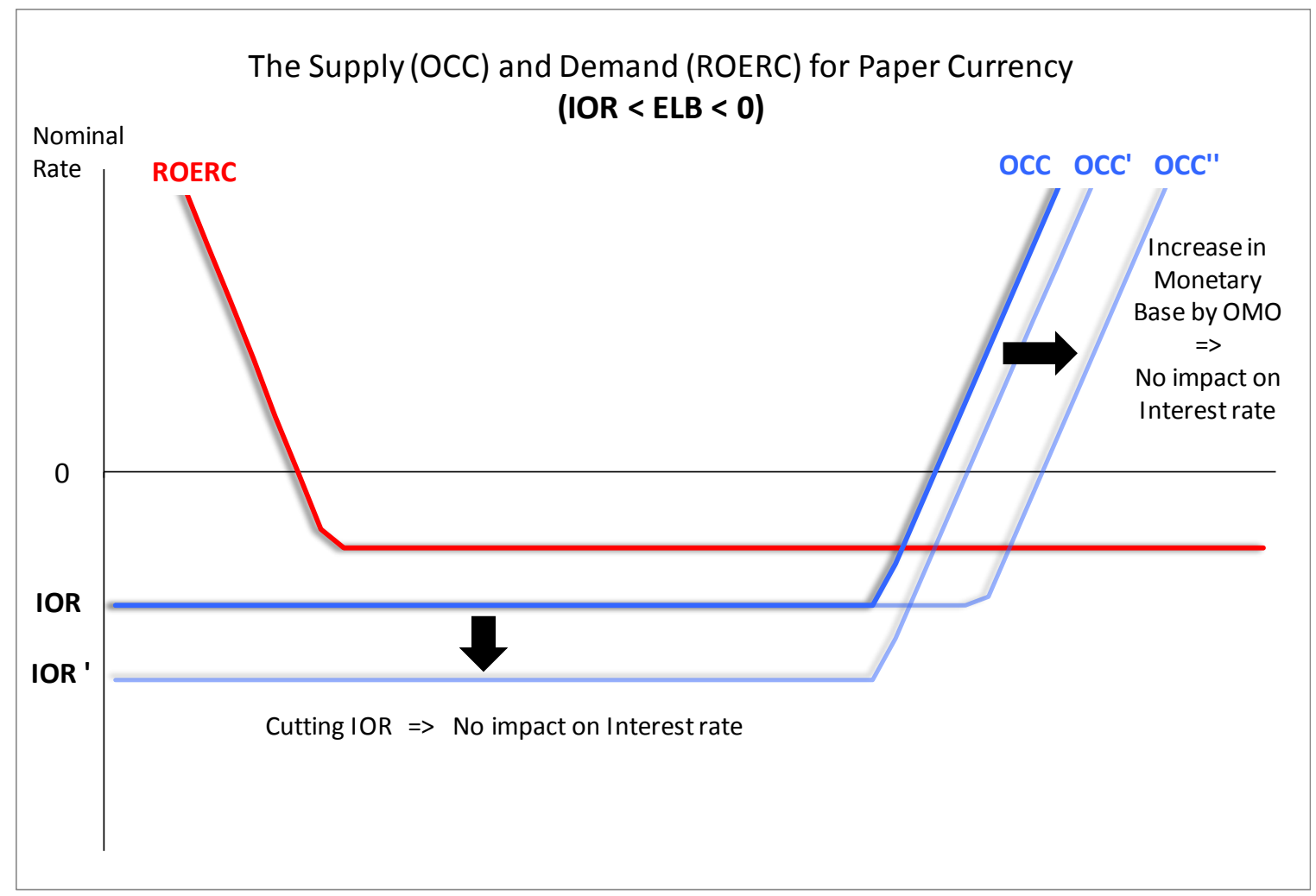

Figure 4: The Supply and Demand for Paper Currency with an Effective Lower Bound

Starting from the initial situation shown in Figure 4 without primes (in which the effective return on cash is above the IOR), increasing the monetary base through open market operations (OMO) will do nothing to the interest rate, which will stay at the ELB. This can be seen as a rightward shift of the OCC. Similarly, reductions in the IOR will do nothing to the interest rate. This can be seen as a downward shift in the OCC curve.

Figure 4 illustrates the key obstacle for enabling deep negative rates. The option to store paper currency ensures that the rate of effective return on holding paper currency is bounded below at a level not far below zero. This renders monetary policy ineffective after a certain point. In the policy changes shown, neither expanding the monetary base nor cutting the interest rate on reserves has any effect on the interest rate prevailing in the market.

\section{The Clean Approach: Cutting Interest on Reserves and PCIR in Tandem}

Sticking for simplicity with a flat ROERC curve beyond a certain point, having paper currency gradually depreciate relative to reserves shifts the ROERC curve downward. In particular, consider cutting the paper currency interest rate (PCIR) at the same time as interest on reserves (IOR), as shown in Figure 5. (It is not necessary, but Figure 5 shows a larger reduction in PCIR than in IOR.) Cutting policy rates in tandem with cutting the PCIR ensures that there is no arbitrage opportunity, enabling a 'clean' pass through of negative rates beyond the commercial banks. Under this approach, as long as the central bank 
cuts all government borrowing rates, including the PCIR, the central bank can cut rates as much as needed to stimulate the economy.

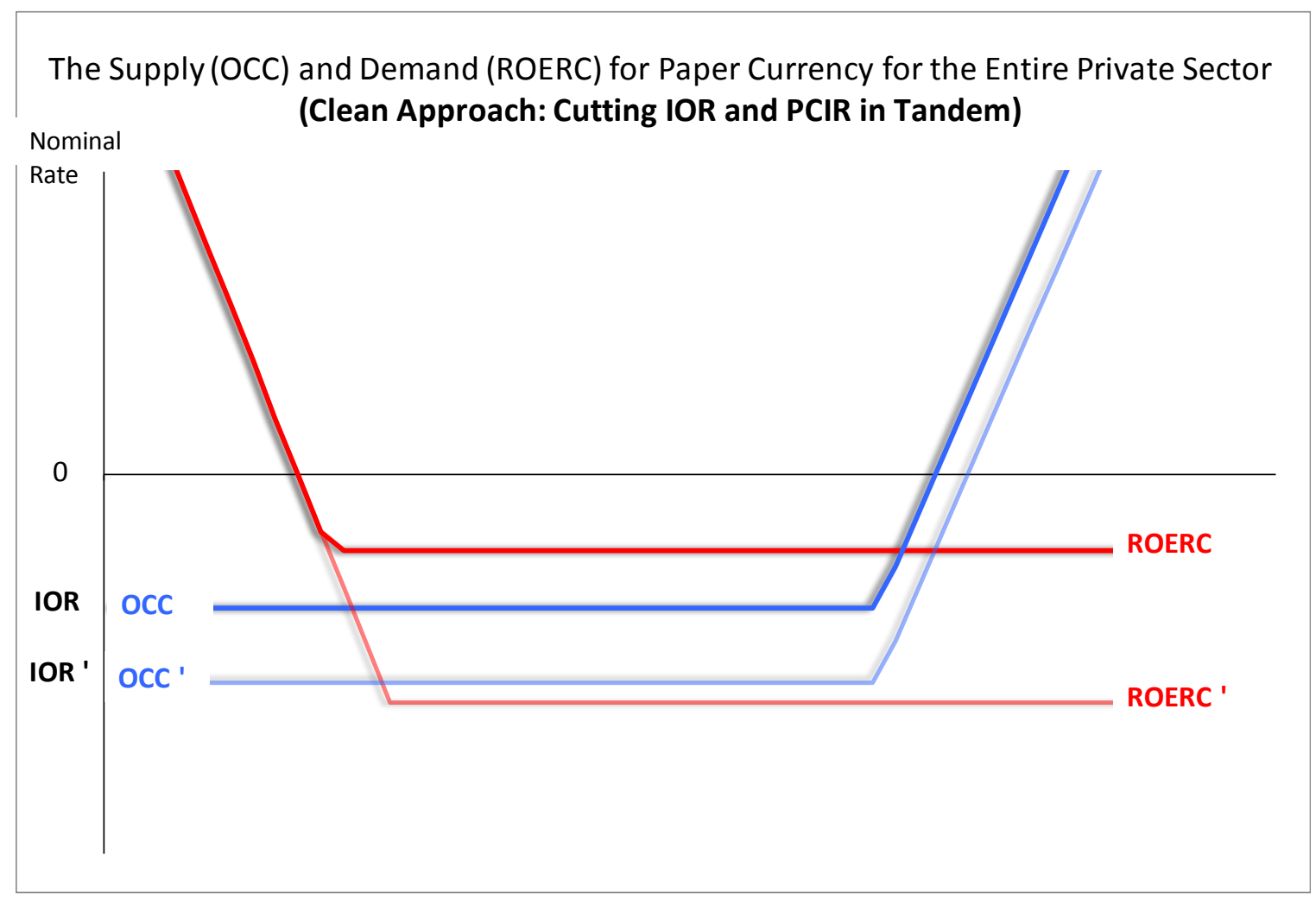

Figure 5: The Clean Approach: Cutting IOR and PCIR in Tandem

\section{E. The Rental Fee Approach: Cutting the IOR and Increasing the Rental Fee in Tandem}

The graph for the demand and supply of paper currency in the rental fee approach looks identical to the graph for the clean approach, but the ROERC has a subtle difference in interpretation. Up to now, the ROERC curve could be seen as the demand for paper currency for the entire private sector. In the rental fee approach, by contrast, the ROERC curve represents the demand for paper currency by banks and other firms within the domain of rental-fee contracts, both for themselves and to pass on to others beyond the domain of rental-fee contracts. Under rental fee contracts, banks or other firms that pass on paper currency to others beyond the domain of rental-fee contracts are treated as if they were themselves holding the paper currency on which they are paying rent, but have passed on to those beyond the domain of rental-fee contracts. In order to think of the monthly or annual rate of effective return on paper currency that is passed on beyond the domain of rental-fee contracts, one must think of the value to a firm within the range of rental contracts of having that cash to pass on a month or a year sooner.

That is, in the clean approach and below under the prohibition approach (without the rental fee) it is fine to think of the benefits and opportunity cost of cash to the private sector as a whole, but in the rental fee approach we need to distinguish between banks and other firms that face the rental fee in the same form 
as that imposed at the cash window, and other agents that do not. (If the banks are able to easily pass through the rental fee to a wide range of its customers then this distinction in the interpretation of the ROERC curve under the clean and rental fee approaches is less important.)

Under the rental fee approach, the impact of an increase in the rental fee (or equivalently a reduction in the PCIR) leads to a downward shift in the ROERC curve, as banks with access to the cash window incur a flow cost for withdrawing cash from the cash window-pushing the flat part of the ROERC curve down. When this is done in tandem with a cut in the IOR and a large enough monetary base to bring the policy rate down close to the IOR, the central bank will be able to cut rates as much as needed to stimulate the economy (Figure 6). Unlike the clean approach, however, keeping paper currency at par with electronic currency and using a rental fee may come with side effects (as discussed above). The central bank should stand ready to implement tools to mitigate those side effects.

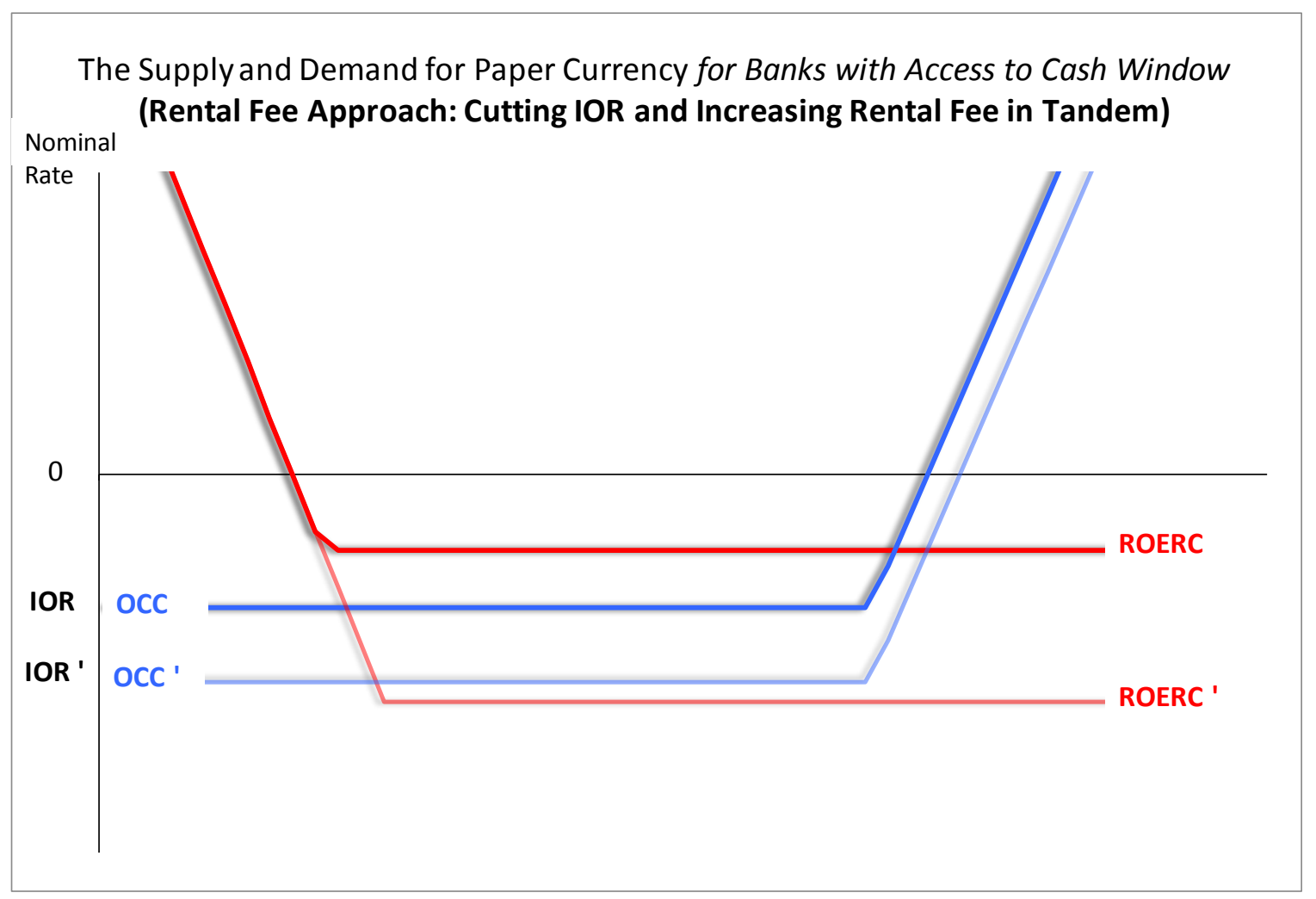

Figure 6: The Rental Fee Approach: Cutting IOR and Increasing Rental Fee in Tandem

\section{F. The Prohibition Approach: Cutting the IOR while Implementing Demand-Side Restrictions on Cash Storage}

Under the prohibition approach (without the use of a rental fee), the goal of the central bank is to increase the effective storage cost of paper currency to limit arbitrage opportunities. The demand-side restrictions of the prohibition approach push the rate of effective return of paper currency down - and further down the larger the quantity of paper currency: the difficulty of storing paper currency without discovery by 
the government grows with the quantity to be stored. That makes the ROERC curve downward-sloping everywhere, instead of having a flat portion. The more effective the prohibition, the steeper and further down the ROERC curve will be. The downward slope of the ROERC curve under the prohibition approach makes the analysis of paper currency demand and supply qualitatively different from the analysis under the clean or rental fee approaches.

With a downward sloping ROERC curve at the point where ROERC equals IOR, a cut in the IOR will be effective in lowering the economy-wide interest rate deeper into negative territory (Figure 7). The increased quantity of paper currency storage drives the marginal cost of paper currency storage up enough to bring the rate of effective return of paper currency down to the new, lower IOR. If the demandside restrictions are particularly effective, then the demand for cash curve will have a steeper downward slope - that is, it will be more inelastic - which would allow the central bank to cut policy rates with less cash hoarding.

The prohibition approach may also help limit disintermediation beyond the consequences of its effect on cash hoarding, since even for cash hoarders, doing a large share of transactions in cash instead of using electronic means of payment might look suspicious. ${ }^{40}$ Nevertheless, the likelihood of widespread disintermediation - at least by small-time agents who only need to do small-scale paper currency storage - is a big problem with the prohibition approach. Subsidizing zero rates for small deposit accounts would be especially important in the prohibition approach - it would reduce disintermediation from people shifting to small-scale paper currency storage. Those who have bank accounts with unused capacity to get a zero rate on additional funds would have no incentive to store additional paper currency.

Note that in the particular case picture in Figure 7, open market operations without any reduction in IOR would not affect the interest rate, since the monetary base is already large enough to make the opportunity cost of cash equal to the IOR. If instead we considered the case in which the monetary base is not large enough to make the opportunity cost of cash equal to the IOR, reductions in the IOR would not lower the interest rate, but open market operations would. A downward sloping ROERC renders monetary policy effective, enabling deeper negative rates either through lower IOR or open market operations, depending on the situation.

\footnotetext{
${ }^{40}$ Matthew Rognlie's (2016) model discussed below also emphasizes the importance of inelasticity of paper currency demand.
} 


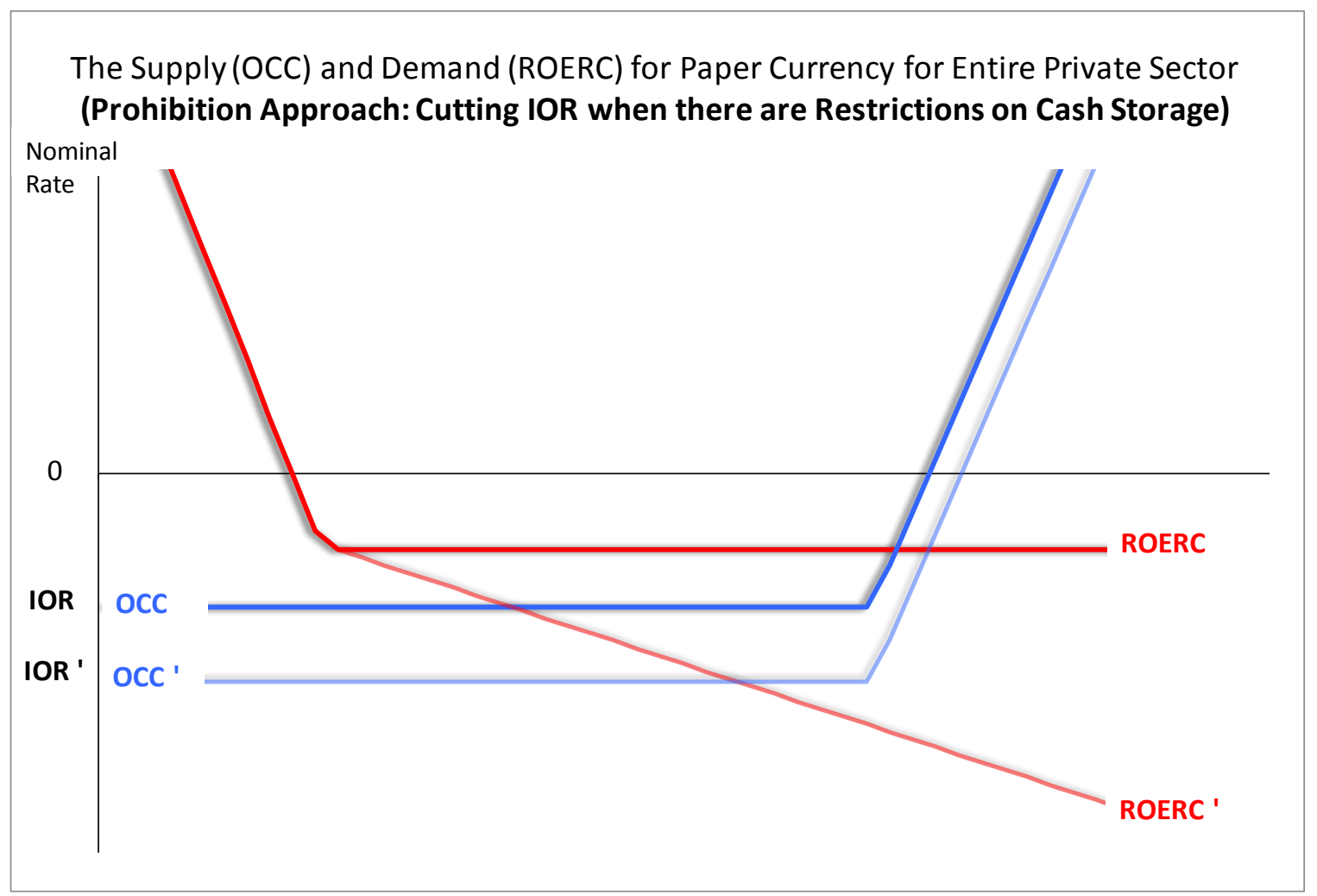

Figure 7: The Prohibition Approach: Cutting IOR with Restrictions on Cash Storage

\section{Brief Literature Review on the Impact of Negative Rates on Bank Profitability and on the Transmission Mechanism}

There is a theoretical literature on negative interest rate policy arguing that pass-through to deposit rates and lending rates can break down when the policy rate goes below a certain level. Saliently, Markus Brunnermeier and Yann Koby (2016) define the 'reversal rate' as the rate at which interest rate cuts become contractionary for lending (ignoring other channels through which interest rate cuts could stimulate the economy). In their model the 'reversal' occurs when the net interest margin of banks decreases faster than the recapitalization gains from banks' balance sheets in response to a cut in interest rates. That is, in their setup the amount of lending is almost entirely driven by the health of banks' balance sheets, and a reversal occurs when the reduction in net interest margins outweighs the capital gains on the banks' fixed interest rate holdings. Importantly, in their setup the rate at which the reversal occurs can be positive-it need not be negative.

Another salient set of papers are by Eggertsson et al. (2017, 2019), augmenting a New Keynesian model with a storage cost of money and a banking sector with nominal frictions, among other elements. Their model delivers an effective lower bound for deposit rates since customers have an option of using paper currency instead of bank accounts, if bank accounts earn a lower rate of return. In their setup the central bank is able to stimulate aggregate demand by lowering the policy rate until the rate reaches the effective lower bound. At the effective lower bound, reducing policy rates further is not expansionary. 
All three of these papers are important benchmarks in the theoretical literature on negative interest rates. However, the key takeaway from these papers is not that negative interest rates are ineffective, but that in the absence of a policy to lower the paper currency interest rate - and in the absence of subsidies for the banking system - there may be limits to the banking channel of monetary policy transmission. We agree: the success of a deep negative interest rate policy depends on at least one of the following: (a) a negative paper currency interest rate, (b) other measures to insure bank profitability, or (c) transmission channels that do not involve banks (or involve banks in a limited way that even sickly banks can manage). Going forward, for a better understanding of the bank lending channel, there is a need for more theoretical work that explicitly accounts for the widely-used practice of central banks supporting bank profitability by giving them subsidies.

In this section, we discuss these three papers, a paper by Matthew Rognlie more closely related to our proposals, the empirical literature on the health of banks under negative interest rates, then revisit our perspective.

\section{A. Brunnermeier and Koby (2016)}

In Brunnermeier and Koby's setup, the reversal rate largely arises from the effect of low interest rates on bank profits and therefore bank balance sheets. To squarely focus on conditions under which the reversal rate arises, they leave out the possibility of the central bank counteracting the bank profit and balance sheet effects of negative interest rates with other policies. What this means is that the reversal rate can be pushed down as low as needed if steps are taken to keep bank balance sheets healthy. One possible step to maintain bank profitability and bank net worth in a negative interest rate environment is to reduce the PCIR (through either the clean approach or the rental fee approach), which would allow banks to lower the rates they pay depositors without having to worry about depositor flight into paper currency. (In the clean approach, depositors would have no reason to want to flee into paper currency, since depreciation reduces the rate of return for paper currency. In the rental fee approach, it would be difficult or expensive for depositors to get enough paper currency to use in place of deposits.) Another possible step to maintain bank profitability and bank net worth is for the central bank to make what in effect are transfers to private banks. Tiered interest on reserves formulas, as in the case of the BoJ, SNB, and Danmarks Nationalbank, in which higher interest is paid on reserves up to a certain level, are one way to do this. (Our proposal to tie the IOR formula to the amount of funds in deposit accounts up to a per-adult limit serves this purpose as well as a defensive political purpose for the central bank.) Loans from the central bank to private banks at below market interest rates - as in the case of the ECB - are another way to make what in effect are transfers to private banks.

Thus, as we emphasize above, effective transfers from the central bank to commercial banks are already familiar, well-trodden policy for many central banks that have used negative rates. And it is likely that central banks could easily come up with other mechanisms for effectively transferring funds to 
commercial banks to keep their profits and net worth healthy, and so avoid a binding reversal rate. Brunnermeier and Koby recognize this in their conclusion:

For the sake of tractability, we have omitted other channels through which monetary policy can affect banks as well as the real economy. In particular, we believe that policies such as ECB's Long Term Refinancing Operations could reduce some of the consequences of low interest rates environments on banks' margins, hence alleviating concerns about banks' margins.

Thus, from our perspective, the concept of a "reversal interest rate" is intriguing, but should not be seen as a serious barrier to negative interest rate policy. Rather, the concept of a "reversal interest rate" points to the operational importance for central banks of keeping an eye on bank profits and bank balance sheets when lowering rates.

\section{B. Eggertsson et al. $(2017,2019)$.}

Eggertsson et al. $(2017,2019)$ also omit from their model subsidies that central banks pursuing negative rates could (and in negative interest rate situations, often do) provide to commercial banks. Moreover, to highlight the limits of the standard monetary framework, they leave out other mechanisms (such as the clean approach or the rental fee approach) that could lower the PCIR. In the discussion section of their 2017 paper they write:

We do not attempt to incorporate this extension [the clean approach] to our model, but note that it seems relatively straightforward, and has the potential of solving the ZLB problem. Indeed, the take-away from the paper should not be that negative nominal rates are always nonexpansionary, simply that they are predicted to be so under the current institutional arrangement. This gives all the more reason to contemplate departures from the current framework, such as those mentioned briefly here and discussed in detail by the given authors.

Thus, Eggertsson, Juelsrud and Wold (2017) point to the importance of considering changes to paper currency policy.

\section{Matthew Rognlie (2016)}

Matthew Rognlie introduces a model in which policy rates can be pushed below zero due to paper currency storage costs. In his model negative rates are optimal since the benefit to boosting aggregate output outweighs the costs of providing an inefficient subsidy to holders of cash. Another key insight of Matthew Rognlie's paper is that negative rates are most useful when paper currency demand is relatively inelastic. The prohibition approach makes paper currency demand more inelastic than it would otherwise be. The clean approach and the rental fee approach make the demand for cash inelastic at all policy rates above the PCIR. Eliminating paper currency would make paper currency demand completely inelastic at zero. 


\section{Empirical Literature on the Health of Banks under Negative Interest Rates}

There is a growing empirical literature examining bank performance at low or negative rates. Borio et al. (2017) argue low interest rates can reduce bank profitability, and that the sensitivity of profitability to rate reductions is enhanced as interest rates fall; Borio and Gambacorta (2017) find that bank lending becomes less responsive to reductions in policy rates as these approach zero. Delis and Kouretas (2011) find that bank risk tolerance increases at low interest rates.

Bikker and Vervliet (2017) find using panel data for the U.S. that the reduction in net interest margins tends to reduce bank profitability at low interest rates, but that banks are able to support overall profitability by adjusting other margins. Arteta et al. (2018) find that many of the key financial variables have evolved more or less as implied by the standard transmission channels, with no conclusive evidence as yet of a significant impact on bank profitability or leverage.

Bech and Malkhozov (2016) study negative interest rates in four European countries since 2014 and find that the transmission between policy rates and money market interest rates is similar under negative and low interest rates, but retail deposit rates are insulated from negative rates.

Turk (2016) in an IMF paper examines a sample of Danish and Swedish banks and finds that bank profits have been broadly stable, since lower interest income was offset by reductions in wholesale funding costs and higher fee income. She also finds evidence of deposit rate stickiness at zero, and reports that "a majority of larger corporate deposits in Denmark have already turned negative and imposition of negative interest rate on deposits for small and medium enterprises is becoming more common. In Sweden, only some large corporates and institutional clients earn negative deposit rates."

Eggertsson, Juelsrud, Summers, and Wold (2019) argue that while the first two rate cuts by the Riksbank into negative territory had transmission to lower lending rates for mortgages, transmission to mortgage rates may have weakened for subsequent rate cuts. Henrik Erikson and David Vestin (2019a,b), two senior advisors from the Riksbank, provide more disaggregated lending data for Sweden and argue that the detailed evidence does not support the claim in Eggertsson et al. (2019) that the traditional bank lending channel of monetary policy seems to break down. They argue that the pass-through of policy rates below zero to the economy has been reasonably good in Sweden. They show that negative policy rates in Sweden seem to have had a strong and immediate pass-through both to bond market yields and to lending rates to businesses. In addition, they demonstrate that pass-through to mortgage rates appeared to have worked well for the initial rate cuts, while for the latest rate cuts it may have been somewhat slower and weaker (depending on the data series one focuses on). They conclude that in Sweden several transmission channels were fully active at negative rates, while the bank lending channel might have been slightly muted and delayed for households in the later period (but not for lending to businesses).

Several studies examine heterogeneous effects on bank activity under negative rates. Heider et al. (2016) find that in the euro area banks with greater reliance on deposit funding were more likely to reduce 
lending and reallocate lending towards riskier firms. Basten and Mariathasan (2018) examine 68 Swiss banks, using the share of excess reserves as a proxy for exposure to negative rates. They find that in a negative rate environment, banks with higher excess reserves raised fees and interest income to compensate for the drag on profitability from negative rates. Demiralp et al. (2017) find in a panel of euro area banks that different types of banks adjust their portfolio differently under negative rates: banks that rely heavily on deposit funding extend more loans, investment banks adjust by reducing excess liquidity, and wholesale banks raise the share of government bonds in their portfolios.

In a comprehensive study, Jose Lopez, Andrew Rose, and Mark Spiegel (2018) examine the effect of negative policy rates on bank behavior in a cross-country panel of over 5100 banks in 27 countries between 2010 and 2016 - covering all advanced countries that experienced negative nominal rates. When they compare negative nominal interest rates with low positive rates, they find that savings on deposit expenses and gains in non-interest income almost exactly offset bank losses in interest income. They find that low-deposit banks have enjoyed strong gains in non-interest income, likely from capital gains on securities, and in their sample high deposit banks did not seem disproportionately vulnerable to negative rates. They conclude that "Overall, our results indicate surprisingly benign implications of negative rates for commercial banks thus far."

\section{E. Our Perspective on the Power of Negative Interest Rate Policy in the Light of the Empirical Evidence}

While these studies enrich our understanding of bank behavior and profitability and monetary policy transmission with mildly negative rates, there has not yet been any experience with rates below $-1 \%$. That lack of experience gives rise to concerns about unknowns about what bank profitability would look like with deeply negative rates, but what evidence we have means one should be skeptical of overly simple models of bank profitability in a negative rate environment.

On what the experience with mild negative rates says about the potency of negative rates in stimulating aggregate demand, it is important to emphasize that interest rate cuts - in either the positive or negative region - should be judged by how much they do per basis point. One should not expect a 10 basis point (one tenth of one percentage point) cut to have a huge effect simply because it is in the negative region. Because of it unlimited potential dosage, we argue in Agarwal and Kimball (2015) that the clean approach to enable deep negative rates makes it possible to stimulate investment and net exports as much as needed to revive the economy, even when inflation, interest rates, and economic activity are quite low. The rental fee approach should be similarly powerful, though with greater side effects. The withdrawal limit approach is guaranteed to eliminate any lower bound on rates, though with what we consider even worse side effects. The deposit limit approach should work, other than doubts about the credibility of future deposit limits. We think it likely that a combination of a deposit limits with a hopefully nonbinding withdrawal limit should have a better combination of effectiveness, credibility and side effects than either a withdrawal limit or a deposit limit separately. Finally, the ultimate 
effectiveness is hardest to guess for the prohibition approach, but we suspect it would also work, though we predict for it the worst side effects of all.

\section{Is the Transmission Mechanism Different Once the Zero Lower Bound has been Broken?}

Having discussed many approaches to enabling deep negative rates, we turn to the question of whether the transmission mechanism is different in negative interest rate territory. That is, if central banks can freely choose any interest rate in negative territory — without worrying about cash hoarding-is there something different about monetary policy with deeply negative rates? The short answer is, "No." In saying this, we agree with Assenmacher and Krogstrup (2018), who write:

In conclusion, we see no reasons to anticipate that monetary policy transmission to savings and investment behavior would be hampered with deeply negative interest rates. The main uncertainty is the unknown effects of deeply nominal rates due to money illusion. Associated risks can be minimized with appropriate communication and education efforts, and are likely to be transitional.

In standard models, without nominal illusion, it is the real interest rate that matters. Therefore, if a higher steady state inflation from a higher inflation target would make a zero nominal rate more stimulative, negative rates should be more stimulative than zero with no change in inflation, as long as the paper currency problem and the bank profitability problem are addressed. As Kimball (2015) writes:

... it is not necessary to have full agreement on exactly how a lower real interest rate stimulates the economy. For all of those who agree that interest rate policy matters, a cut in the nominal interest rate will have much the same effect as an increase in inflation with the nominal interest rate held fixed. So if an increase in inflation operates through conventional means, so does a cut into negative territory of the full set of nominal government interest rates - target rate, interest on reserves, lending rate, between-tax-year rate, postal savings rate and paper currency interest rate. In that sense, a negative interest rate policy is a conventional monetary policy.

Nevertheless, some observers have doubted whether interest rate cuts have the same effect in the negative region as in the positive region. In part (as in many of the papers discussed in the literature review above), this has to do with assumptions about complementary policies such as paper currency policy and policies to support bank profits. But it is also because negative interest rates have reinvigorated old debates in monetary theory. Negative interest rates have made all of the old questions in monetary theory new again. Therefore, it is worthwhile to review the wide range of transmission mechanisms by which lower interest rates increase aggregate demand. 
Here is the basic story for the effects of lower interest rates: In any nook or cranny of the economy where interest rates fall, whether in the positive or negative region, those lower interest rates create more aggregate demand by:

1. a substitution effect on both the borrower and lender;

2. effective wealth impacts that - aside from the overall expansion of the economy-are of equal and opposite size for the borrower and lender in any borrowing-lending relationship but are likely to interact with a higher marginal propensity to consume for a borrower than for a lender;

3. exchange rate effects;

4. the knock-on effect from the overall expansion of the economy-a multiplier for interest-rate effects.

For the purpose of discussion, let us set aside the foreign exchange markets for a moment (we will return to this issue later) by imagining that interest rates are being cut by 1 percentage point by all the central banks in the world. In some countries this would be a cut to a lower positive interest rate. In other countries, it would be a cut to a negative interest rate or to a deeper negative interest rate, which for countries already at significant negative interest rates might call for lowering the paper currency interest rate as well. Since all countries would be cutting their rates by 1 percentage point in tandem, there should be only modest effects on international capital flows and hence only modest effects on exchange rates and trade balances. With a global cut in interest rates by 1 percentage point, different countries are getting to a low real interest rate in different ways-some in part by having had higher inflation to begin with, some by negative nominal interest rates. But the effects are similar. What is the effect of this interest rate cut on the economy?

\section{A. The Principle of Countervailing Wealth Effects}

It is easy to focus on some wealth effects while forgetting about others that are just as important. The Principle of Countervailing Wealth Effects ${ }^{41}$ is the principle that wealth effects come in offsetting pairs: the wealth effect for the borrower and for the lender in each borrower-lender relationship. Much as double-entry accounting helps in making sure one doesn't miss a ledger item, the Principle of Countervailing Wealth Effects can help in making sure one hasn't missed a wealth effect. If one leaves aside the effect of the overall expansion or contraction of the economy (which is the source of a multiplier but doesn't change the overall direction of the effect of a rate cut) the effective sizes of the pair of wealth shocks for each borrower-lender relationship are equal and opposite. Therefore, the net

\footnotetext{
${ }^{41}$ The discussion here is based on a series of blog posts from 2016 which also provide additional details in the argument. Kimball (2016a) introduces the Principle of Countervailing Wealth Effects. We refer the reader to Kimball (2016c, 2016d) for some discussion of the case of countries where the government or businesses have done significant borrowing denominated in foreign currencies. Monetary policy transmission and optimal monetary policy for countries where the government or businesses have done significant borrowing denominated in foreign currencies is a complex topic for which we only scratch the surface in this paper. But what is clear is that all of the mechanisms and all of the logic discussed in this paper are a part of the story even in very complex cases.
} 
wealth effect comes down to who has the bigger marginal propensity to spend - the borrower or the lender.

\section{B. The Effect of Redistributions}

It is worth clarifying why the wealth effects from interest rate changes would have to be zero if everyone were identical, aside from the multiplier from any expansion or contraction in the economy. In aggregate, the material balance condition ensures that the flow of payments from human and physical capital net of investment has not only the same present value but also the same time path and stochastic pattern as consumption. To get into the spirit of this point, think of an out-of-equilibrium movement of the interest rate in a Lucas tree model. A fall in the interest rate would raise the present discounted value of future income (fruit from the tree), but would also raise the present discounted value of future consumption by an equal amount. Hence, the representative household is effectively no richer than before. Only the substitution effect will be left. ${ }^{42}$ (Note that the substitution effect is likely to be especially large for investment goods and other durables.)

Thus - apart from any expansion of the production of the economy as a whole as a result of the change in monetary policy - any effect of interest rate changes on the present value of society's assets overall is cancelled out by the effect of interest rate changes on the present value of the planned path and pattern of consumption. Of course, what is actually done will be affected by the change in interest rates, but the envelope theorem says that the wealth effects can be calculated based on the flow of payments and consumption flows that were planned initially.

When allowing for heterogeneity between agents, the key point is that borrowers almost always have a higher marginal propensity to spend than lenders. (We use "marginal propensity to spend" to mean the sum of the marginal propensity to consume, the marginal propensity to invest and the marginal propensity to do government purchases given a fall in rates. One should not focus on the marginal propensity to consume alone.) There is a reason the marginal propensity to spend tends to be higher for borrowers than lenders: borrowers tend to be borrowers because they have a high average propensity to spend, and lenders tend to be lenders because they have a low average propensity to spend. And there is a high correlation between average and marginal propensities to spend.

\section{The Fiscal Arm of the Government as a Party to Borrower-Lender Relationships}

An important example of how easy it is to forget the other side of a borrower-lender relationship is when focusing on the reduction in spending by short-term government Treasury bill holders when interest rates go down. This is a genuine effect. But think of the other side of this borrower-lender relationship: the fiscal arm of the government. Interest rate cuts reduce a key measure of government deficits; in a recession, most governments would spend the savings on interest payments they enjoy due to lower

\footnotetext{
${ }^{42}$ There is no multiplier in this case because aggregate demand has no effect on output.
} 
rates. Indeed, we suspect that the marginal propensity to spend out of savings from lower interest rate payments is close to $100 \%$ for most governments.

Note that our point of view is that reactive changes in government spending due to either the wealth effect or the substitution effect from lower rates should be considered part of the monetary policy transmission mechanism, rather than part of fiscal policy. From this point of view, certain policies of the fiscal arm of the government can enhance monetary policy transmission: in particular, monetary policy transmission is enhanced by policies to strengthen the substitution effect on government spending by pursuing capital spending in an interest-sensitive way.

As a borrower, the fiscal arm of the government also provides the most important exception to the general regularity that borrowers have a higher marginal propensity to spend than lenders. However, this exception is for hyperinflationary situations, not the deflationary situations that motivate negative interest rate policy. Think of the situation described in "Some Unpleasant Monetarist Arithmetic" (Sargent and Wallace, 1981), viewed from a fiscal-theory-of-the-price-level perspective. Imagine thatother than the implicit inflation tax - a particular government is expected to spend in present value beyond the present value of its taxes. Suppose that its central bank raises rates to try to contain the resulting inflation, but the fiscal arm of the government does not reduce primary spending (spending other than interest payments). The low MPC implied by the lack of change in spending could well be lower than the MPC of those investing in Treasury bills whose interest income goes up because of the central bank's action (Kimball 2016b).

"Fiscal dominance" in this sense of a lower marginal propensity to spend for the government than for those lending to it is much more likely in a hyperinflationary situation than in a deflationary situation. The two cases are different because it is fundamentally easier to raise government spending than it is to cut it. Many governments do cut primary spending when interest rates go up (thereby maintaining monetary dominance). But the fraction of fiscal authorities that do not cut primary spending in response to interest rate increases in a hyperinflationary situation is likely to be greater than the fraction of fiscal authorities that do not raise primary spending in response to interest rate cuts. Note that this claim is consistent with observing a "fiscal austerity" reaction to increased government deficits in a recession or a rise in interest rates paid by the government due to a higher default premium. Both of these dimensions of fiscal austerity are actually reflections of the concern with the government deficit that cuts in interest rates by the central bank helps to alleviate. ${ }^{43}$

\footnotetext{
${ }^{43}$ The fact that interest rate cuts tend to reduce the government deficit makes many so-called monetary policy "hawks" concerned that the desire to reduce the government deficit will improperly influence monetary policy. We have four remarks in response: (1) The ability to eliminate any lower bound on interest rates does not provide any relief from a central bank's duty to judiciously determine the best target rate to achieve its mandate. Debates — even heated debates - about the best target rate to set would and should continue after any lower bound on rates has been eliminated. (2) While it is important for the central bank to be able to make wise commitments, we do not consider a lower bound on interest rates a wise commitment since it interferes with other, more important commitments - for example, commitments to an inflation target or commitments to keep output gaps small. (3) Early on during the Great Recession, there were periods of time during which many who had a
} 
Let us round out this subsection with several examples of the fiscal arm of the government as a party to borrower-lender relationships.

Governments and Treasury Bill Holders: Those who like to roll over their wealth in the form of shortterm Treasury Bills are likely to be especially unhappy about low interest rates. But their loss is the government's gain. As noted above, since lower interest rates on Treasury Bills show up as a reduction in conventional measures of the government budget deficit, this money is especially likely to be spent by the government. So the redistribution in this case tends to lead to greater aggregate demand.

As for the substitution effect, many people have been frustrated that the substitution effect for government investment is so low. Most governments seem to pay too little attention to interest rates in deciding whether an investment project such as refurbishing roads and bridges is a good idea or not. But it is unlikely that the logic that low interest rates make government investment projects a better idea will forever fall on deaf ears in every nation in which interest rates fall.

Governments and Holders of Long-Term Government Bonds: It may well be that negative interest rates in most countries are preceded by quantitative easing that shifts government financing decisively toward Treasury bills. But there are likely to be some long-term government bonds left. In this case, there is much less of a redistribution between the government and the bond-holders. The committed payments stay the same for some time. With less redistribution, it makes sense to focus on the substitution effect even more than in the other examples above. As mentioned above, the substitution effect for the government may be low (much lower than it should be), but the holders of the long-term bonds have reason to shift their consumption forward in time.

Government Lending: For the most part, the focus in this subsection has been on the government as a borrower. A government may also be a lender. Much government lending is done through long-term fixed-rate loans that are not directly affected by cuts in the central bank's target rate. If a government did, for example, make student loans, mortgage loans, or business loans on a short-term or floating rate basis, it is not clear which side of that borrower-lender relationship would have a higher marginal propensity to spend out of changes in interest rate payments, the government or the borrower.

\section{The Central Bank and Private Banks as Parties to Borrower-Lender Relationships}

If the central bank lending rate and interest rate on reserves are in line with the target rate and the Treasury bill rate, any redistribution from interest rate cuts is in large measure between savers and those

strong reputation as monetary policy hawks also wished it were easier to cut rates below zero than it was under the traditional paper currency policy — which was taken as a given by almost all monetary policy makers and the bulk of monetary policy commentators at the time. One reason for this wish that it were easier to cut rates was a concern with the possible side effects of the large-scale asset purchases that were used instead of interest rate cuts. (4) It is precisely those central banks that have had a good record as inflation fighters that are most likely to wind up in a situation where the effective lower bound on rates from a traditional paper currency policy is an issue. These are precisely the central banks that because of their institutional history and culture can best be trusted to use deep negative rates. Central banks that have shown little prowess at fighting inflation don't need negative nominal rates! They can get deep negative real rates from their high inflation rates. 
banks borrowing from the central bank, with the central bank only a conduit and not itself subject to much of a wealth effect. However, central banks tend to have a positive net wealth position. Like many other entities in positive net wealth positions, most central banks have a relatively low marginal propensity to spend on salaries, buildings and other expenses directly, but any funds they remit to the fiscal arm of the government is likely to be associated with a high marginal propensity to spend, as discussed above. And central bank funds are often used to shore up private banks in one way or another. Any discretion the central bank has about when it remits funds to the fiscal arm of the government and how it helps private banks gives the central bank more power to stabilize the economy, but in the US at least, there is a trend toward less discretion for the Fed in when it remits funds to the fiscal arm of the government ${ }^{44}$ and less discretion in how the Fed can shore up private banks.

Paper currency is itself an asset of the central bank. People using paper currency for tax evasion may well have a high marginal propensity to consume, but the more serious criminals who hold most of the rest of paper currency by value probably have a low marginal propensity to consume; laundering money through businesses legitimate enough that it is safe to spend the money takes time, so for the most financially successful criminals, consumption must often be deferred. (Think of the trouble the protagonists in "Breaking Bad" had in spending their money in the present without calling too much attention to themselves.) Lowering the paper currency interest rate is mostly a transfer from criminals of these two types to the central bank, where it adds to central bank seignorage (and often is then sent on to the fiscal arm of the government.

Because of the importance to the economy of having healthy banks, wealth effects on private banks deserve the special attention we have given already above. A simple approximation to begin to account for the importance of banks in the economy is to treat banks as if they had a marginal propensity to spend above $100 \%$. The bottom line about banks' balance sheets is that banks as a whole would benefit from interest rate cuts except for the difficulty they feel in passing on low rates to their depositors. This is where we recommend central banks give assistance to private banks: Effective subsidies through the interest-on-reserves formula to encourage banks to exempt small accounts from negative interest rates (with rules that prevent getting the subsidy on a large amount of deposits divided between different banks). This helps both the banks and depositors who are likely to have a high marginal propensity to spend.

There are two reasons why subsidizing the provision of zero rates to small deposit accounts is likely to be one of the most politically beneficial ways of helping banks. First, it avoids negative rates for small depositors who are both numerous and likely to have a hard time understanding and coming to terms with negative rates on their deposits. Second, to the extent subsidizing zero rates for small deposits helps

\footnotetext{
${ }^{44}$ See blog post on "Budgetary sleight-of-hand" by Ben Bernanke (2015) discussing the Congress "raiding" the Federal Reserve's capital surplus account in 2015 to finance highway spending (November 9, 2015). Then in February 2018, for a second time in three years, the Congress directed the Federal Reserve to send funds ( $\$ 2.5$ billion) to the Treasury.
} 
banks, this can be explained in part as the flipside of helping depositors and in part as undoing the harm to banks that would otherwise arise from a negative interest rate on reserves.

\section{E. Adding in Borrower-Lender Relationships that Do Not Involve the Government}

Aside from the complex relationships between arms of the government and the private sector, we challenge the reader to think of other cases in which the marginal propensity to spend of a lender is higher than the marginal propensity to spend of the borrower that particular lender is lending to. The best we can do is the case of retirees holding the bonds of a company that has no potential investment projects anywhere near having a positive present value, and that also has a low marginal propensity to pay out dividends with respect to cash-on-hand. Adding up across borrower-lender relationships means that such cases must be balanced against the many other cases in with borrowers have a higher propensity to spend than lenders. Adrien Auclert (2016) does such an adding-up exercise in "Monetary Policy and the Redistribution Channel." His computations suggest that, appropriately weighted, borrowers overall have a higher marginal propensity to spend than lenders.

Interest rates show up in many parts of the economy. Generally, interest rates move up and down together. Those rates where there is more risk of default or where money is locked up for longer periods of time tend to have a higher average level, so a move to negative short-term safe rates is likely to mean lower, but still positive rates for most consumer loans and bank loans, for example. It is worth taking a look at how, in each borrower-lender relationship, lower interest rates tend to stimulate aggregate demand overall. It is also good to notice how a loan done in a regular bank office is only a modest share of all borrower-lender relationships. This subsection provides examples.

Mortgages: Houses are easier to buy and to build when interest rates are lower. The effective wealth of those who own mortgages tends to go down when interest rates fall, especially when people use a prepayment option to refinance at a lower interest rate, but those who need to pay the mortgage get a corresponding improvement in their financial situation that enables them to spend more. Those who need to pay the mortgage typically have a higher propensity to consume.

Car Loans: Cars are easier to buy when interest rates are lower. This stimulates aggregate demand, and is mostly a substitution effect. Car buyers and car dealers benefit from lower interest rates. Their increased effective wealth makes up for the reduction in effective wealth of those who own securities backed by car loans who hope to roll over their existing loans into more car loans. Apart from the effects of that loss in effective wealth, those looking to roll over car loans they hold into more car loans have an incentive to shift the spending of what resources they have left toward the present over the future. That substitution effect also contributes to aggregate demand.

Venture Capital: It is easier and cheaper to get money for a startup when interest rates are low. This has a substitution effect toward more burn to write new software or develop a new medical treatment. There are wealth effects favoring those who have ideas over those who have a pile of money to invest. 
Those who have ideas tend to have a higher propensity to spend on making their ideas a reality (not consumption spending, but spending nonetheless) than the direct propensity to spend of those with the pile of money for investment.

Commercial Paper: Those whose bank accounts would exceed the limit for being shielded from negative interest rates need to put their money somewhere. For large amounts of money, paper currency is not that attractive to begin with, and can be kept from being too attractive by keeping the paper currency interest rate equal to the central bank's target rate (for example, the federal funds rate or a repo rate). So those who want to hold liquid wealth are still likely to want to have some version of money market funds, even when those funds have a negative interest rate. Or it may be that a new type of fund would arise serving the same function. Lower interest rates make it less costly for businesses to borrow in the commercial paper market and so make it easier for those businesses to make it from one month to the next without running out of funds. These businesses may even feel they can take a somewhat bigger risk in the direction of expansion. Those with part of their pile of funds invested in the commercial paper market suffer a loss in effective wealth, but that is made up for by the increase in effective wealth of those borrowing in the commercial paper market. Leaving aside those wealth effects, those with their funds invested in the commercial paper market have a bit of a substitution effect in favor of consuming more.

Firms with Liquid Asset Hoards: Farthest from needing any bank loan are companies that already have large liquid asset hoards that, under current interest rates, they see as earning a better risk-adjusted return when sitting earning interest than if invested in a new factory, new machinery, or a new business venture. When interest rates go down, these firms will begin to pay a heavy price for simply earning interest with a liquid asset hoard, and those within the company who want to champion a new business venture will meet with more success in internal corporate deliberations. This is particularly valuable for the economy if firms were applying too high a hurdle rate for proposed projects even at the old higher interest rate - as Clay Christensen and Derek van Bever argue in their Harvard Business Review article "The Capitalist's Dilemma." In this context, negative interest rates might help greatly in getting not only the financial side of the firm, but also the production-and-sales side of the firm to realize that interest rates are low, and to realize what that should mean for business decisions.

All of the forgoing is about the substitution effect for firms with liquid asset hoards. As for wealth effects, a firm holding a large hoard of liquid assets is likely to have a lower marginal propensity to spend than a typical firm (if they hold a diversified portfolio of stocks and bonds and commercial paper) or the government (if they hold Treasury bills).

\section{F. Effects of Interest Rate Cuts on International Capital Flows and Exchange Rates}

The examples above show that the aggregate demand effects from lower interest rates-including negative interest rates - do not depend solely on international capital flows! But an open economy 
generates many complications. This subsection lays out those complications. The view of international finance taken here is the traditional one among policymakers and in basic textbooks.

While the effects of interest rate cuts on international capital flows should be modest if all countries cut interest rates at the same time, capital flows and therefore net exports can be strongly affected by rate cuts when other countries hold their rates fixed. In a serious worldwide recession, a country that can get an aggregate demand boost from cutting rates, holding other countries' rates fixed, is more likely to do so, whether it is initiating a cycle of rate cuts or responding to another country's rate cuts. (Framing a rate cut as a response to another country's actions could be politically beneficial in some circumstances.) Given the fact that negative interest rates would work for the whole world and so are not zero-sum, the fact that early adopters get an extra kick from higher net exports is a feature, not a bug. These international effects are likely to hasten the spread of negative interest rates as part of the monetary policy toolkit. But this feature depends on a central bank getting an increase in aggregate demand from a rate cut, holding the rates of other central banks fixed.

Note that - as long as the full set of effects doesn't reverse the direction of the effect of a rate cut on aggregate demand - monetary policy can compensate for any dampening in the power of a rate cut by cutting further. And, in principle, in the topsy-turvy case in which the full set of effects does reverse the direction of the effect of a rate cut on aggregate demand, then a central bank would still not be powerless over aggregate demand: it could raise rates to stimulate the economy. Only in the knife-edge case of a zero effect of interest rates on aggregate demand would a central bank be powerless to affect aggregate demand.

\section{i. International Capital Flows as an Additional Substitution Effect}

In an open economy, central bank rate cuts lead portfolio investors to shift away from domestic assets toward foreign assets. These capital outflows, if unchecked, lead to depreciation of the international exchange rate that causes a matching increase in net exports. ${ }^{45}$ That effect on net exports makes the aggregate demand stimulus from rate cuts larger. This effect is especially powerful relative to the size of the domestic economy in small open economies.

The empirical importance of rate cuts on international capital flows, exchange rates and net exports during the last few years does not imply that international capital flows are the only way negative rates can work. If other countries do not match rate cuts, the effect of rate cuts on international capital flows can indeed be the dominant effect for a small open economy such as Switzerland, Sweden or Denmark, and substantial even for an economy as large as the eurozone economy. If a central bank gets enough extra aggregate demand quickly from international effects, it is unlikely to continue cutting interest rates

\footnotetext{
${ }^{45}$ This leads to flows of funds from the now lower rate country (call it the home country) toward other countries that have not cut their rates, as those funds seek a good return. The fact that foreign assets are purchased directly or indirectly by domestic currency then makes the rest of the world awash in domestic currency-more than the rest of the world outside the domestic currency zone is likely to want. Exchange rates adjust until the domestic currency makes it way back to the domestic currency zone-primarily to pay for an increase in net exports.
} 
far enough to see much action from the other channels. But if other central banks cut interest rates too in accordance with what their own economies need, then the central banks that started the round are more likely to find they need to cut interest rates far enough for the other channels to kick in in a big way.

This is an example of a general principle: transmission mechanism $\mathrm{X}$ being important historically doesn't mean transmission mechanism $\mathrm{X}$ was essential. There could easily be many transmission mechanisms in reserve that didn't have to do much work historically because transmission mechanism $\mathrm{X}$ was so powerful. But if transmission mechanism $\mathrm{X}$ was blocked or cancelled out for some reason (as the capital flow channel is largely cancelled out when other central banks match one's rate cuts), other channels could kick in.

Also, when people ask about how effective negative interest rates are at stimulating aggregate demand, it is important to emphasize again that interest rate cuts - in either the positive or negative regionshould be judged by how much they do per basis point. One should not expect a 10 basis point (.1 percentage point) cut to have a huge effect simply because it is in the negative region. For those countries that choose as a matter of policy to keep an effective lower bound on interest rates by keeping paper currency policy unchanged, there may not be enough basis points to cut to have a big effect on aggregate demand. But for any central bank willing to go off the paper standard, there is no limit to how low interest rates can go other than the danger of overheating the economy with too strong an economic recovery.

\section{ii. Wealth Effects in an Open Economy}

Wealth effects of rate cuts in an open economy vary by asset type. When domestic actors are on both sides of an asset market, the analysis loses little by speaking as if the netting out were a domestic borrower-lender relationship. When domestic assets net out between two domestic actors, the analysis is as in the previous subsections, and so as argued should tend toward a positive effect of a rate cut on aggregate demand.

However, when assets denominated in a foreign currency net out between domestic actors on the borrowing and the lending side, depreciation of the home currency from a rate cut generates a capital gain and therefore an additional positive wealth effect for the domestic actor lending that foreign asset and a capital loss and therefore a negative wealth effect for the domestic actor borrowing that foreign asset. If, as we have argued above, the lender typically has a lower marginal propensity to spend than the borrower of that foreign asset, depreciation causes a redistribution among domestic actors that tends to reduce aggregate demand. Thus, borrowing and lending of foreign-currency denominated assets, even among domestic actors, is likely to reduce the effectiveness of rate cuts in raising aggregate demand. 
Wealth effects from net international positions in a given asset can be analyzed in terms of a $2 \times 2$ table: domestic/foreign asset; and net lender/borrower internationally (Table 5). For simplicity, the additional dimension of long-term/short-term asset is not considered in the table.

Wealth Effects from Rate Cuts Interacting with the Net International Investment Positions of a Small Open Economy, "Domesticia"

\begin{tabular}{|c|c|c|}
\hline $\begin{array}{c}\text { Local Currency } \\
\text { Denominated Assets }\end{array}$ & $\begin{array}{c}\text { Pesitive International Position in the Asset } \\
\text { domestic lenders + No effect of currency depreciation } \\
\text { negative wealth effect for domestic lenders >> positive wealth } \\
\text { effect of foreign borrowers times fraction of spending by foreign } \\
\text { borrowers done in Domesticia }\end{array}$ & $\begin{array}{c}\text { Negative International Position in the Asset } \\
\text { Increased power of rate cut due to positive wealth effect for } \\
\text { domestic borrowers + No effect of currency depreciation } \\
\text { effect of foreign lenders times fraction of spending by foreign } \\
\text { borrowers done in Domesticia }\end{array}$ \\
\hline $\begin{array}{c}\text { Foreign Currency } \\
\text { Denominated Assets }\end{array}$ & $\begin{array}{c}\text { Increased power of rate cute due to effect of currency } \\
\text { depreciation } \\
\text { depreciation of currency leads to positive wealth effect for } \\
\text { domestic lenders of foreign currency denominated assets } \\
\text { (if it were a large open economy, lowering the foreign interest rate } \\
\text { would add a negative wealth effect to this positive wealth effect) }\end{array}$ & $\begin{array}{c}\text { (if it were a large open economy, lowering the foreign interest rate } \\
\text { would add a positive wealth effect to this negative wealth effect) }\end{array}$ \\
\hline
\end{tabular}

Note: The wealth effects involving local currency denominated assets are larger when these assets are short-term or have a prepayment option. Short-term vs. long-term does not matter for effects due to currency appreciation. But for a large open economy that can affect foreign interest rates, the additional wealth effect from lowering foreign interest rates is larger per basis point for short-term assets (or those that have a prepayment option).

Table 5: Wealth Effects from Net International Positions for a Small Open Economy

When a country has a net position in domestic assets, that yields an interest rate effect for that country that is not fully subject to the principle of countervailing wealth effects. If the country is a net lender in domestic assets, this gives rate cuts a negative wealth effect from that net position that is not canceled out by the wealth effect on the foreign borrower. One way to put this is that the marginal propensity to spend domestically is likely to be greater for the domestic lender, even if the domestic lender has a lower marginal propensity to spend overall. This reduces the power of a rate cut to raise aggregate demand.

On the other hand, when a country is a net borrower in domestic assets (as the US is), an interest rate cut has a positive wealth effect for domestic actors that is not fully subject to the principle of countervailing wealth effects. After a rate cut, the foreign lender in domestic assets is unlikely to reduce domestic spending enough to offset the increased spending from the wealth effect on the net borrowing in domestic assets - both because lenders generally have lower marginal propensities to spend and because only a fraction of the reduced spending by the foreign lender is likely to be a reduction in domestic spending.

Turn now to borrowing and lending in foreign-currency-denominated assets. The wealth effects of a rate cut interacting with either net lending or net borrowing in domestic assets is bigger when the assets are short-term assets. By contrast, for net lending or net borrowing in a foreign asset, a small open economy is unlikely to change the foreign interest rate much - and so there is little distinction between wealth effects for long-term foreign assets and short-term foreign assets. If a country has a large economy 
compared to the world economy, then foreign market rates will be influenced in the same direction as domestic rates (even in the absence of any foreign central bank reaction), and foreign assets have a wealth effect directly from changed interest rates in the same direction as domestic assets.

In most cases, the largest interest-rate-related wealth effect from net lending in foreign-currency assets or net borrowing in foreign-currency assets is from the capital gains to those assets when the domestic currency depreciates. If a country is a net lender in foreign-currency assets, the capital gain in these foreign assets adds to the power of rate cuts in stimulating aggregate demand. But if a country is a net borrower in foreign-currency assets, there will be a negative wealth effect when domestic rate cuts lead to depreciation. Unfortunately, it is all too common for countries to be net borrowers in foreigncurrency-denominated assets. This situation dampens down and in some cases might reverse the direction of the effects of rate cuts on aggregate demand. We consider borrowing in foreign-currencydenominated assets - whether sovereign borrowing or borrowing by private domestic actors - as something that should be discouraged because of its consequences for monetary policy.

As mentioned above, if a central bank fully understands the net effect of a rate cut on aggregate demand, it will only be powerless in a knife-edge case. In the topsy-turvy case, it might need to use negative rates in order to reduce aggregate demand and thereby reduce inflationary pressures! (For example, negative rates that lead to depreciation of the domestic currency might put domestic actors more deeply in debt to foreign actors, and thereby restrain aggregate demand.)

\section{iii. $\quad$ Sovereign Wealth Funds}

One final wrinkle that is apparent when thinking about some open economies, but is not strictly due to an open economy is the possible existence of a sovereign wealth fund as an additional institution. A sovereign wealth fund is likely to have a lower marginal propensity to spend than the regular fiscal arm of the government. If a sovereign wealth fund borrows at the Treasury bill rate to fund investments, and has a lower marginal propensity to spend than Treasury bill holders, that creates a negative wealth effect. However, this difference in marginal propensities to spend might be small compared to how much larger the marginal propensity to spend is of those who borrow domestically from the sovereign wealth fund than the marginal propensity to spend of the sovereign wealth fund itself. And many sovereign wealth funds have positive net wealth positions, so that their lending has a bigger effect on the economy than their borrowing.

In some cases the marginal propensity to spend domestically may be lower for a sovereign wealth fund than for a foreign actor. That would change some of the analysis above.

\section{Alternative Policies and Complementary Policies to Negative Interest Rate Policy}

As we discuss in Agarwal and Kimball (2015), 
According to some observers eliminating the zero lower bound is unnecessary since the combination of fiscal policy, quantitative easing, and other monetary policy tools such as forward guidance or nominal GDP level targeting is sufficient to stimulate a recovery at the zero lower bound. A similar line of argument also suggests that we should avoid experimenting with expanding the toolkit since the economy will fix itself. However, the experience of the lost decades in Japan, and the recent experience of advanced countries facing the zero lower bound with persistent deflation or low inflation suggest that the combination of existing tools used has not been sufficient to bring about a recovery anywhere near as quickly as desirable, and that the welfare costs of such episodes can be quite large.

Below we discuss the effectiveness of negative interest rate policy vs. fiscal policy or QE in escaping a liquidity trap.

\section{A. Fiscal Policy vs. Negative Interest Rate Policy}

Monetary policy and fiscal policy are not equally good as ways to stimulate the economy. Traditional monetary policy (i.e., lowering the short-term interest rate) has two key advantages over traditional fiscal policy. First, it does not add to the national debt (by contrast cutting taxes or raising spending adds to the national debt). Second, because many countries have - however controversially — been willing to let monetary policy be handled by an independent and technocratic central bank, monetary policy is not fated to be tangled up politics to the same extent that discretionary fiscal policy inevitably gets tangled up in long-running political disputes about taxing and spending.

In this context, as we discuss in Agarwal and Kimball (2015),

There is a political economy reason why it is difficult to make fiscal policy technocratic: taxing and spending are relevant not only for short-run stabilization but also for long-run issues of incentives, redistribution and government spending priorities. Although the short-run and longrun use of fiscal policy can in principle be distinguished, it is not surprising that in fact the two different roles of fiscal policy—short-run and long-run—are tangled up politically.

While monetary policy has been constrained by the effective lower bound, fiscal policy has already been working hard. However, the experience of Japan and the global economy in the Great Recession demonstrates that trying to keep aggregate demand up without using lower interest rates requires quite extreme fiscal policy.

By contrast, it seems clear that in many countries governments have given central banks broad enough authority that negative interest rate policy beyond what has been done so far in that country could be executed by an independent central bank without additional legislation. Politicians can then distance themselves from the negative interest rate policy. A central bank that does so will, of course, get some blowback, but central bankers pride themselves on being willing to raise interest rates when appropriate 
even when such a move meets with criticism. They should take a similar pride in being willing to lower interest rates deeper below zero when appropriate even when that move meets with criticism.

\section{B. Quantitative Easing vs. Negative Interest Rate Policy}

Several advanced country central banks have engaged in quantitative easing (QE), which involves issuing central bank reserves to purchase either public assets beyond Treasury bills or to purchase private or semi-private assets. In the case of public assets, QE is essentially a maturity transformation by the central bank: the central bank buys long maturity government debt in exchange for short maturity reserves. While, experience with QE suggests that the outcomes were better than they might have been otherwise, they were not good in any absolute sense. Moreover, QE has been associated with uncertain effectiveness, various market distortions, unknown side effects, and harmful distributional consequences. These issues are likely to emerge again when central banks consider using QE in the future.

Let us examine some of the issues that arise for QE in greater detail. First, scaling up quantitative easing does not necessarily yield unlimited monetary stimulus power, since the effect of higher quantities on the relevant spreads may reach an asymptote. Second, although somewhat modified spreads may be a positive change even apart from monetary policy, spreads that are far enough from the historical average could easily have undesirable side effects. Third, we simply don't understand quantitative easing very well. In simple models, quantitative easing does nothing, for Modigliani-Miller/Ricardian Equivalence type reasons. The exact effects of quantitative easing, which would need to be understood in order to assess costs and benefits of scaled-up quantitative easing, depend on the particular model used to escape the equivalence benchmark. Moreover, the simple maturity transformation can be achieved by the fiscal authority on its own (something various Treasuries around the world have done in the past), and it's not fully clear why central banks doing such maturity transformation should have dramatic effects. Part of the effectiveness of QE when a central bank engages in it the first time could be driven by the 'shockand-awe' effect. However, it is quite hard to retain the shock-and-awe effect for marginal asset purchases, mainly because it is easy for central banks to engage in it (thereby reducing the signal value of the actions). To maintain the shock-and-awe effect the central bank may need engage in very large purchase quantities - but that amplifies the side effects. As we discuss in Agarwal and Kimball (2015),

By contrast, simple models say that it is only real interest rates that matter-which if true implies that past experience can provide excellent guidance for the effect of negative nominal rates within an important range. For negative interest rates, the real-world counterparts to nonstandard model elements are a worry, but not the essence. For quantitative easing, the real-world counterparts to nonstandard, little-understood model elements are everything. Empirically, we know the amount of quantitative easing actually used was insufficient to yield quick recovery; we simply don't know what larger doses of quantitative easing would have done. 


\section{Cost of Delays When Using the Alternatives}

Moreover, there is a set of arguments that work equally against both fiscal policy and quantitative easing as alternatives to negative interest rate policy. A large enough dosage of either fiscal policy or quantitative easing is likely to have important side effects. Fear of these side effects is likely to keep the dosage of fiscal policy and quantitative easing below the dosage that would be necessary to get quick recovery during a serious recession in which interest rates were not cut very much. And waiting to see if a dosage of quantitative easing within historical experience or a dosage of fiscal policy within the most likely range can deliver enough stimulus is likely to lead to a delay in recovery costing trillions of dollars worth of social welfare relative to going to deep negative interest rates immediately. Promptly pursuing at least some intensification of negative interest rate policy (along with whatever expansion of fiscal policy and QE is pursued) is likely to lead to better outcomes. For example, as discussed below in Section XV, "Using Communication Tools to Overcome Political Challenges in Implementing Deep Negative Rates," even a very small dosage change in paper currency policy might have a substantial "shock and awe" effect.

Another way of putting the argument that delay is very costly, in relation to quantitative easing, is that the "buying time" that Mohamed El-Erian (2019) talks about in "How Western Economies Can Avoid the Japan Trap" is a bad thing, not a good thing:

Large-scale balance sheet operations like quantitative easing $(\mathrm{QE})$ can buy time by seeking to inject more liquidity directly into the system. But they don't address the underlying issues, and they come with their own set of costs, forms of collateral damage, and unintended consequences.

Negative interest rate policy that includes reducing the rate of return on paper currency below zero is the straightforward solution to a liquidity trap: the liquidity trap is simply gone once one changes paper currency policy, and interest rate policy by the central bank can then proceed without constraint. Longrun real interest rates and long-run productivity growth are beyond the power of monetary policy to change directly. But enabling deep negative rates allows monetary policy to do its job of stabilizing the economy, removing a large distraction that takes many economists and policymakers away from discussing ways to raise long-run productivity growth. (And note that raising long-run productivity growth would also tend to raise the long-run real interest rate.)

\section{Microprudential and Macroprudential Policies as Complementary Policies to Negative Interest Rate Policy}

Since the Financial Crisis in 2008, central banks have become keenly concerned about the effect of lower rates on financial stability. However, the ability to get economic stimulus from lower rates makes it possible to increase capital requirements and toughen other macroprudential measures to alleviate these financial stability concerns without worrying about the aggregate demand consequences of those 
macroprudential measures. Hence, we view macroprudential measures as complements to negative interest rate policy.

Let us make two points about the interaction of this pair of complementary policies - negative rates and tough macroprudential measures. First, while asset prices should be high when interest rates are low, a distinction needs to be made between temporarily low interest rates and chronically low interest rates. Temporarily negative interest rates could actually help by raising long-term rates. One possible cause of chronically low short-term interest rates and associated low long-term interest rates is being up against the zero lower bound with a continuing output gap that depresses the real rental rate for investments. To put it bluntly, if the markets believe there is a good chance one might be headed for one's own version of Japan's lost decades, they may see low interest rates far off into the future for a nation stuck at the zero lower bound. Therefore, in this context enabling central banks to implement deep negative rates when needed, can convince markets that the zero bound has been effectively broken, and that a central bank will vigorously use negative interest rates to bring the output gap to zero- thereby making higher interest rates in the future more likely that are appropriate to match the higher real rental rate for investment in a non-depressed economy.

Second, lower rates may make it harder to detect deterioration in credit quality (as the monthly loan payment of a given firm relative to its operating income falls when interest rate falls). Such risk of lending to potentially insolvent borrowers (or zombie firms) can be addressed by use of various prudential tools that may need to be tightened when interest rates are lower. For example, one can (i) require a strict loan to income ratio, restricting the ability of firms with low operating income to lever up significantly, (ii) impose amortization requirements that ensure that firms effectively pay back a portion of the principal in each period (without such requirements the loan origination standards may not be sensitive to the fact that typical loan contracts have a lower payback rate in the sense of the minimum 'operating income' required to meet the debt obligations when interest rates are low) ${ }^{46}$, and (iii) use an improved supervisory approach for monitoring and classifying non-performing loans to ensure early detection of problem loans (as low payback rates due to low interest rates can make it easier for firms to hide deterioration in credit quality).

\section{Using Communication Tools to Overcome Political Challenges in Implementing Deep Negative Rates}

The deeper the recession an economy is in, the lower a central bank needs to push interest rates in order to stimulate the economy. This statement can be backed up by both the experience of central banks and by theoretical reasoning.

\footnotetext{
${ }^{46}$ In present values, total payments equal the value of the loan itself. Let us define the 'payback rate' in any year as the total payments made by the borrower (both interest and principal repayments) in that year as a fraction of the remaining value of the loan. The payback rate differs from the amortization rate because it includes the interest payments. This can be motivated by the present value perspective. But the main reason the payback rate is a useful concept is that it indicates the minimum operating income needed for that operating income to cover the full required principal and interest payments. More broadly, ability to meet a given payback rate is one measure of a firm's viability and its ability to generate funds.
} 
Empirically, while there is ongoing debate about the robustness of central bank reaction functions, for the U.S., Bernanke (2015) demonstrates that the predictions of a modified Taylor rule with a weight of 1 on the output gap are generally quite close to actual Fed policy over the past two decades - until the Fed hit what it treated as the zero lower bound in late 2008. Thus, broadly speaking, holding other things constant, the Fed has responded to larger output gaps with larger interest rate cuts. Similar reaction functions have been estimated for other advanced country central banks.

Theoretically, the behavior of investment is crucial for macroeconomic models. ${ }^{47}$ Many models share the feature that a negative output gap lowers the attractiveness of investment. If the level of investment cannot adjust instantly, so that the output gap has some dependence on the past- - beyond the dependence of the output gap on the capital stock and the distribution of prices - then the more negative the output gap, the lower the interest rate it will take to engender a given level of investment plans. Thus, the deeper the recession an economy is in, the lower a central bank needs to push interest rates in order to stimulate the economy. ${ }^{48}$

In this context, if the economy is experiencing a deep recession, and the central bank fails to provide sufficient stimulus - for example due to a perceived zero lower bound-recovery is likely to be slow. Slow recoveries can bring central banks under attack. Most people do not fully understand how central banks do their jobs, or what constraints a central bank views itself as being under, but have some inkling that it is the job of central banks to keep inflation on track and to keep recessions short. Slow recoveries look like bad job performance. This, in our view, along with the role of some central banks in bailouts, helps account for the decline in public trust in central banks and worsening of public views of central banks since 2008 (Gros and Roth 2009; Walti 2012).

If a central bank attempts to stimulate the economy with persistent mildly low rates rather than be shortlived deep negative rates, it is also likely to face another political danger. To many in the general public, and even to many within the financial community, it may begin to appear that the central bank has the power to control interest rates in the medium run and even in the long run - that is, as if the central bank could control the natural interest rate. This danger is evidenced by the questions many central bank officials have received about the effects of their policies on pension funds and retirement saving more generally, for which it is long-run returns that matter. (For one example of this issue, see the discussion in Kimball (2016b).

The key point is that once a deep recession has begun, whatever political costs there are to deep negative interest rates, the alternative is not political smooth sailing for a central bank. In that situation, whatever action a central bank takes, it will get flack. The political costs of deep negative rates must be put in the balance against the political costs of not using deep negative rates. An honest appraisal of the political

\footnotetext{
${ }^{47}$ See Barsky, House, Kimball (2007).

${ }^{48}$ As noted, this is a quite general point for a wide range of models with the realistic features mentioned. But for the sketch of a particular model that may help fix ideas here, see Kimball (2014a and 2014b).
} 
costs to the central bank - as well as the broader social welfare costs - of business as usual with deep negative rates off the table is the right starting place for thinking about the political costs of deep negative rates.

Our view is that most central banks have only a short period (say two years) to get their job done before getting blamed for a slow recovery and perhaps even for a low natural rate. We think that for that window of time, given a careful communication strategy, the typical central bank can get away with dramatic action. By "get away with dramatic action" we do not mean that a central bank can escape heated criticism, but that this criticism will fade over time in its punch as the success of dramatic action in bringing economic recovery is demonstrated. If a central bank is fortunate enough to have a reasonable degree of independence, criticism that fades over time in the light of a successful recovery will not be enough to stop the central bank from doing its job.

Many central bankers worry that an unpopular action will ultimately lead to a reduction in its independence. But unpopular results—-such as slow recoveries — can also lead to a reduction in central bank independence. And the purpose of independence in the first place is to make it possible for central banks to take actions that are unpopular in real time. Central bankers are trained and prepared to face the flack that comes from pushing interest rates higher than many people would like in real time; they also need to be trained and prepared to face the flack that comes from pushing interest rates lower than many people would like in real time.

Although the political costs of deep negative rates cannot be avoided, they can be mitigated in three basic ways: first, by having the deep negative rates be as much as possible an out-of-equilibrium phenomenon that a central bank only needs to defend hypothetically, second, by explaining the tools of deep negative rates as well as possible, both in advance and during their use, and third, by subsidizing zero rates for small deposit accounts.

Above, we noted that once a deep recession has begun, whatever political costs there are to deep negative interest rates, the alternative is not political smooth sailing for a central bank. Another key point about political costs is that paying a modest political cost now to defend deep negative rates hypothetically can have a big payoff in reducing political costs of deep negative rates when they are actually needed. Defending deep negative rates hypothetically can have a big payoff in reducing the probability that actual deep negative rates need to be defended.

Interestingly, there is a promising empirical measure of how well a central bank has defended deep negative rates hypothetically. An effective communication strategy should include such an assessment of how well a central bank has convinced the markets it is ready and able to take vigorous action if needed to stimulate the economy. With that in mind, here are the three steps we recommend in a communication plan: 
1. Measuring markets' perception of the effective lower bound and treating it as a policy instrument.

2. Making the market aware of central bank tools that can eliminate the effective lower bound and can manage the associated side effects (if possible before the economy enters a recession).

3. Convince the markets that the central bank is willing to use the new tools as called for:

- demonstrating that the central bank has tools to reduce political costs of negative interest rates (such as avoiding negative rates on small households), and

- demonstrating implementation of the paper currency deposit fee or the paper currency rental fee at a small dosage (e.g. 5 bps) to show that rates are not sticky at zero. (Note that the Swiss National Bank and the Bank of Japan have already demonstrated the paper current rental fee at a small dosage. However, they did not do much to communicate how important and how powerful this tool is.)

Each of these measures is discussed in more detail in its own subsection.

\section{A. Measuring Markets'Perception of the Effective Lower Bound}

Market views of the effective lower bound can be measured using information in the term structure of interest rates. For instance, a recent paper by staff of the European Central Bank and Deutsche Bank develops a modified arbitrage-free 'shadow rate' term structure model to infer the market perception of the effective lower bound on euro-area interest rates (Lemke and Vladu, 2016). They find that, "A decrease in the lower bound parameter leads to assigning positive probabilities to rate realizations that had been infeasible under the old lower bound. This leads, ceteris paribus, to a decrease in expected rates, forward rates and spot rates. The strength of the effect is stronger, the closer forward and spot rates were ranging to the lower bound before its shift. Overall, these results have an important implication for monetary policy: if the central bank manages to decrease the market's perceived location of the lower bound, it can thereby decrease forward and spot rates, even in a situation where the lower bound is not yet binding." In this regard, they view the market's perception of the effective lower bound as a policy instrument — one that the central bank can influence, but cannot directly control.

Kortela (2016) and Grisse, Krogstrup and Schumacher (2016) do a similar exercise, and come to similar conclusions. Grisse, Krogstrup and Schumacher (2016), use an event study of yield reactions to selected negative interest rate announcements in a panel of advanced economies, and find that long rates tended to drop in response to changed market beliefs about the location of the lower bound. They conclude:

... central bank communication about the possible use of negative interest rates, or limits to this use, can have important effects on the monetary policy stance through the effect on markets' beliefs about the location of the lower bound. 
In agreement with these papers, our recommendation is that central banks facing the zero lower bound should act and communicate to drive down perceptions of the effective lower bound. This is consistent with treating markets' perception of the effective lower bound as a new policy tool. There are various benefits of doing this. First, as discussed, it can lower long rates. Second, shifting the perceptions of the effective lower bound, and so lowering the floor on long-term rates, enhances the impact of quantitative easing (Rostagno et al., 2016). Third, it increases credibility for the inflation target in two ways: directly due to a lower perceived floor on short-term rates, and indirectly due to a lower perceived floor on longterm rates.

Note that at some point, pushing down the perceived effective lower bound may raise rather than lower long-term rates. If markets' perception of the effective lower bound is low enough, the downward pressure on long-term rates from fear that central banks will be stuck for a long time at the effective lower bound is alleviated. This leads to a "hope for return to the Great Moderation" and "hope for the return of a normal yield curve," which could act to raise the long-term rate. In a recessionary situation, it is a good thing if the long-term rate is raised by expectations of a stronger economy in the near future.

If the perceived effective lower bound is pushed down far enough to raise long-term interest rates, that should have a positive effect on financial stability: low long-term rates tend to raise asset prices and make them more volatile because a few basis points is such a big proportion of a low long-term rate. By contrast, even deep negative short-term rates do not necessarily raise asset prices much if they are expected to be very briefly applied. It may require a cycle in which deep negative rates are actually used to establish the market expectation that - because of their effectiveness - deep negative rates only need to be applied briefly, but if such a market expectation is established, confidence that the deep negative rate policy is likely to be short-lived will also reduce the effects of uncertainties about the detailed path of negative rates on asset prices.

\section{B. Make the Market Aware of Central Bank Tools to Eliminate the Zero Lower Bound}

Lowering market perceptions of the effective lower bound involves two key steps. First, making the market aware of tools that eliminate any effective lower bound and mitigate the associated side effects. We argue it is likely to be especially valuable to spread awareness of the bank-centric tools working through the price system that we emphasize in this paper: the clean approach and the rental-fee approach. Spreading awareness of these tools, studying them, and frequently communicating about them can help in lowering perceptions of the effective lower bound. It is important to communicate about these tools in normal times, and not only when the economy is in a deep recession. This has two benefits: it prepares the market in advance and increases confidence in the ability of the central bank to fight deep recessions (which also prevents downward pressure on the yield curve).

We are not alone in recommending that central banks spread awareness of tools to enable deep negative rates during normal times. At the 2016 Brookings Hutchins Center Event on negative interest rates, both former Minneapolis Federal Reserve President Narayana Kocherlakota and former Federal Reserve 
Chairman Ben Bernanke emphasized the need for more effective Fed communication about negative interest rates to make them seem a more acceptable monetary policy tool when they are needed. Kocherlakota said:

That's a problem that should be solved right now by the Fed talking openly about 'we've got a bunch of tools that we might use'... it shouldn't be talking about negative rates as something that would only be used in an extreme event.

Bernanke added:

If they have the confidence, for example, that even under extreme circumstances the Fed...can address deflation, that affects the setting of interest rates today.

\section{Convince Markets that the Central Bank is Prepared to Use New Tools}

The second step in lowering markets' perception of the effective lower bound is to convince the markets that the central bank is willing to use the new tools as called for. An effective way to do this, beginning from where things stand now, might involve (1) demonstrating that the central bank has tools to reduce political costs of negative interest rates (such as avoiding negative rates on small households), and (2) demonstrating implementation of paper currency deposit fee at a small dosage (e.g. 5 basis points) to show that rates are not sticky at zero. And if a central bank demonstrates willingness to pay at least a modest political price even without having its back to the wall, it should increase market confidence that the central bank will be willing to pay the larger political price of actually implementing deep negative rates if necessary down the road.

One of the most important ways of demonstrating that the central bank has tools to reduce the political costs of negative rates is signaling a commitment to avoiding negative rates on small household accounts. In this context, the policy of using the interest on reserves formula to subsidize zero rates for small households is quite helpful. We discussed this measure in connection with the the rental fee approach, but it would be helpful in conjunction with all of the approaches we discuss. This policy can be demonstrated during periods of mild negative rates. Indeed, several central banks that have already implemented negative rates have used a tiering system to subsidize banks, recognizing that the banks will not pass on negative rates to small households. But no central bank has yet gained the political benefits we argue would come from making explicit the link between the subsidies to banks and shielding small household accounts from negative rates.

Demonstrating implementation of a paper currency deposit fee (as described under the 'clean approach') at a small dosage (e.g. 5 bps) can also go a long way in convincing the markets that the rates are not sticky at zero and could sizably lower the effective lower bound at relatively low political cost. Let us lay out, point by point, the advantages to initially implementing the paper currency deposit fee at a small dosage, well in advance of when deep negative rates are needed: (i) it is likely send a strong signal to markets and boost the credibility of the central bank by demonstrating that it stands ready to innovate in 
its toolkit and do whatever it takes to meet its objectives, (ii) based on evidence from cutting rates into negative territory one can expect that such a move will both reduce the markets' perception of the effective lower bound and affect long rates, (iii) the experience with the small dosage will allow the central bank staff to get all the technical details and to refine procedural issues before they may need to implement the paper currency deposit fee at larger dosages, (iv) the impact of the paper currency deposit fee at such a small dosage is also unlikely to affect most daily transactions since banks and retailers are unlikely to pass on such a small fee to most of their customers, allowing this to be a largely technical innovation without immediately affecting the experience of most individuals with the banking system and (v) correspondingly will give considerable room to the central bank to credibly defend against the critics, by concentrating the expected hyper-ventilation against central bank innovation in a period when the costs of the paper currency deposit fee are likely to be low due to the small dosage.

As noted above, in recent years, the Swiss National Bank and Danmarks Nationalbank have actually implemented versions of the paper currency rental fee at low dosages - and Japan's policy was only one step away from the paper currency rental fee- but none of these central banks used the imposition of a paper currency rental fee as a communication opportunity beyond the barest mention of the fact. The rental fee approach needs framing and emphasis — something we hope this paper provides.

\section{Benefits of Increasing Central Bank and Broader Government Confidence in Tools to Eliminate the Effective Zero Lower Bound}

Once the central bank and the broader government have confidence that they have tools to eliminate (or push down) the effective lower bound, it comes with several benefits. First, the ability to rely on negative interest rate policy affects the optimal inflation target. For example, in the case of the Bank of Canada, the ability to rely on negative rates (thereby reducing the frequency of hitting a binding effective lower bound) was one of the reasons provided to not raise their inflation target when they recently reviewed their inflation-targeting framework (Witmer and Yang, 2016). Ben Bernanke makes a similar point in his post comparing negative interest rate policy to raising the inflation target (Bernanke, 2016). The extent to which a central bank in the future may be able to revise their inflation target downwards will depend on their view of the effective lower bound. Based on this logic, Agarwal and Kimball (2015) discuss how eliminating the zero lower bound through the clean approach opens up the possibility of having a zero inflation target for major central banks in the future, and discuss the benefits of such a framework. Despite the additional side effects of the rental fee approach, a central bank unwilling or unable to use the clean approach may find that ability to use the rental fee approach reduces its optimal inflation target substantially compared to the inflation target that would be optimal if the effective lower 
bound were a law of nature rather than a policy choice — or compared to the inflation target that would be optimal if, say, only the prohibition approach were feasible. ${ }^{49}$

Another benefit of the ability to rely on negative interest rate policy is that it removes the concern that macroprudential measures might reduce lending and therefore aggregate demand. That is, the choice of two unencumbered tools for two policy objectives (financial stability and aggregate demand) removes the tradeoff between financial stability and aggregate demand.

\section{E. Distinguishing a Policy of Deep Negative Rates for Brief Periods of Time from Zero or Mildly Negative Rates for Long Periods of Time}

In addition to its explicit attention to bank profits and avoiding negative rates on small deposit accounts, the policies we have recommended differ from the experience of negative rates in the past because they envision deep negative rates for brief periods of time rather than mildly negative rates for a long time. Some concerns people express about negative rates stem from what is likely a misconception: that negative rates would need to prevail for a long time. As long as the long-run natural rate is still positive in nominal terms (however low that positive value) deep negative rates that quickly close the output gap can then quickly be raised and converted to positive rates again. We do not know of any theoretical reason why any output gap likely in the next recession (even if it is quite serious) could not be largely closed within 18 months or so given large enough interest rate cuts. (The policies we have discussed can remove any limit on how large interest rate cuts can be.) Quick recoveries are not only desirable in and of themselves, they also allow deep negative interest rates to quickly return to normal. By contrast, if mildly negative rates are not sufficient to bring a quick recovery, the slowness of recovery is not only quite costly in a direct sense, it also means the mildly negative rates will need to be in place for a long time.

\section{Conclusion}

A lower bound on interest rates has proved to be a serious obstacle to recession-fighting. However, despite the specter of the next recession looming in a world of limited monetary policy space above the traditional zero lower bound, central banks have faced serious political challenges in expanding their toolkit to enable deep negative rates. The central message of this paper is that there are set of readily available approaches to enable deep negative rates that empowers the central bank to end recessions within a short time. These approaches allow the central bank to "do a lot with a little" —and are thus more likely to be politically feasible and more likely to be within the authority of the central bank. To

\footnotetext{
${ }^{49}$ Though the optimal inflation target should be lower the easier it is to enable deep negative rates, it may be that the optimal inflation target if, say, the level of the effective lower bound were a fixed law of nature, might be above $2 \%$. For example, several prominent economists have recommended a $4 \%$ inflation target, on the assumption that the effective lower bound is not far below zero (Blanchard, Dell'Ariccia and Mauro 2010; Ball 2013). As with the Bank of Canada's formal inflation target decision, negative rate options might prevent increases in the inflation target above $2 \%$ rather than lead to targets below $2 \%$.
} 
demonstrate this, we survey all known approaches to enabling deep negative rates, adding some new approaches and important nuances to old approaches.

We argue that the best approaches for enabling deep negative rates (i.e. both at a minimum distance from the current monetary framework and the least costly politically) are those that both rely on banks for transmission and do not impose quantity restrictions on cash. The two approaches that meet this criteria are what we call the "clean approach" and the "rental fee approach." We argue that both can be implemented with ease without requiring a radical departure from the current monetary framework. All that is needed is for the central bank to create a negative paper currency interest rate at its cash window. Nevertheless, the 'newness' of such policies puts a high premium on communicating the logic and commitment behind central bank efforts to fight recessions using deep negative rates. In particular, it is important to communicate the idea that deep negative rates can get the job of righting the economy done in a short time.

An important part of the logic behind the use of deep negative rates is the theory of why, with appropriate complementary policies, interest rate cuts in the negative region have similar transmission to interest rate cuts in the positive region. In addition, we argue that communicating the logic and commitment behind deep negative rates, and the range of tools available, is the key to minimizing the political costs of deep negative rates. We also argue there that the remaining political costs of deep negative rates must be counterposed against the political costs of not using deep negative rates when in a deep recession, and that the fortitude required of central bankers to implement deep negative rates in a deep recession despite the flack they will receive is analogous to the fortitude required of central bankers to implement high rates when the economy is overheating.

As we have emphasized, to calm the political waters, for all of the approaches we discuss, a key complementary policy is to encourage and support banks in providing zero interest rates on small deposit accounts even in situations where a wide range of assets - including large deposit accounts - are subject to negative interest rates. That complementary policy should be considered a key element of each approach.

Finally, recognizing all of the theoretical, empirical, legal and practical issues in enabling deep negative rates that we have not resolved in this paper, let us end with a call for more work in this area by economists, financial and banking experts, lawyers, other researchers, policymakers, and economic journalists. We consider this a noble endeavor for those inclined to intellectual pursuits: the option to enable deep negative rates will be critical for central banks to maintain effectiveness of monetary policy in the future and will help mitigate the hardships associated with prolonged recessions. 


\section{References}

Agarwal, R. and Kimball, M., 2015. Breaking Through the Zero Lower Bound (No. 15/224).

International Monetary Fund.

Assenmacher, K. and Krogstrup, S., 2018. Monetary Policy with Negative Interest Rates: Decoupling Cash from Electronic Money. International Monetary Fund.

Auclert, A., 2017. Monetary Policy and the Redistribution Channel (No. w23451). National Bureau of Economic Research.

Ball, Laurence, 2013. The Case for 4\% Inflation. Central Bank Review (Central Bank of the Republic of Turkey), May.

Barsky, R.B., House, C.L. and Kimball, M.S., 2007. Sticky-Price Models and Durable

Goods. American Economic Review, 97(3), pp. 984-998.

Basten, C. and Mariathasan, M., 2018. How Banks Respond to Negative Interest Rates: Evidence from the Swiss Exemption Threshold (No. 6901). CESifo Group Munich.

Bech, M. and Malkhozov, A., 2016. How Have Central Banks Implemented Negative Policy Rates?.

Bernanke, B., 2015. Budgetary Sleight-of-Hand. Blog post, November 9, 2015.

Bernanke, B., 2016. Modifying the Fed's Policy Framework: Does a Higher Inflation Target Beat Negative Interest Rates?. Blog post, September 13, 2016.

Bernanke, B., 2017. How Big a Problem is the Zero Lower Bound on Interest Rates?. Blog post, April 12, 2017.

Bikker, J.A. and Vervliet, T.M., 2018. Bank Profitability and Risk Taking Under Low Interest Rates. International Journal of Finance \& Economics, 23(1), pp.3-18.

Borio, Claudio, and Leonardo Gambacorta, (2017), Monetary Policy and Bank Lending in a Low Interest Rate Environment: Diminishing Effectiveness? Journal of Macroeconomics, 54(B), 217-231.

Borio, Claudio, Leonardo Gambacorta, and Boris Hofmann, (2017). The Influence of Monetary Policy on Bank Profitability. International Finance, 20, 48-63

Brunnermeier, M.K. and Koby, Y., 2016. The Reversal Interest Rate: An Effective Lower Bound on Monetary Policy. Unpublished paper, Princeton University.

Buiter, W.H., 2007. Is Numérairology the Future of Monetary Economics?. Open Economies Review, 18(2), pp.127-156.

Buiter, W.H., 2009. Negative Nominal Interest Rates: Three Ways to Overcome the Zero Lower Bound. The North American Journal of Economics and Finance, 20(3), pp.213-238.

Cipriani, M., Martin, A., McCabe, P.E. and Parigi, B., 2014. Gates, Fees, and Preemptive Runs (No. 670). Federal Reserve Bank of New York. 
Delis, M.D. and Kouretas, G.P., 2011. Interest Rates and Bank Risk-Taking. Journal of Banking \& Finance, 35(4), pp.840-855.

Dell'Ariccia, M.G., Blanchard, O.J. and Mauro, M.P., 2010. Rethinking Macroeconomic Policy. International Monetary Fund.

Demiralp, S., Eisenschmidt, J. and Vlassopoulos, T., 2017, March. Negative Interest Rates, Excess Liquidity and Bank Business Models: Banks' Reaction to Unconventional Monetary Policy in the Euro Area. Koc University-TUSIAD Economic Research Forum.

Dutu, R. and Rocheteau, G., 2005. The Tale of Gresham's Law. Federal Reserve Bank of Cleveland, Economic Commentary, (Oct).

Eggertsson, G.B., Juelsrud, R.E. and Wold, E.G., 2017. Are Negative Nominal Interest Rates Expansionary? (No. w24039). National Bureau of Economic Research.

Eggertsson, G.B., Juelsrud, R.E., Summers, L., and Wold, E.G., 2019. Negative Nominal Interest Rates and the Bank Lending Channel (No. w25416). National Bureau of Economic Research.

Eisler, R., 1932. Stable Money, the Remedy for the Economic World Crisis: A Programme of Financial Reconstruction for the International Conference, 1933. The Search Pub. Co.

El-Erian, M., 2019. How Western Economies Can Avoid the Japan Trap. Project Syndicate, 8 April 2019.

Erikson, H. and Vestin, D., 2019a. Riksbank staff memo: Pass-Through at Mildly Negative Policy Rates: The Swedish Case.

Erikson, H. and Vestin, D., 2019b. Pass-Through at Mildly Negative Policy Rates: The Swedish Case. VoxEu.com, 22 January 2019.

Gesell, Silvio, 1916. Die Natuerliche Wirtschaftsordnung, Rudolf Zitzman Verlag, available in English as The Natural Economic Order, Peter Owen Ltd, London, 1958.

Goodfriend, Marvin, 2000. Overcoming the Zero Bound on Interest Rate Policy. Journal of Money, Credit, and Banking, Vol. 32(4)/2000, S. 1007 - 1035.

Grisse, C., Krogstrup, S. and Schumacher, S., 2017. Lower Bound beliefs and Long-Term Interest Rates. International Monetary Fund.

Gros, D. and Roth, F., 2009. The Crisis and Citizens' Trust in Central Banks. VoxEU. com, 10, p.4.

Heider, F., Saidi, F. and Schepens, G., 2016. Life Below Zero: Negative Policy Rates and Bank Risk Taking. Mimeo, 2016.

Jensen, C.M. and Spange, M., 2015. Interest Rate Pass-Through and the Demand for Cash at Negative Interest Rates. Danmarks Nationalbank Monetary Review, 2nd quarter.

Kiley, M.T. and Roberts, J.M., 2017. Monetary Policy in a Low Interest Rate World. Brookings Papers on Economic Activity, 2017(1), pp. 317-396. 
Kimball, M.S., 2014a. On the Great Recession. Blog post, February, 24, 2014.

Kimball, M.S., 2014b. The Medium-Run Natural Interest Rate and the Short-Run Natural Interest Rate. Blog post, July, 24, 2014.

Kimball, M.S., 2015. Negative Interest Rate Policy as Conventional Monetary Policy. National Institute Economic Review, 234(1), pp.R5-R14.

Kimball, C. and Kimball, M., 2015. However Low Interest Rates Might Go, the IRS will Never Act Like a Bank. posted on Quartz, 15.

Kimball, M.S., 2016a. Even Central Bankers Need Lessons on the Transmission Mechanism for Negative Interest Rates. Blog post, March, 01, 2016.

Kimball, M.S., 2016b. Mario Draghi Reminds Everyone that Central Banks Do Not Determine the Medium-Run Natural Interest Rate. Blog post, May, 4, 2016.

Kimball, M.S., 2016c. How the Original Sin of Borrowing in a Foreign Currency Can Reduce the Effectiveness of Monetary Policy for Both the Borrowing and Lending Country. Blog post, September, $28,2016$.

Kimball, M.S., 2016d. More on Original Sin and the Aggregate Demand Effects of Interest Rate Cuts: Olivier Wang and Miles Kimball. Blog post, March 1, 2016.

Kimball, M.S., 2017. Paper Currency Deposit Fees as Unrealized Interest Equivalents. Blog post, January, 17, 2017.

Kortela, T., 2016. A Shadow Rate Model with Time-Varying Lower Bound of Interest Rates (No. 19/2016). Bank of Finland.

Lemke, W. and Vladu, A.L., 2016. Below the Zero Lower Bound: A Shadow-Rate Term Structure Model for the Euro Area (No. 32/2016). Deutsche Bundesbank, Research Centre.

Lopez, J.A., Rose, A.K. and Spiegel, M.M., 2018. Why Have Negative Nominal Interest Rates Had Such a Small Effect on Bank Performance? Cross Country Evidence (No. w25004). National Bureau of Economic Research.

Mankiw, N. Gregory, 2009, "It May Be Time for the Fed to Go Negative," in New York Times, April 18.

Reis, R., 2016. Funding Quantitative Easing to Target Inflation (No. 86222). London School of Economics and Political Science, LSE Library.

Rognlie, M., 2016. What Lower Bound? Monetary Policy with Negative Interest Rates. Unpublished Manuscript.

Rogoff, K., 2015. Costs and Benefits to Phasing Out Paper Currency. NBER Macroeconomics Annual, 29(1), pp. 445-456.

Rogoff, K.S., 2017a. The Curse of Cash: How Large-Denomination Bills Aid Crime and Tax Evasion and Constrain Monetary Policy. Princeton University Press. 
Rogoff, K., 2017b. Dealing with Monetary Paralysis at the Zero Bound. Journal of Economic Perspectives, 31(3), pp. 47-66.

Rostagno, M., Bindseil, U., Kamps, A., Lemke, W., Sugo, T. and Vlassopoulos, T., 2016, June. Breaking Through the Zero Line: the ECB 's Negative Interest Rate Policy. In Presentation at the Seminar on Negative Interest Rates: Lessons Learned... So Far, Brookings Institution, Washington, DC, USA (Vol. 6).

Sargent, T.J. and Wallace, N., 1981. Some Unpleasant Monetarist Arithmetic. Federal Reserve Bank of Minneapolis Quarterly Review, 5(3), pp.1-17.

Turk, R., 2016. Negative Interest Rates: How Big a Challenge for Large Danish and Swedish Banks?. International Monetary Fund.

Wälti, S., 2012. Trust no More? The Impact of the Crisis on Citizens' Trust in Central Banks. Journal of International Money and Finance, 31(3), pp.593-605. 